INEEL/EXT-2000-00489

April 2000

\title{
Modifications made to the MELCOR Code for Analyzing Lithium Fires in Fusion Reactors
}

B. J. Merrill 


\title{
Modifications made to the MELCOR Code for Analyzing Lithium Fires in Fusion Reactors
}

\author{
Brad J. Merrill \\ Published April 2000 \\ Idaho National Engineering and Environmental Laboratory \\ Fusion Safety Program \\ Idaho Falls, Idaho 83415-3860 \\ Prepared for the \\ U.S. Department of Energy \\ Office of Fusion Energy Science \\ Under DOE Idaho Operations Office \\ Contract DE-AC07-99ID13727
}




\begin{abstract}
This report documents initial modifications made to the MELCOR code that allows MELCOR to predict the consequences of lithium spill accidents for evolving fusion reactor designs. These modifications include thermodynamic and transport properties of lithium, and physical models for predicting the rate of reaction of and energy production from the lithium-air reaction. A benchmarking study was performed with this new MELCOR capability. Two lithium-air reaction tests conducted at the Hanford Engineering Development Laboratory (HEDL) were selected for this benchmark study. Excellent agreement was achieved between MELCOR predictions and measured data. Recommendations for modeling lithium fires with MELCOR and for future work in this area concluded this report.
\end{abstract}




\section{SUMMARY}

Liquid lithium metal has long been considered as a potential coolant and breeder for magnetic and inertial deuterium-tritium (DT) fusion reactors. Lithium is a material that captures neutrons produced by the reactions of fusion plasmas to produce tritium fuel and convert the neutron kinetic energy into heat. Liquid lithium also exhibits excellent heat transfer properties as a coolant. However, lithium has one very potentially serious safety concern that must be accommodated in reactor design, that is that lithium is very chemically reactive with air, water, and concrete. Because these reactions are exothermic, the energy liberated by these reactions can elevate the temperatures of activated reactor structures and thereby release radioactive material from these structures by mechanisms such as surface oxidation. This radioactive material, plus the byproducts of the lithium reactions, will form aerosol particles that when combined with the convective air patterns produced by the lithium fire could result in the release of radioactive material to the environment during accident conditions.

With these safety concerns in mind, initial modifications to the MELCOR code have been completed that allows MELCOR to predict the consequences of lithium spill accidents for evolving fusion reactor designs. These modifications include the thermodynamic and transport properties of lithium, and physical models for predicting the rate of reaction of and energy production from the lithium-air reaction. Two lithiumair reaction tests conducted at the Hanford Engineering Development Laboratory (HEDL) were selected to benchmark this new capability in MELCOR. These tests were conducted in the $850 \mathrm{~m}^{3}$ containment vessel of the Containment Systems Test Facility (CSTF). Lithium pool temperature, vessel atmosphere, vessel wall, and oxygen and nitrogen consumption were measured. These experiments were designated as a deep pool spill test, where $43 \mathrm{~kg}$ of liquid lithium at a temperature of $600{ }^{\circ} \mathrm{C}$ was transferred into a reaction pan, resulting in a pool diameter to depth ratio of 16 , and a shallow pool spill test, where $100 \mathrm{~kg}$ of liquid lithium at a temperature of $500{ }^{\circ} \mathrm{C}$ was transferred into a reaction pan, resulting in a pool diameter to depth ratio of 0.9. Excellent agreement was achieved between MELCOR predictions and measured data. Recommendations for modeling lithium fires with MELCOR and for future work in this area concluded this report. 


\section{ACRONYMS}

\begin{tabular}{|c|c|}
\hline $\mathrm{A}_{\mathrm{s}}$ & Surface area \\
\hline$c_{\mathrm{v}, \mathrm{p}}$ & Specific heat capacity at constant volume, pressure \\
\hline CSTF & Containment Systems Test Facility \\
\hline $\mathrm{CV}$ & Containment vessel \\
\hline${ }^{\circ} \mathrm{C}$ & Degrees Celsius \\
\hline $\mathrm{D}$ & Mass diffusion coefficient \\
\hline DT & Deuterium-tritium \\
\hline EOS & Equation of State \\
\hline FCPI & Forced convection pool interface \\
\hline g & Gravitational constant \\
\hline Gr & Grashof number \\
\hline HEDL & Hanford Engineering Development Laboratory \\
\hline$h_{\mathrm{a}}$ & Atmosphere convective coefficient \\
\hline$h_{f}$ & Heat of fusion \\
\hline$h_{V}$ & Vapor enthalpy \\
\hline $\mathrm{h}_{\mathrm{I}}$ & Ice enthalpy \\
\hline$h_{R}$ & Heat of reaction \\
\hline $\mathrm{k}$ & Thermal cond uctivity \\
\hline $\mathrm{kg}$ & Kilograms \\
\hline $\mathrm{K}$ & Degrees Kelvin \\
\hline $\mathrm{K}_{\mathrm{f}}$ & Film mass flow rate \\
\hline $\mathrm{K}_{\mathrm{m}}$ & Mass transfer coefficient \\
\hline $\mathrm{L}$ & Heat structure characteristic length \\
\hline $\mathrm{Li}_{2} \mathrm{O}$ & Lithium oxide \\
\hline $\mathrm{Li}_{3} \mathrm{~N}$ & Lithium nitride \\
\hline $\mathrm{m}$ & Meters \\
\hline $\mathrm{M}_{\mathrm{A}, \mathrm{B}}$ & Molecular weights of gas A and B \\
\hline MJ & MegaJoules \\
\hline NCPI & Natural convection pool interface \\
\hline $\mathrm{NCRH}$ & Natural convection reduced heat of reaction \\
\hline $\mathrm{Nu}$ & Nusselt number \\
\hline $\mathrm{p}$ & Pressure \\
\hline $\operatorname{Pr}$ & Prandlt number \\
\hline $\mathrm{q}_{\text {cond }}$ & Conduction heat flux \\
\hline $\mathrm{q}_{\text {conv }}$ & Convection heat flux \\
\hline Q & Heat flow \\
\hline $\mathrm{s}$ & Entropy \\
\hline $\mathrm{Sc}$ & Schmidt number \\
\hline $\mathrm{Sh}$ & Sherwood number \\
\hline $\mathrm{T}$ & Temperature \\
\hline $\mathrm{u}$ & Internal energy \\
\hline $\mathrm{V}_{\varphi}$ & Phase velocity \\
\hline W & Watts \\
\hline $\mathrm{X}_{\varphi}$ & Phase characteristic heat transfer length \\
\hline
\end{tabular}




\section{SYMBOLS}

$\beta \quad$ Thermal expansion coefficient

$\delta \quad$ Film or ice thickness

$\Delta \mathrm{T} \quad$ Temperature difference

G Mass flux

$\mu \quad$ Viscosity

Hm Micron

$\Omega_{\mathrm{D}} \quad$ Collision integral

f Phase designation

? Density

$\sigma_{\mathrm{A}, \mathrm{B}} \quad$ Collision diameter of gas A and B

$\sigma_{\mathrm{B}} \quad$ Stefan-Boltzmann constant

$\theta \quad$ Angle of inclination from horizontal 


\section{CONTENTS}

ABSTRACT ….........................................................

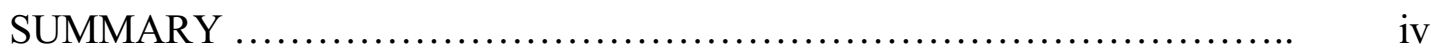

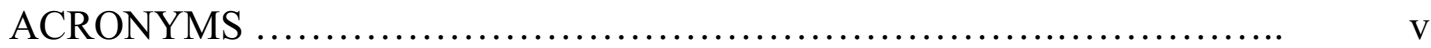

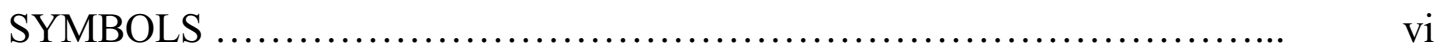

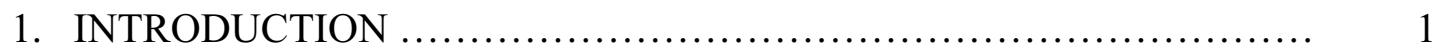

2. LITHIUM THERMODYNAMIC PROPERITES ....................... 1

2.1 Equation of State ............................................. 1

2.2 Extrapolation of EOS Below the Triple Point ....................... 4

2.3 Films on Cold Structures ............................................. 5

3. LITHIUM-AIR REACTION MODEL .................................. 7

3.1 Lithium Reaction Equations ................................... 7

3.2 MELCOR Inter-phase Heat and Mass Transfer Model ................. 11

4. BENCHMARK STUDY ............................................... 12

4.1 HEDL Lithium Spill Tests ............................................ 13

4.2 MELCOR Model of the HEDL CSTF ................................ 20

4.3 Test LA-4 Benchmark Study Results ................................ 21

4.4 Test LA-5 Benchmark Study Results .............................. 28

5. CONCLUSIONS AND RECOMMENDATIONS ........................ 33

6. REFERENCES …................................................ 36

Appendix A - FORTRAN Listing of MELCOR Modifications to Allow

MELCOR to Access the Fusion Safety Fluid Property Database ............. A-1

Appendix B - FORTRAN Listing of MELCOR Modifications for Lithium-Air Reaction Kinetics

B-1

\section{FIGURES}

1. CSTF lithium pool-air reaction test schematic .............................. 13

2. Reaction pan and catch pan schematic of Test LA-4 ...................... 14

3. Reaction pan and catch pan schematic of Test LA-5 ..................... 14

4. Lithium pool temperatures during Test LA-4 .......................... 17

5. Lithium pool temperatures during Test LA-5 .......................... 17 
6. Containment vessel pressure, average atmosphere temperature and average vessel wall temperature during Test LA-4 ....

7. Containment vessel pressure, average atmosphere temperature and average vessel wall temperature during Test LA-5 ................ 18

8. Nitrogen and oxygen consumption during Tests LA-4 and LA-5 .......... 19

9. Schematic of MELCOR CSTF containment vessel model ............... 20

10. Comparison of MELCOR predicted pool temperature with data from Test LA-4 .................................... 24

11. Comparison of MELCOR predicted oxygen consumption with that

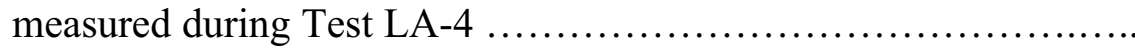

12. Comparison of MELCOR predicted nitrogen consumption with that measured during Test LA-4 ...

13. Comparison of MELCOR predicted CV atmosphere temperature with that measured during Test LA-4 .

14. Comparison of MELCOR predicted $\mathrm{CV}$ wall temperature with that measured during Test LA-4

15. Comparison of MELCOR reduced heat of reaction case predicted lithium pool temperature with that measured during Test LA-4

16. Comparison of MELCOR reduced heat of reaction case predicted CV atmosphere temperature with that measured during Test LA-4 .......

17. Comparison of MELCOR reduced heat of reaction case predicted CV wall temperature with that measured during Test LA-4 ............

18. Comparison of MELCOR predicted pool temperature with data

19. Pool surface emissivity use by MELCOR to match pool temperature data from Test LA-5

20. Comparison of MELCOR predicted oxygen consumption with that measured during Test LA-5 ...............................

21. Comparison of MELCOR predicted nitrogen consumption with that measured during Test LA-5 . ...

22. Comparison of MELCOR predicted CV atmosphere temperature with that measured during Test LA-5

23. Comparison of MELCOR predicted $\mathrm{CV}$ wall temperature with that measured during Test LA-5 


\section{Modifications made to the MELCOR Code for Analyzing Lithium Fires in Fusion Reactors}

\section{INTRODUCTION}

Liquid lithium metal has long been considered as a potential coolant and breeding material for magnetic and inertial deuterium-tritium (DT) fusion reactors. Lithium is a material that captures neutrons produced by the reactions of fusion plasmas to produce tritium and convert the neutron kinetic energy into heat. Liquid lithium also exhibits excellent heat transfer properties as a coolant. However, lithium has one very potentially serious safety concern that must be accommodated in a reactor design, that is that lithium is very chemically reactive with air, water, and concrete. Because these reactions are exothermic, the energy liberated by these reactions can elevate the temperatures of activated reactor structures and thereby release radioactive material from these structures by mechanisms such as surface oxidation. This radioactive material, plus the byproducts of the lithium reactions, will form aerosol particles that when combined with the convective air patterns produced by the lithium fire could result in the release of radioactive material to the environment during accident conditions. With these safety concerns in mind, initial modifications to the MELCOR code [1] have been completed that allows MELCOR to predict the consequences of lithium spill accidents for evolving fusion reactor designs. This report details these MELCOR modifications.

The following sections of this report describe the modifications required to include the thermodynamic and transport properties of lithium in MELCOR, the physical models adopted for predicting the rate of reaction of and energy production from the lithium-air reaction, a benchmarking study performed with this new MELCOR capability, and conclusions and modeling recommendations derived from the work presented in this report.

\section{LITHIUM THERMODYNAMIC PROPERITES}

Modifications have been made to the MELCOR code to allow lithium as the working fluid rather than water. These modifications deal with three specific areas: the Equation of State (EOS), transport properties, and heat structure condensate film growth. The following sub-sections describe the equations used to accomplish these modifications of the MELCOR code.

\subsection{Equation of State}

The MELCOR code EOS for water is based on the polynomials that can be found in Appendix A of Reference [2]. These polynomials relate pressure, specific internal energy, specific entropy and heat capacity to temperature and density, and are express in terms of the Helmholtz free energy (?) as follows: 


$$
?=?{ }_{\mathrm{o}}(\mathrm{T})+\mathrm{R} \mathrm{T}[\ln ?+? \mathrm{Q}(?, \mathrm{t})]
$$

where

$$
?_{\mathrm{o}}=\sum_{\mathrm{i}=1}^{6} \mathrm{C}_{\mathrm{i}} / \mathrm{t}^{\mathrm{i}-1}+\mathrm{C}_{7} \ln \mathrm{T}+\mathrm{C}_{8}(\ln \mathrm{T}) / \mathrm{t}
$$

and

$$
\mathrm{Q}=\left(\mathrm{t}-\mathrm{t}_{\mathrm{c}}\right) \sum_{\mathrm{j}=1}^{7}\left(\mathrm{t}-\mathrm{t}_{\mathrm{aj}}\right)^{\mathrm{j}-2}\left[\sum_{\mathrm{i}=1}^{8} \mathrm{~A}_{\mathrm{ij}}\left(?-?_{\mathrm{aj}}\right)^{\mathrm{i}-1}+\mathrm{e}^{-\mathrm{E} ?} \sum_{\mathrm{i}=9}^{10} \mathrm{~A}_{\mathrm{ij}} \mathrm{f}^{\mathrm{i}-\mathrm{9}}\right]
$$

In Equations 1 through 3, the temperature (T) is in degrees Kelvin, the density (?) is in $\mathrm{g} / \mathrm{cm}^{3}, \mathrm{t}$ denotes $1000 / \mathrm{T}^{\mathrm{a}}$ Given these basic polynomials, the pressure, as an example, can be determined as follows:

$$
\mathrm{p}(?, \mathrm{~T})=?^{2}\left(\frac{\partial ?}{\partial ?}\right)_{\tau}=? \mathrm{R} \mathrm{T}\left[1+? \mathrm{Q}+?^{2}\left(\frac{\partial \mathrm{Q}}{\partial ?}\right)_{\tau}\right]
$$

Additional thermodynamic properties required by MELCOR are also derived from thermodynamic relationships involving Helmholtz free energy and Equations 1 through 3, such as fluid internal energy $(\mathrm{J} / \mathrm{kg})$, enthalpy $(\mathrm{J} / \mathrm{kg})$, entropy $(\mathrm{J} / \mathrm{kg}-\mathrm{K})$, specific heat $(\mathrm{J} / \mathrm{kg}-\mathrm{K})$, and derivatives of pressure (Equation 4) with respect to temperature and density. Properties derived from these equations accurately represents either the liquid or vapor phase of water from near zero pressure to $100 \mathrm{MPa}$, and from $273.15 \mathrm{~K}$ to $1573 \mathrm{~K}$. Single phase water properties are calculated in MELCOR by subroutine H2O1PH. For a two-phase mixture, the above polynomials are used to develop saturated liquid and vapor thermodynamic property arrays for the two-phase steam dome of a P-v-T diagram. The properties of these arrays are at equal temperature increments along the saturation line between the triple point and the critical point of water. These arrays are interpolated by MELCOR to obtain saturated properties based on the fluid temperature and to generate two-phase properties based on the mixture quality calculated from the fluid density. Two-phase water properties are calculated in MELCOR by subroutine H2O2PH. Water transport properties of thermal conductivity and viscosity for saturated liquid and vapor are determined from lookup tables contained in MELCOR subroutine MPDFVL. Water surface tension is obtained from a polynomial and used in the surface boiling heat transfer subroutine HSBOIL. Thermal expansion coefficient for water is defined by block data assignments in MELCOR. Binary diffusion coefficient for water vapor in a gas mixture is defined in subroutine MPDIF. The purpose of the modifications describe in this section is to replace these water properties with those of lithium. The approach taken was to modify MELCOR so that it could access the Fusion Safety fluid property database.

\footnotetext{
${ }^{a}$ For information regarding values for the constant terms of these equations refer to Reference 2
} 
The Fusion Safety fluid property database was originally developed for the ATHENA code $[3,4,5]$. This database contains the thermodynamic and transport properties for thirteen fluids. The modifications discussed in this section allowed MELCOR to access nine of these fluids, those fluids that are of interest to fusion. These fluids are water, hydrogen, lithium, potassium, helium, nitrogen, sodium, $\mathrm{NaK}$, and lithium-lead. ${ }^{\text {a }}$ This database is an extension of the RELAP5 [6] environmental library. The RELAP5 library contains a water properties table and interpolation subroutines that compute thermodynamic properties from the water properties table based on specific fluid properties as inputs. For example, subroutine STH2X4 returns the properties of pressure, internal energy, enthalpy, coefficient of thermal expansion, specific heat capacity, isothermal compressibility, entropy, stream quality, and saturation pressure for a single phase fluid state (saturated liquid and vapor values for a two-phase state) given water temperature and specific volume as inputs. This database also contains transport property subroutines called THCOND and VISCOS that contain equations for liquid and vapor thermal conductivity and viscosity, and a subroutine called SURFTN that contains equations for saturated liquid surface tension. In addition to the above mentioned subroutines of the fluid property database, there are initialization routines that read in the fluid thermodynamic properties table, and triple point and critical point properties.

Given this background, five major modifications were made to the MELCOR code to change the working fluid of MELCOR from water to lithium. First, the water equations contained in subroutine $\mathrm{H} 2 \mathrm{O} 1 \mathrm{PH}$ where removed and replaced with a call to a new subroutine call FLUIDEOS. This subroutine accessed the fluid property database by calling subroutine STUPX4, a multi-fluids version of STH2X4. Subroutine FLUIDEOS then computes and returns the thermodynamic property information to subroutine $\mathrm{H} 2 \mathrm{O} 1 \mathrm{PH}$ as required by the MELCOR code. Second, a subroutine called INITFLD was written that on startup of a MELCOR problem calls the fluids database initialization subroutine ICMPNX and initializes properties required by $\mathrm{H} 2 \mathrm{O} 2 \mathrm{PH}$. Subroutine INITFLD searches the local user file directory for the thermodynamic properties table. The file in which these properties reside has an acronym for a filename that contains a 'tpf' preceding the fluid chemical name, for example the file for lithium is tpfli. ${ }^{\mathrm{b}}$ The user must supply this file before MELCOR will execute. This search follows the order of the nine fluids listed above. The first file found by INITFLD becomes the working fluid of choice, which choice INITFLD notifies the user of by writing the fluid name to the user's computer monitor. After the fluid has been identified INITFLD calls subroutine ICMPNX to read the thermodynamic properties table. INITFLD then develops the saturation properties required by subroutine $\mathrm{H} 2 \mathrm{O} 2 \mathrm{PH}$ by calling subroutine FLUIDEOS, and finally INITFLD redefines the fluid molecular weight, and Lennard-Jones parameters used by MPDIF. Third, subroutine MPPRP1 was modified to call subroutines THCOND and VISCOS when fluid transport properties are required, and subroutine HSBOIL was changed to call subroutine SURFTN for fluid surface tension. Fourth, the subroutine

${ }^{\mathrm{a}}$ The order of these name reflect the fluid number assumed by MELCOR, that is fluid one is water, two is hydrogen, etc.

${ }^{b}$ The other file names are tpfh2o for water, tpfh 2 for hydrogen, tpfk for potassium, tpfhe for helium, tpfn 2 for nitrogen, tpfna for sodium, tpfnak for $\mathrm{NaK}$, and tpflipb for lithiumlead. 
FLCOK that predicts choked flow in MELCOR flow paths was modified to treat fluids other than water. Subroutine FLCOK contains water specific polynomials that compute choked flow conditions given upstream fluid stagnation pressure and enthalpy [7]. These polynomials are analytic fits to the predictions from the Henry-Fauske correlation for sub-cooled water flow, and the Moody correlation for saturated water flow. For fluids other than water, subroutine FLCOK has been modified to call subroutine GCSUB. This subroutine is from the RELAP5 code, and it computes the critical mass flow for a liquid based on an iterative solution of the Henry-Fauske correlation. Finally, fluid triple point temperature and critical point temperature, pressure and density was propagated thoughout the MELCOR code where needed by the use of the common block EOSPARM, and printing to output files was changed to indicate the adopted fluid.

\subsection{Extrapolation of EOS Below the Triple Point}

If during a calculation the fluid temperature drops below the triple point temperature $\left(\mathrm{T}_{\mathrm{TP}}\right)$ a strategy must be adopted to allow MELCOR to continue executing properly. The strategy adopted in this multi-fluids version of MELCOR is similar to that used for water previously [8] but with a simplifying assumption regarding fluid specific heat capacity. The adopted strategy for defining the fluid thermodynamic properties below $\mathrm{T}_{\mathrm{TP}}$ relies on the assumptions that the:

1) fluid vapor is an ideal gas,

2) liquid density and derivatives of pressure with temperature are independent of temperature,

3) heat of fusion can be accounted for by an effective heat capacity, and

4) heat capacities of the ice/vapor are constant below $T_{\mathrm{TP}}$.

With these assumptions, the pressure is determined from:

$\mathrm{p}(?, \mathrm{~T})=\mathrm{p}\left(?, \mathrm{~T}_{\mathrm{TP}}\right)+\left(\frac{\partial \mathrm{p}}{\partial \mathrm{T}}\left(?, \mathrm{~T}_{\mathrm{TP}}\right)\right)_{?}\left[\mathrm{~T}-\mathrm{T}_{\mathrm{TP}}\right]$

where the pressure $\left[\mathrm{p}\left(?, \mathrm{~T}_{\mathrm{TP}}\right)\right]$ and partial derivative of pressure with temperature $([? \mathrm{p} / ? \mathrm{~T}]$ ? $)$ at $\mathrm{T}_{\mathrm{TP}}$ are determined from the fluid EOS discussed in the previous section.

The specific internal energy below $\mathrm{T}_{\mathrm{TP}}$ is found by integrating the following equation [9]:

$d u=c_{v} d T+\left[T\left(\frac{\partial p}{\partial T}\right)-P\right] d v$

Assuming that the liquid heat of fusion $\left(\mathrm{h}_{\mathrm{f}}\right)$ can be treated as an effective specific heat capacity defined as the heat of fusion $(\mathrm{J} / \mathrm{kg})$ divided by an arbitrary temperature change ? $(=1 \mathrm{~K})$, the "ice" internal energy for $\mathrm{T}_{\mathrm{TP}}-$ ? $<\mathrm{T}<\mathrm{T}_{\mathrm{TP}}$ can be calculated from,

$\mathrm{u}_{1}(?, \mathrm{~T})=\mathrm{u}_{1}\left(?, \mathrm{~T}_{\mathrm{TP}}\right)+\frac{\mathrm{h}_{\mathrm{f}}}{?}\left[\mathrm{~T}-\mathrm{T}_{\mathrm{TP}}\right]$ 
If the additional assumption is made that the ice specific heat capacity below this temperature is constant and equal to that of the liquid at $\mathrm{T}_{\mathrm{TP}}$, then ice specific internal energy for $\mathrm{T}<\mathrm{T}_{\mathrm{TP}}-$ ? becomes:

$\mathrm{u}_{1}(?, \mathrm{~T})=\mathrm{u}_{1}\left(?, \mathrm{~T}_{\mathrm{TP}}-?\right)+\left.\mathrm{c}_{\mathrm{v1}}\right|_{\mathrm{TP}}\left[\mathrm{T}-\mathrm{T}_{\mathrm{TP}}+\right.$ ? $]$

For a constant vapor heat capacity defined below $\mathrm{T}_{\mathrm{TP}}$, the vapor specific internal energy becomes:

$\mathrm{u}_{\mathrm{v}}(?, \mathrm{~T})=\mathrm{u}_{\mathrm{v}}\left(?, \mathrm{~T}_{\mathrm{TP}}\right)+\left.\mathrm{c}_{\mathrm{vv}}\right|_{\mathrm{TP}}\left[\mathrm{T}-\mathrm{T}_{\mathrm{TP}}\right]$

The specific entropy below $\mathrm{T}_{\mathrm{TP}}$ is found by integrating by the following equation [10]:

$\mathrm{ds}=\mathrm{c}_{\mathrm{v}} \frac{\mathrm{dT}}{\mathrm{T}}+\left(\frac{\partial \mathrm{p}}{\partial \mathrm{T}}\right)_{\mathrm{v}} \mathrm{dv}$

With the above specific heat capacity assumptions, the result is the following ice specific entropy below $\mathrm{T}_{\mathrm{TP}}$ :

$$
\begin{array}{ll}
\mathrm{s}_{1}(?, \mathrm{~T})=\mathrm{s}_{1}\left(?, \mathrm{~T}_{\mathrm{TP}}\right)+\frac{\mathrm{h}_{\mathrm{f}}}{?} \ln \left(\frac{\mathrm{T}}{\mathrm{T}_{\mathrm{TP}}}\right) & ; \mathrm{T}_{\mathrm{TP}}-?<\mathrm{T}<\mathrm{T}_{\mathrm{TP}} \\
\mathrm{s}_{1}(?, \mathrm{~T})=\mathrm{s}_{1}\left(?, \mathrm{~T}_{\mathrm{TP}}-?\right)+\left.\mathrm{c}_{\mathrm{v} 1}\right|_{\mathrm{TP}} \ln \left(\frac{\mathrm{T}}{\mathrm{T}_{\mathrm{TP}}-?}\right) & ; \mathrm{T}<\mathrm{T}_{\mathrm{TP}}-?
\end{array}
$$

And finally, the vapor phase the specific entropy becomes:

$$
\mathrm{s}_{\mathrm{v}}(?, \mathrm{~T})=\mathrm{s}_{\mathrm{v}}\left(?, \mathrm{~T}_{\mathrm{TP}}\right)+\left.\mathrm{c}_{\mathrm{vv}}\right|_{\mathrm{TP}} \ln \left(\frac{\mathrm{T}}{\mathrm{T}_{\mathrm{TP}}}\right) ; \mathrm{T}<\mathrm{T}_{\mathrm{TP}}
$$

An arbitrary fluid viscosity of $10^{4} \mathrm{~kg} / \mathrm{m}$-s is assigned to the 'liquid' state below $\mathrm{T}_{\mathrm{TP}}$. This assumption simulates the formation of ice from the liquid phase by creating a highly viscous fluid that should remain nearly stationary after formation. The thermal conductivity of a fluid below the $T_{T P}$ is maintained at a constant value that equals that of the ice at this temperature. The vapor viscosity and thermal conductivity are also set equal to those at $\mathrm{T}_{\mathrm{TP}}$. These extrapolations are meant only as approximations, and may require refinements in the future.

\subsection{Films on Cold Structures}

Condensation of vapor will occur on walls that are below the saturation temperature of the vapor. The condensed vapor will transfer energy to the wall, and form a film that will decrease the heat flow to the wall by acting as a thermal resistance. Version 1.8.2 of the MELCOR code has a heat structure film model that accounts for the thermal resistance, energy transfer, and stored energy associated with a film. It also has a crude conservation of mass model for the film. This model assumes that the condensed vapor will cause the film to grow until the film reaches a maximum value (default of 0.15 $\mathrm{mm}$ ), after which thickness any additional condensate will drain directly into the enclosure pool. This film will remain on the heat structure until the heat structure temperature exceeds the vapor saturation temperature, causing the film to evaporate. 
This model was modified in two ways. The first modification adds the solution of a mass balance equation to predict the thickness of films on non-horizontal heat structures. This equation is as follows:

$?_{\mathrm{f}} \mathrm{L} \frac{\partial \mathrm{d}}{\partial \mathrm{t}}=\mathrm{L} \Gamma_{\mathrm{c}}-\mathrm{K}_{\mathrm{f}}$

where

$\rho_{\mathrm{f}}=$ film density $\left(\mathrm{kg} / \mathrm{m}^{3}\right)$

$\mathrm{L}=$ heat structure characteristic length $(\mathrm{m})$

$\delta=$ film thickness (m)

$\Gamma_{\mathrm{c}}=$ condensation mass flux $\left(\mathrm{kg} / \mathrm{m}^{2}\right)$

$\mathrm{K}_{\mathrm{f}}=$ film mass flow rate per unit width

The adopted film mass flow rate relationship is that derived by Nusselt for laminar films [11], and is defined as follows:

$\mathrm{K}_{\mathrm{f}}=\left[\frac{?_{\mathrm{f}}\left(?_{\mathrm{f}}-?_{\mathrm{v}}\right) \mathrm{g} \sin ? \mathrm{~d}^{3}}{3 \mu_{\mathrm{f}}}\right]$

where

$\rho_{\mathrm{v}}=$ vapor density $\left(\mathrm{kg} / \mathrm{m}^{3}\right)$

$\mathrm{g}=$ gravitational constant $\left(\mathrm{m} / \mathrm{s}^{2}\right)$

$\theta=$ angle of heat structure inclination from horizontal

$\mu=$ film viscosity $(\mathrm{kg} / \mathrm{m}-\mathrm{s})$

Equations 13 and 14 are solved in finite difference form to give the time-dependent film thickness, which film thickness can exceed the user-specified maximum value. For horizontal heat structures (i.e., floors and ceilings) the standard MELCOR film model is used.

If the heat structure surface is colder than $T_{T P}$, the film will freeze to the heat structure. To account for this possibility, the film model switches from the solution of a mass balance equation to the solution of an energy balance equation written for the structure surface to determine the rate of film growth. This energy balance equation assumes that the net heat flux at the surface results in either liquid freezing or ice melting. This equation can be written as:

$? \mathrm{~h}_{\mathrm{f}} \frac{\partial \mathrm{d}}{\partial \mathrm{t}}=\mathrm{q}_{\text {cond }}-\mathrm{q}_{\text {conv }}-\mathrm{G}_{\mathrm{c}}\left(\mathrm{h}_{\mathrm{v}}-\mathrm{h}_{\mathrm{i}}\right)$

where

$$
\begin{array}{ll}
? & =\text { ice density }\left(\mathrm{kg} / \mathrm{m}^{3}\right) \\
\mathrm{h}_{\mathrm{f}} & =\text { heat of fusion }(\mathrm{J} / \mathrm{kg}) \\
\mathrm{d} & =\text { ice thickness }(\mathrm{m}) \\
\mathrm{q}_{\text {cond }} & =\text { heat flux conducted through ice }\left(\mathrm{W} / \mathrm{m}^{2}\right) \\
\mathrm{q}_{\mathrm{conv}} & =\text { heat flux convected to ice surface by atmosphere }\left(\mathrm{W} / \mathrm{m}^{2}\right) \\
\mathrm{h}_{\mathrm{v}} & =\text { vapor enthalpy }(\mathrm{J} / \mathrm{kg}) \\
\mathrm{h}_{\mathrm{i}} & =\text { ice enthalpy }(\mathrm{J} / \mathrm{kg})
\end{array}
$$

The conducted and convected heat fluxes are defined as follows: 
$\mathrm{q}_{\text {conv }}=\mathrm{h}_{\mathrm{a}}\left(\mathrm{T}_{\mathrm{a}}-\mathrm{T}_{\mathrm{i}}\right)$

$\mathrm{q}_{\mathrm{cond}}=\frac{\mathrm{k}}{\mathrm{d}}\left(\mathrm{T}_{\mathrm{i}}-\mathrm{T}_{\mathrm{s}}\right)$

where

$\mathrm{k}=$ thermal conductivity of ice $\left(\mathrm{W} / \mathrm{m}^{2}-\mathrm{K}\right)$

$\mathrm{T}_{\mathrm{i}} \quad=$ ice surface temperature $(\mathrm{K})$

$\mathrm{T}_{\mathrm{s}} \quad=$ structure surface temperature $(\mathrm{K})$

$\mathrm{h}_{\mathrm{a}} \quad=$ convective coefficient from atmosphere $\left(\mathrm{W} / \mathrm{m}^{2}-\mathrm{K}\right)$

$\mathrm{T}_{\mathrm{a}} \quad=$ temperature of atmosphere $(\mathrm{K})$

The ice surface temperature for this model is the equilibrium temperature found by setting the left-hand side of Equation 15 to zero. If this temperature is above $T_{T P}$ then it is set equal to $T_{T P}$. If it is below $T_{T P}$ by $1 \mathrm{~K}$, then Equation 13 is used with the film mass flow rate set to zero. Equations 15 through 17 are solved at all surfaces that are below the $T_{T P}$, regardless of heat structure orientation. However, the rate of growth of the ice layer is limited to the time dependent flow of mass condensing on a given surface, that is the product of the heat structure surface area times the condensation mass flux.

A FORTRAN listing of the more extensively modified MELCOR subroutines regarding the changes describe in Section 2 is contained in Appendix A.

\section{LITHIUM-AIR REACTION MODEL}

This section presents the chemical kinetics equations proposed for modeling lithium-air reactions with MELCOR. In addition, this section reviews the MELCOR pool-atmosphere interface mass and heat transport model of a MELCOR non-equilibrium control volume. Parallels are drawn between this model and the adopted lithium-air reaction model.

\subsection{Lithium Reaction Equations}

Lithium reacts with both major constituents of air. Lithium reacts with oxygen to form lithium oxide and with nitrogen to form lithium nitride. The chemical molar reaction equations that described these reactions are as follows:

$4 \mathrm{Li}+\mathrm{O}_{2} \rightarrow 2 \mathrm{Li}_{2} \mathrm{O}$

and

$6 \mathrm{Li}+\mathrm{N}_{2} \rightarrow 2 \mathrm{Li}_{3} \mathrm{~N}$

The lithium-air reactions are exothermic, and the energy liberated is temperature dependent. Equations that describe the heat of reaction as a function of temperature were developed from the HSC code [12] for these modifications. The heat of reaction (J/gmole) for lithium oxide and lithium nitride are:

$\mathrm{h}_{\mathrm{R}_{\mathrm{Li} 2 \mathrm{O}}}=4187 \times\left(143.05+2.284 \times 10^{-3} \mathrm{~T}-3.376 \times 10^{-6} \mathrm{~T}^{2}\right)$ 
$\mathrm{h}_{\mathrm{RL} \mathrm{LiN}}=4187 \times\left(39.26+2.832 \times 10^{-3} \mathrm{~T}-1.034 \times 10^{-6} \mathrm{~T}^{2}\right)$

for $\mathrm{T}<180^{\circ} \mathrm{C}$, and

$\mathrm{h}_{\mathrm{R}_{\mathrm{Li} 2 O}}=4187 \times\left(144.60+2.172 \times 10^{-3} \mathrm{~T}-3.679 \times 10^{-6} \mathrm{~T}^{2}+4.385 \times 10^{-10} \mathrm{~T}^{3}\right)$

$\mathrm{h}_{\mathrm{R}_{\mathrm{Li3N}}}=4187 \times\left(41.19+6.315 \times 10^{-3} \mathrm{~T}-1.148 \times 10^{-5} \mathrm{~T}^{2}+8.405 \times 10^{-10} \mathrm{~T}^{3}\right)$

for $180^{\circ} \mathrm{C}<\mathrm{T}<1600{ }^{\circ} \mathrm{C}$.

The above equations describe the chemical composition and energy release from these lithium reactions, but they do not describe the rate at which the reaction proceeds. The reaction rate model adopted for this model is the same model adopted for the LINT code [15]. That is, the reaction rate proceeds as fast as nitrogen or oxygen can diffuse to the lithium pool surface through a gas boundary layer that exists above this reacting surface. Because convective mass and heat transfer through surface boundary layers can be described by analogous boundary layer conservation equations [13], it has been determined that the surface boundary layer mass transfer coefficient can be related to heat transfer coefficient though the following relationship [14]:

$\mathrm{Sh}=\mathrm{Nu}\left(\frac{\mathrm{Sc}}{\mathrm{Pr}}\right)^{1 / 3}$

where,

$$
\begin{aligned}
& \mathrm{Sh}=\text { Sherwood number }=\frac{\mathrm{K}_{\mathrm{mi}} \mathrm{L}}{\mathrm{D}_{\mathrm{i}}} \\
& \mathrm{Nu}=\text { Nusselt number }=\frac{\mathrm{h}_{\mathrm{a}} \mathrm{L}}{\mathrm{k}} \\
& \mathrm{Sc}=\text { Schmidt number }=\frac{\mu}{\rho \mathrm{D}} \\
& \mathrm{Pr}=\text { Prandlt number }=\frac{\mu \mathrm{c}_{\mathrm{p}}}{\mathrm{k}}
\end{aligned}
$$

and where

$\mathrm{K}_{\mathrm{mi}}=$ specie mass transfer coefficient $(\mathrm{m} / \mathrm{s})$

$\mathrm{L} \quad=$ surface characteristic length $(\mathrm{m})$

$\mathrm{D}_{\mathrm{i}} \quad=$ specie mass diffusion coefficient $\left(\mathrm{m}^{2} / \mathrm{s}\right)$

$\mathrm{h}_{\mathrm{a}} \quad=$ atmosphere heat transfer coefficient $\left(\mathrm{W} / \mathrm{m}^{2}-\mathrm{K}\right)$

$\mathrm{k}=$ atmosphere thermal conductivity $(\mathrm{W} / \mathrm{m}-\mathrm{K})$

$\mu \quad=$ atmosphere viscosity $\left(\mathrm{kg} / \mathrm{m}^{2}-\mathrm{s}\right)$

$\rho \quad=$ atmosphere density $\left(\mathrm{kg} / \mathrm{m}^{3}\right)$

$\mathrm{c}_{\mathrm{p}} \quad=$ atmosphere specific heat $(\mathrm{J} / \mathrm{kg}-\mathrm{K})$. 
If the assumption is made, as is the case in the LINT code [15], that the appropriate atmosphere heat transfer coefficient is that obtained from the following correlation for turbulent natural convection on a horizontal surface:

$\mathrm{Nu}=0.13(\mathrm{Gr} \operatorname{Pr})^{1 / 3}$

where

$$
\begin{array}{ll}
\text { Gr } & =\text { Grashof number }=\mathrm{g} \beta \Delta \mathrm{T} \mathrm{L}^{3}\left(\frac{\rho}{\mu}\right)^{2} \\
\beta & =\text { atmosphere thermal expansion coefficient }\left(\mathrm{K}^{-1}\right) \\
\Delta \mathrm{T} & =\text { atmosphere to pool temperature difference }(\mathrm{K})
\end{array}
$$

the result is the following relationship for the mass transfer coefficient:

$$
\mathrm{K}_{\mathrm{mi}_{\mathrm{i}}}=0.13\left(\frac{\mathrm{D}_{\mathrm{i}}}{\mathrm{L}}\right)(\mathrm{Gr} \mathrm{Sc})^{1 / 3}
$$

Given this mass transfer coefficient, the mass flux $\left(\mathrm{kg} / \mathrm{m}^{2}-\mathrm{s}\right)$ of oxygen diffusing to the lithium surface, for example, is

$$
\Gamma_{\mathrm{O} 2}=\mathrm{K}_{\mathrm{m}_{\mathrm{O} 2}} \rho_{\mathrm{O} 2}
$$

Because we are assuming that the rate of oxygen consumption equals the rate of oxygen arrival, that is an infinite reaction rate at the pool surface, the rate of oxygen consumption $(\mathrm{kg} / \mathrm{s})$ equals the product of Equation 27 times the pool surface area. This mass consumption has been implemented in MELCOR as a mass sink in the atmosphere conservation of mass equation. The energy liberated (W) by this mass consumption is given by

$\mathrm{Q}_{\mathrm{O} 2}=\Gamma_{\mathrm{O} 2} \mathrm{~A}_{\mathrm{S}} \mathrm{h}_{\mathrm{R}_{\mathrm{Li2} 2}} /\left(2 \mathrm{M}_{\mathrm{O} 2}\right)$

where the factor of 2 represents the molar ratio of oxygen in lithium oxide and $\mathrm{M}_{\mathrm{O} 2}$ is the molecular weight of oxygen. Similar relationships can be derived for the consumption of nitrogen by the lithium. Heating of the lithium pool, added to MELCOR as a liquid bulk heating rate (W), equals the sum of the energy liberated by the oxygen and nitrogen reactions defined as follows:

$\mathrm{Q}_{\mathrm{POOL}}=\mathrm{Q}_{\mathrm{O} 2}+\mathrm{Q}_{\mathrm{N} 2}$

The rate $(\mathrm{kg} / \mathrm{s})$ at which lithium is consumed is added to MELCOR as a mass sink in the pool conservation of mass equation and is defined as follows:

$$
\dot{\mathrm{m}}_{\mathrm{Li}}=-\mathrm{A}_{\mathrm{S}} \mathrm{M}_{\mathrm{Li}}\left(4 \Gamma_{\mathrm{O} 2} / \mathrm{M}_{\mathrm{O} 2}+6 \Gamma_{\mathrm{N} 2} / \mathrm{M}_{\mathrm{N} 2}\right)
$$

The rates at which $\mathrm{Li}_{2} \mathrm{O}$ and $\mathrm{Li}_{3} \mathrm{~N}$ form are determined in a similar manner. A fraction of this material will be mobilized as aerosols, with the remainder will stay in the pool. To 
simulate this aerosol production behavior, the user must activate the aerosol transport option in MELCOR through specifying the appropriate MELCOR user input. This new model will subsequently place a constant fraction, a value determined from experiments as discussed in 4.1, of the $\mathrm{Li}_{2} \mathrm{O}$ and $\mathrm{Li}_{3} \mathrm{~N}$ mass produced into the smallest aerosol bin size specified by the user input. This model assumes that MELCOR aerosol class 13 is $\mathrm{Li}_{2} \mathrm{O}$ and class 15 is $\mathrm{Li}_{3} \mathrm{~N}$, unless the user designates two new aerosol classes that have the names $\mathrm{Li}_{2} \mathrm{O}$ and $\mathrm{Li}_{3} \mathrm{~N}$. This model adds the remaining $\mathrm{Li}_{2} \mathrm{O}$ and $\mathrm{Li}_{3} \mathrm{~N}$ produced to the aerosol mass residing in the control volume pool. If the aerosol transport capability is not invoked, this model will not conserve the resulting $\mathrm{Li}_{2} \mathrm{O}$ and $\mathrm{Li}_{3} \mathrm{~N}$ masses.

Material properties for the above equations are obtained by MELCOR from the Fusion Safety material property database. The binary gas diffusion coefficients $\left(\mathrm{m}^{2} / \mathrm{s}\right)$ are determined from a correlation proposed by Wilke and Lee [16]. This correlation is as follows:

$$
\mathrm{D}_{\mathrm{AB}}=1.01325 \times 10^{-2}\left(3.03-0.98 / \mathrm{M}_{\mathrm{AB}}^{1 / 2}\right) \mathrm{T}^{3 / 2} /\left(\mathrm{p} \mathrm{M}_{\mathrm{AB}}^{1 / 2} \sigma_{\mathrm{AB}}^{2} \Omega_{\mathrm{D}}\right)
$$

where,

$$
\begin{aligned}
& \mathrm{M}_{\mathrm{AB}}=2\left[\left(1 / \mathrm{M}_{\mathrm{A}}\right)+\left(1 / \mathrm{M}_{\mathrm{B}}\right)\right]^{-1} \\
& \mathrm{M}_{\mathrm{A}}, \mathrm{M}_{\mathrm{B}}=\text { molecular weights of gas A and } \mathrm{B}(\mathrm{g} / \mathrm{mol}) \\
& \mathrm{p} \quad=\text { pressure }(\mathrm{Pa}) \\
& \sigma_{\mathrm{AB}}=\left[\sigma_{\mathrm{A}}+\sigma_{\mathrm{B}}\right] / 2 \\
& \sigma_{\mathrm{A}}, \sigma_{\mathrm{B}}=\text { collision diameter of gas A and } \mathrm{B}(\AA) \\
& \Omega_{\mathrm{D}} \quad=\text { collision integral. }
\end{aligned}
$$

For a gas mixture, MELCOR calculates and effective binary diffusion coefficient, $\mathrm{D}_{\mathrm{AM}}$, by a method proposed by Wilke [17], which is as follows:

$$
\frac{1-y_{A}}{D_{A M}}=\sum_{j=1, \neq A}^{M} \frac{y_{j}}{D_{A j}}
$$

where,

$$
\begin{aligned}
& y_{j}=\text { is the mole fraction of gas } j \\
& D_{A j}=\text { binary diffusion coefficient of gas A through gas } j\left(\mathrm{~m}^{2} / \mathrm{s}\right) .
\end{aligned}
$$

As defined, the predicted binary diffusion coefficient is for oxygen diffusing through a gas mixture of nitrogen and lithium vapor.

The MELCOR code will activate this new lithium-air reaction capability if:

1) lithium and oxygen or nitrogen co-exist in the same MELCOR control volume,

2) the MELCOR computational volume has been identified as a non-equilibrium control volume. 
The second item is less obvious than the first. However, if the computational volume is an equilibrium volume then there is no temperature difference between the atmosphere and the pool, the Nusselt number is zero, and by default there will be no mass transfer predicted by this model. Aside from these points, the lithium-air reaction model will activate automatically without additional user input.

It should be mentioned that this model departs from the LINT lithium-air pool surface reaction model in three ways. First, the heat of reaction in LINT does not vary with temperature. Second, the boundary layer gas in LINT is assumed to consist entirely of argon. Third, LINT accounts for lithium-water vapor reaction. However, these are minor differences because:

1) the majority of the heat generated by the lithium-air reaction comes from the oxygen reaction that varies by less than $5 \%$ for the temperature range of $180 \mathrm{C}<$ $\mathrm{T}<1600 \mathrm{C}$,

2) the difference between oxygen binary diffusion coefficients in argon, nitrogen, or air is less than $20 \%$, and

3) the water vapor content of ambient air is minimal.

The majority of the equations for this new MELCOR capability reside in a subroutine named LIFIRE. A FORTRAN listing of this new subroutine is contained in Appendix B.

\subsection{MELCOR Inter-phase Heat and Mass Transfer Model}

This section has been added to illustrate the similarities between the MELCOR heat and mass transport model for non-equilibrium volumes and the lithium-air reaction model described in the previous section, and to form as a basis for future reference during the benchmarking discussion of Section 4. In MELCOR [7], heat flows between the pool and atmosphere as calculated by:

$$
\mathrm{Q}_{\varphi \mathrm{S}}=\mathrm{A}_{\mathrm{s}}\left\lfloor\mathrm{h}_{\varphi}\left(\mathrm{T}_{\varphi}-\mathrm{T}_{\mathrm{I}}\right)+\sigma_{\mathrm{B}}\left(\mathrm{T}_{\varphi}^{4}-\mathrm{T}_{\mathrm{I}}^{4}\right)\right\rfloor
$$

where,

$\mathrm{Q}_{\varphi \mathrm{S}}=$ heat flow from phase $\varphi$ to the pool-atmosphere interface $(\mathrm{W})$

$\mathrm{T}_{\varphi}=$ pool or atmosphere phase temperature $(\mathrm{K})$

$\mathrm{T}_{\mathrm{I}}=$ pool-atmosphere interface temperature $(\mathrm{K})$

$\sigma_{\mathrm{B}}=$ Stefan-Boltzmann radiation constant $\left(\mathrm{W} / \mathrm{m}^{2}-\mathrm{K}^{4}\right)$

$A_{\mathrm{s}}=$ pool surface area $\left(\mathrm{m}^{2}\right)$

The pool-atmosphere interface temperature is found by equating the heat from each phase to this interface. Because this heat transfer depends on the interface temperature, an iterative procedure is used to obtain the interface temperature. The heat transfer coefficient per phase is the maximum value of that predicted from forced 
convection, natural convection, or conduction. For forced convection at the poolatmosphere interface, the following correlation is used:

$$
\mathrm{Nu}_{\text {forced }, \varphi}=0.02 \rho_{\varphi} \mathrm{c}_{\mathrm{p} \varphi} \mathrm{V}_{\varphi} \frac{\mathrm{X}_{\varphi}}{\mathrm{k}_{\varphi}}
$$

where,

$$
\begin{array}{ll}
\mathrm{Nu}_{\text {forced } \varphi}=\text { phase }(\text { pool or atmosphere) forced convection Nusselt number } \\
\rho_{\varphi} \quad=\text { phase density }\left(\mathrm{kg} / \mathrm{m}^{3}\right) \\
\mathrm{c}_{\mathrm{p} \varphi} & =\text { phase specific heat }(\mathrm{J} / \mathrm{kg}-\mathrm{K}) \\
\mathrm{V}_{\varphi} & =\text { phase velocity }(\mathrm{m} / \mathrm{s}) \\
\mathrm{k}_{\varphi} & =\text { phase thermal conductivity }(\mathrm{W} / \mathrm{m}-\mathrm{K}) \\
\mathrm{X}_{\varphi} & =\text { phase characteristic heat transfer length }(\mathrm{m}) .
\end{array}
$$

The characteristic length is the minimum of the diameter of the pool and the height of the pool or atmosphere volume. For natural convection, both laminar and turbulent convection are considered. For the atmosphere, these correlations are:

$$
\mathrm{Nu}_{\text {laminar, A }}=0.54(\mathrm{Gr} \text { Pr })^{1 / 4}
$$

for laminar natural convection, and

$$
\mathrm{Nu}_{\text {turbulent } \mathrm{A}}=0.14(\mathrm{Gr} \operatorname{Pr})^{1 / 3}
$$

for turbulent natural convection. The heat transfer coefficient equals the maximum of the above correlations times the thermal conductivity divided by the heat structure characteristic length for a given phase.

The mass transfer coefficient of vapor at the pool surface is calculated with Equation 24, based on the maximum Nusselt number from Equations 35, 36, and 37. In MELCOR this mass transfer represents the mass of lithium leaving the pool due to evaporation or the mass of lithium leaving the atmosphere due to condensation. The similarity with the lithium-air reaction model of Section 3.1 is that both models use Equation 24. However, the lithium-air reaction model only considers turbulent natural convection for the transport of oxygen or nitrogen through the gas boundary layer, while the MELCOR model considers forced, and laminar or turbulent natural convection for transport of lithium. This point will be addressed again during the benchmarking discussed that follows.

\section{BENCHMARK STUDY}

This section contains a description of two lithium spill tests conducted at the Handford Engineering Development Laboratory (HEDL) in the Containment Systems Test Facility (CSTF). An experimental facility description and the results of two lithium spill tests are present in Section 4.1. The MELCOR model developed to simulate the 
CSTF is detailed in Section 4.2. Comparisons of the lithium spill experimental data with MELCOR predictions are given in Sections 4.3 and 4.4.

\subsection{HEDL Lithium Spill Tests}

A series of lithium reaction test were conducted at the HEDL in the 1980s for the Office of Fusion Energy under the supervision of the Fusion Safety Program at the Idaho National Engineering Laboratory [18]. These experiments we conducted in the CSTF. This facility is essentially a $850 \mathrm{~m}^{3}$ containment vessel (CV) that weighted approximately $7.7 \times 10^{4} \mathrm{~kg}$, had a diameter of $7.6 \mathrm{~m}$, a height of $20.3 \mathrm{~m}$, and an internal surface area of $520 \mathrm{~m}^{2}$. A schematic of this facility appears in Figure 1. Several of the tests conducted in this facility were reported in detail by Reference [18]. Two lithium-air spill tests (LA4 and LA-5) from this reference were selected to benchmark the lithium-air reaction model capability of MELCOR.

During Tests LA-4 and LA-5, liquid lithium was introduced into a reaction pan located at the bottom of the CV. Schematic drawings of the reaction pans for these tests appear in Figures 2 and 3. As can be seen, the cylindrical reaction pan is situated in the center of three concentrically stacked stainless steel (SS316) cylindrical catch pans. Between the first and second catch pan and between the third catch pan and the reaction pan resides a $6.4 \mathrm{~cm}$ thick layer of firebrick. The firebrick acts as a thermal insulator. The reaction pan for Test LA-4 has a diameter of $40.6 \mathrm{~cm}$ and a height of $61.0 \mathrm{~cm}$, and the outer surface of this reaction pan is wrapped with a $7.6 \mathrm{~cm}$ thick layer of KAOWOOL insulation. The reaction pan for Test LA-5 has a diameter of $160 \mathrm{~cm}$ and a height of 25.4 $\mathrm{cm}$. The outer surface of this reaction pan is bare, but a lid has been added to this pan to terminate the lithium-air reaction during the test.

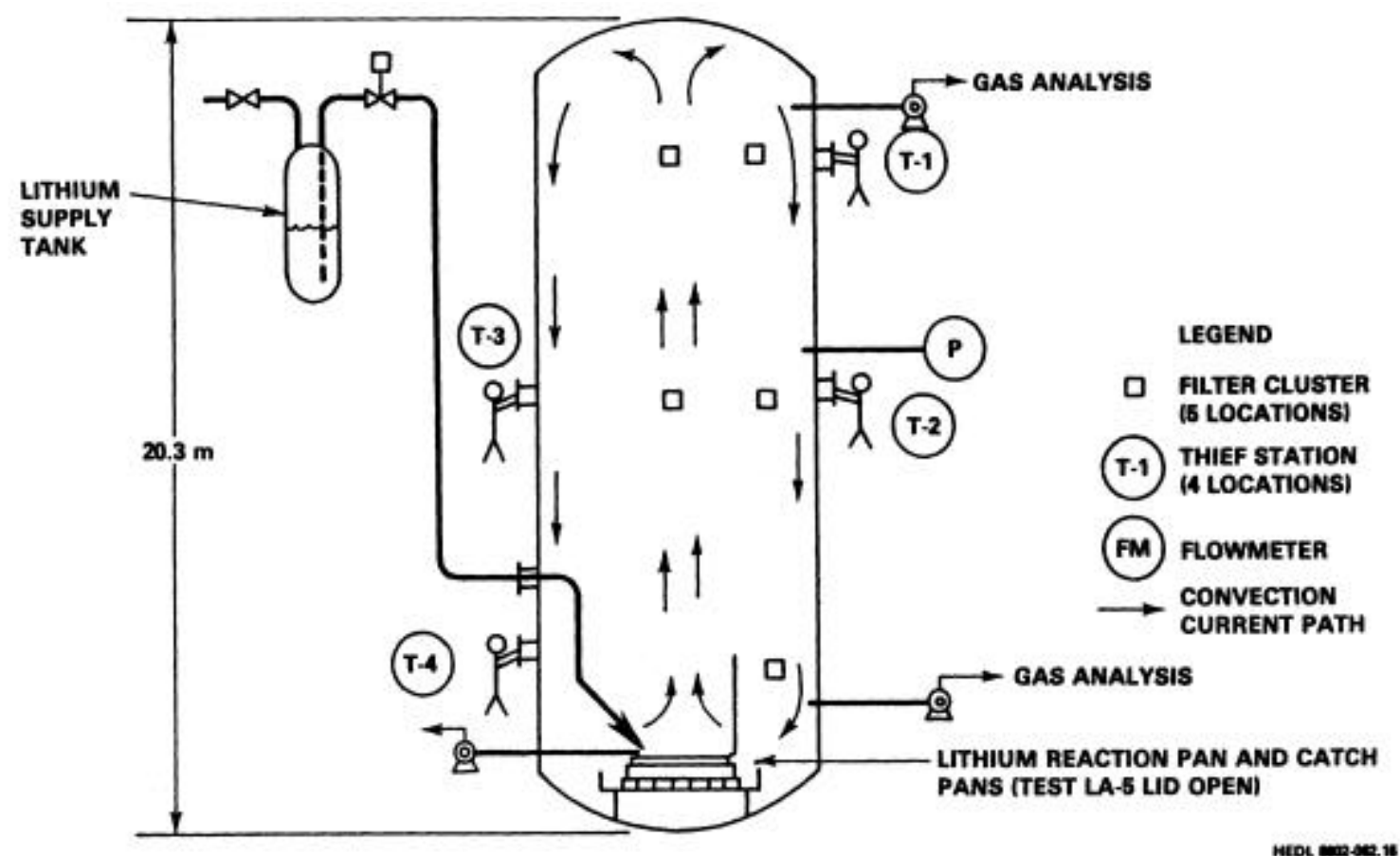

Figure 1. CSTF lithium pool-air reaction test schematic. 


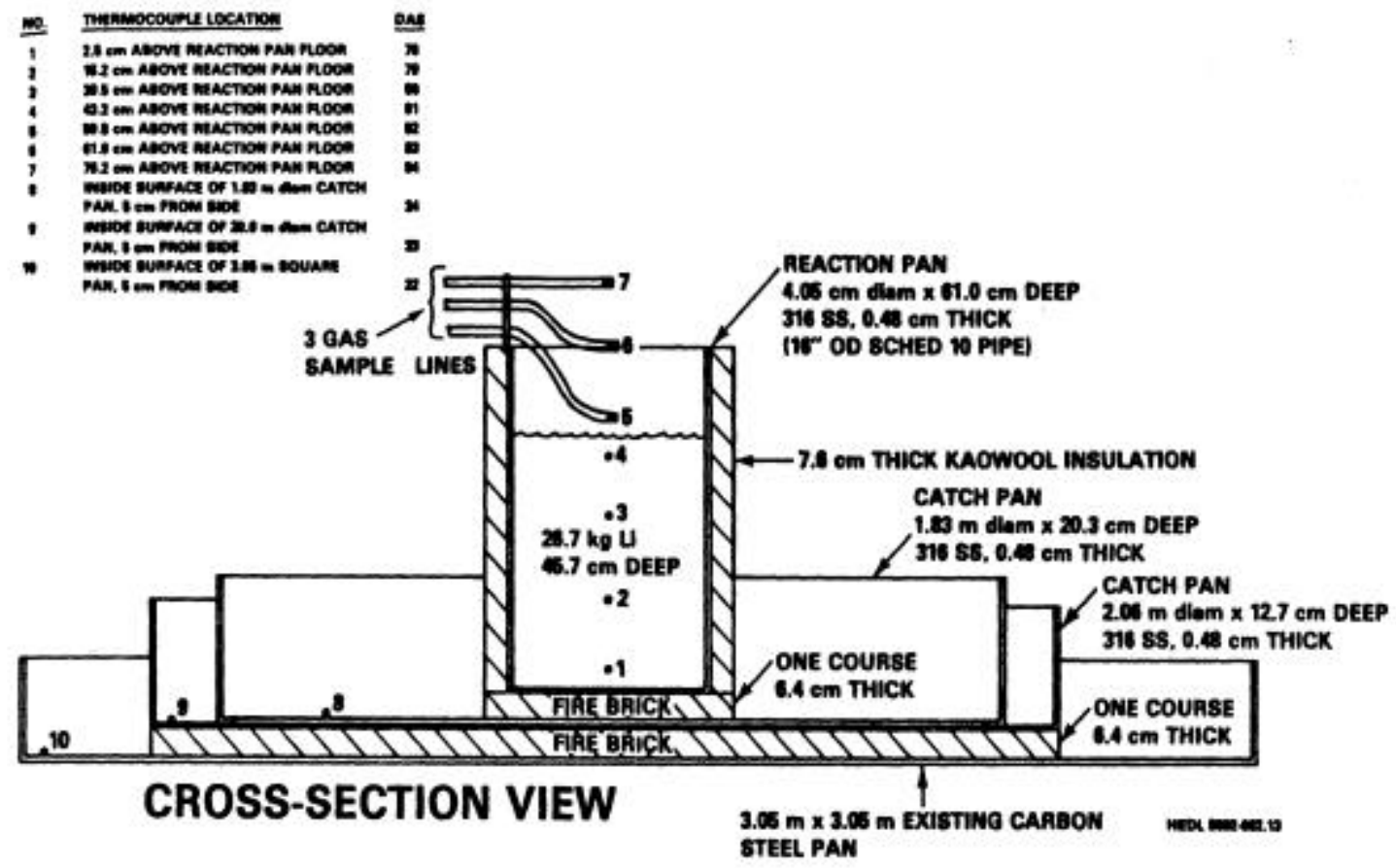

Figure 2. Reaction pan and catch pan schematic of Test LA-4.

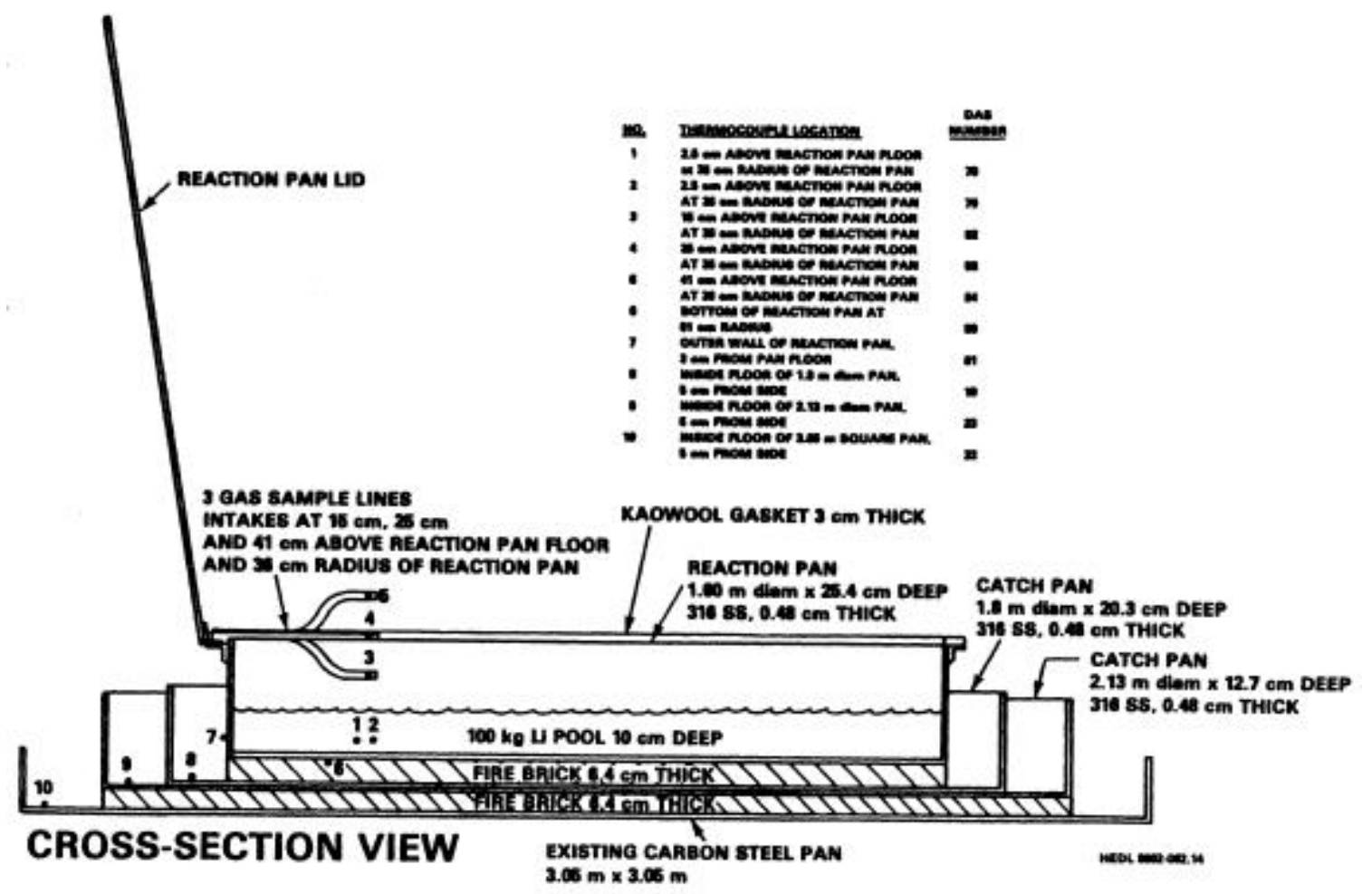

Figure 3. Reaction pan and catch pan schematic of Test LA-5. 
For Test LA-4, $43 \mathrm{~kg}$ of liquid lithium at a temperature of $600{ }^{\circ} \mathrm{C}$ was transferred in 115 seconds into the reaction pan that had been preheated to about $200{ }^{\circ} \mathrm{C}$. This resulted in a lithium pool height of $45.7 \mathrm{~cm}$. For Test LA-5, $100 \mathrm{~kg}$ of liquid lithium at a temperature of $500{ }^{\circ} \mathrm{C}$ was transferred into an unheated reaction pan. The resulting lithium pool height for Test LA-5 was $10 \mathrm{~cm}$. Given the fact that the initial pool diameter to height ratio $(\mathrm{D} / \mathrm{h})$ for Test LA-4 was approximately 0.89 and that for Test LA-5 was approximately 16, Test LA-4 was designated as a deep pool test and Test LA-5 designated as a shallow pool test.

These tests were well instrumented. There were 49 thermocouples located inside and outside of the CV. These thermocouples measure lithium pool, reaction pan, CV atmosphere, and $\mathrm{CV}$ wall temperatures. The arrangement of the pool and pan thermocouples can be seen in Figures 2 and 3. In addition to these thermocouples, the $\mathrm{CV}$ gas pressure and composition (at five locations) were continuously monitored during these tests, and five sampling stations existed for post-test aerosol analysis.

Some of the results obtained from Tests LA-4 and LA-5 are reproduced in Figures 4 through 8. Figure 4 gives the measure pool temperatures for LA-4. Four temperatures are plotted, with each temperature existing at an increasing height in the pool. As can be seen, there is very little temperature difference within the $45.7 \mathrm{~cm}$ deep pool. The temperature continually rises from the initial temperature of $600^{\circ} \mathrm{C}$ to a value of $1070{ }^{\circ} \mathrm{C}$ by 3200 seconds. Beyond this time these temperatures undergo a rapid rise to near $1200{ }^{\circ} \mathrm{C}$. This second rise is caused by a melt through of the reaction pan, and the release of the lithium pool into the catch pan. The pool temperatures for LA-5 are given in Figure 5. The measured temperatures show a very gradually rise beyond $410{ }^{\circ} \mathrm{C}$ over the first 1000 seconds of experiment. As reported in Reference [18]: "During the initial 900 seconds, localized flames were observed as small, "popcorn kernel"-like fires on the surface of the pool. Lithium appeared to wick up on these "kernels," burn and slowly grow in diameter to cover the pool surface." After 1000 seconds, the pool temperature continually rises to reach maximums of about $1100{ }^{\circ} \mathrm{C}$ by 3900 seconds, at which time the reaction pan lid was closed to terminate the reaction experiment.

Figures 6 and 7 contain average atmosphere temperature, average wall temperature, and pressure of the CV for Tests LA-4 and LA-5, respectively. The vessel atmosphere and wall temperatures were obtained by averaging the temperature measurements from nine atmosphere thermocouples and the measurements of seven vessel wall thermocouples, respectively, all located at different locations $(\mathrm{r}, \theta, \mathrm{z})$. Reference [18] did not discuss the logic behind the thermocouple selection process for these average temperature measurements. The average temperatures of Test LA-4 change very little prior to the failure of the reaction pan at 3200 seconds. A larger average temperature change can be noted for Test LA-5.

Figure 8 contains the oxygen and nitrogen consumption for Tests LA-4 and LA-5. The values plotted were calculated from the ideal gas law based on the measured gas composition, temperature, and pressure. The maximum rate of nitrogen consumption was 
$0.27 \mathrm{gmole} / \mathrm{m}^{2}$-s for Test LA-4 and $0.20 \mathrm{gmole} / \mathrm{m}^{2}$-s for Test LA-5. When comparing this result with measurements of pool temperature, it can be seen that the nitrogen reaction in LA-4 begins to drop at about $1030^{\circ} \mathrm{C}$ and nearly terminates by a temperature of $1060{ }^{\circ} \mathrm{C}$. In test LA-5 this transition begins at a lower pool temperature, about $930{ }^{\circ} \mathrm{C}$. The maximum rate of consumption for oxygen was $0.33 \mathrm{gmole} / \mathrm{m}^{2}-\mathrm{s}$ for Test LA-4 and 0.17 gmole $/ \mathrm{m}^{2}$-s for Test LA-5. Note the rather dramatic drop in oxygen consumption rate between these tests. This will be discussed in more detail in Section 4.4.

Based on post test examinations of the aerosols on CV walls and deposition trays, and aerosol collection stations that monitored suspended aerosol concentrations during these tests, Reference [18] was able to estimate that $10 \%$ of the lithium that reacted during Test LA-4 became an aerosol while $3.4 \%$ of the lithium during Test LA-5 became an aerosol. The initial size of the aerosol particles suspended in the atmosphere was reported as being between $0.1 \mu \mathrm{m}$ and $1.0 \mu \mathrm{m}$. These particles grew from the process of agglomeration to obtain mass median diameters of about $6 \mu \mathrm{m}$ with a geometric standard deviation of about 2.4 by $10^{4}$ seconds. Whether these particles originated by homogeneous nucleation of vapor from the $\mathrm{CV}$ atmosphere or were ejected as particulate from the surface of the pool as a consequence of the energetic lithium-air reaction was not reported by Reference [18]. 


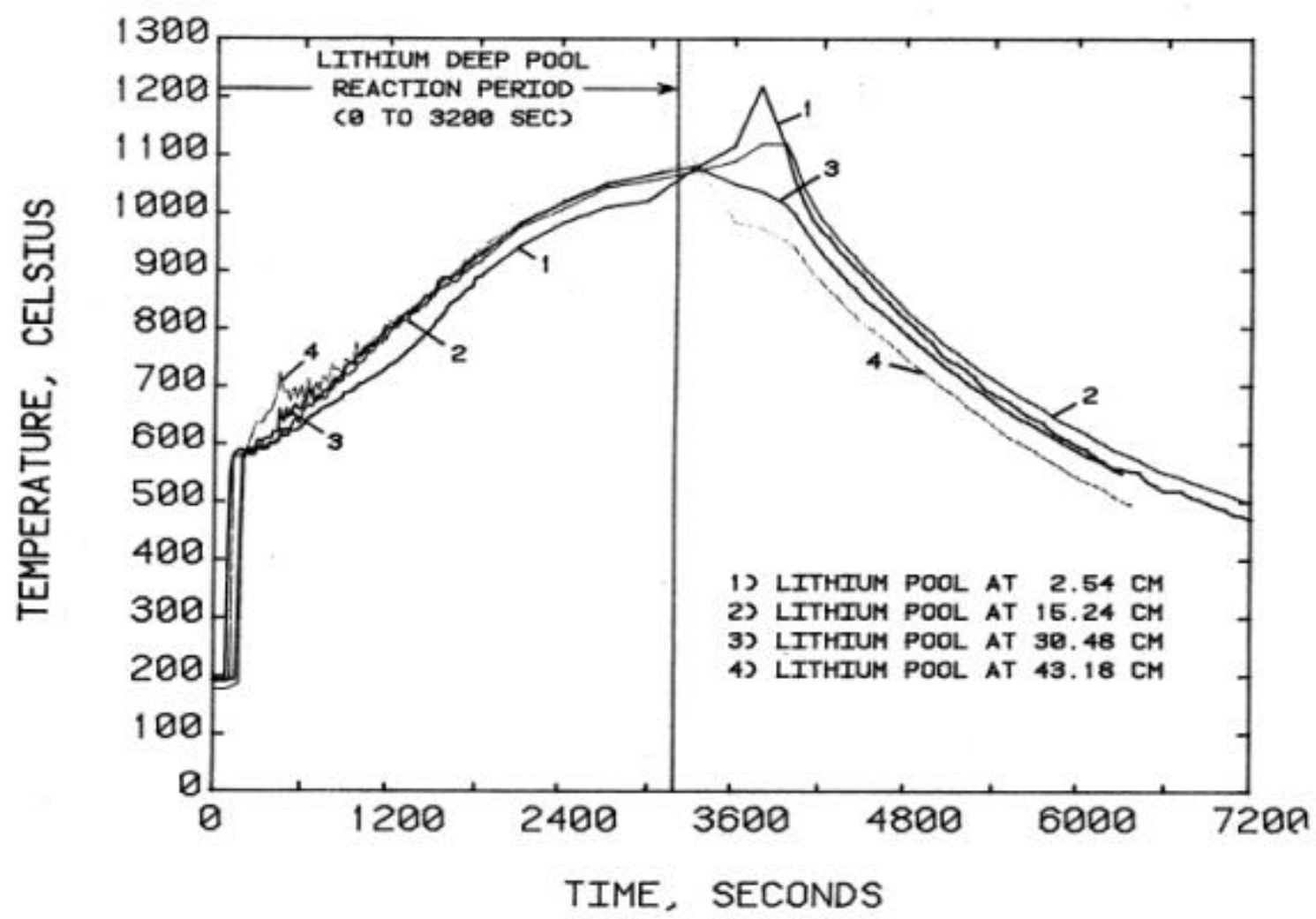

Figure 4. Lithium pool temperatures during Test LA-4.

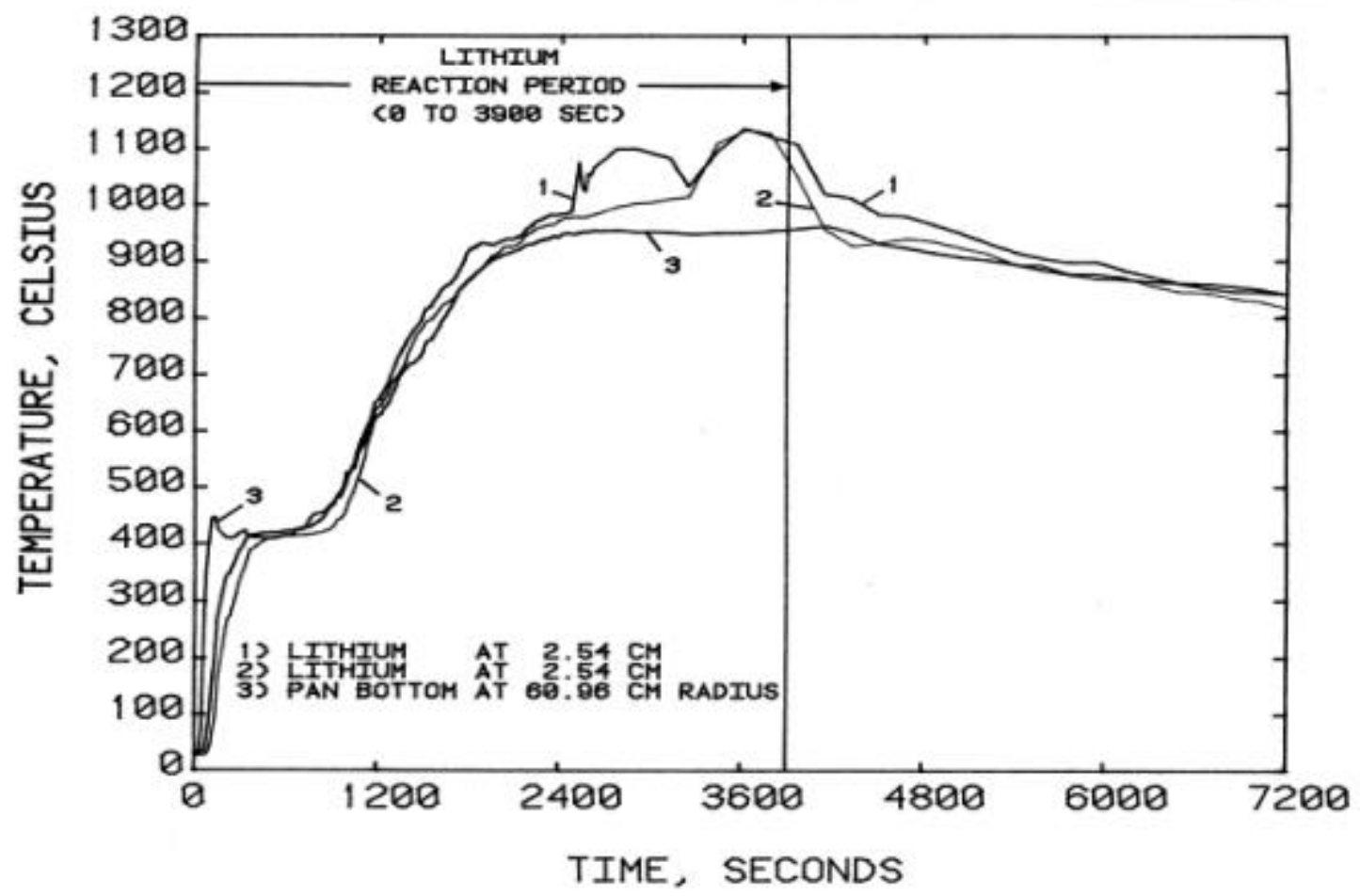

Figure 5. Lithium pool temperatures during Test LA-5. 


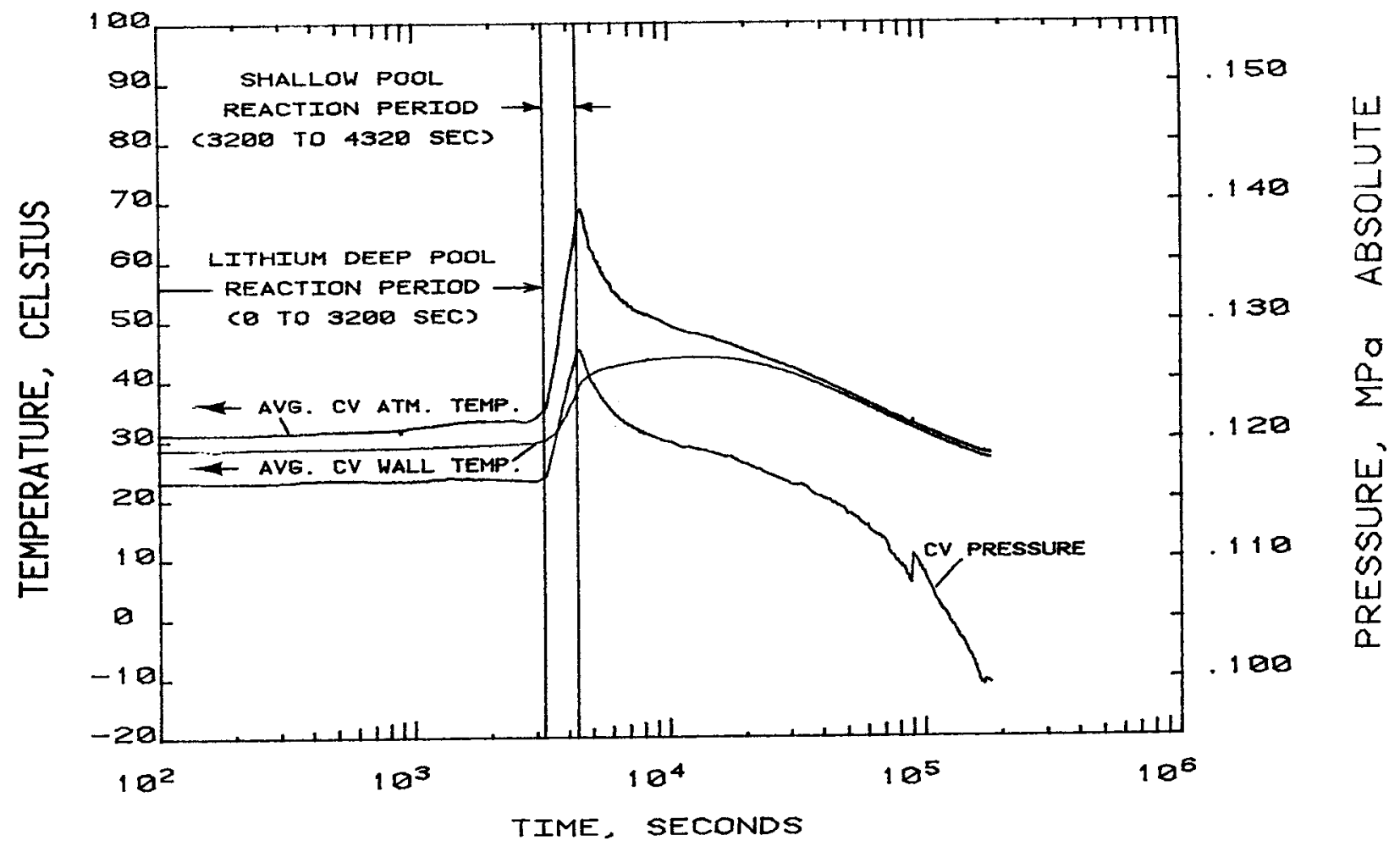

Figure 6 Containment vessel pressure, average atmosphere temperature and average vessel wall temperature during Test LA-4.

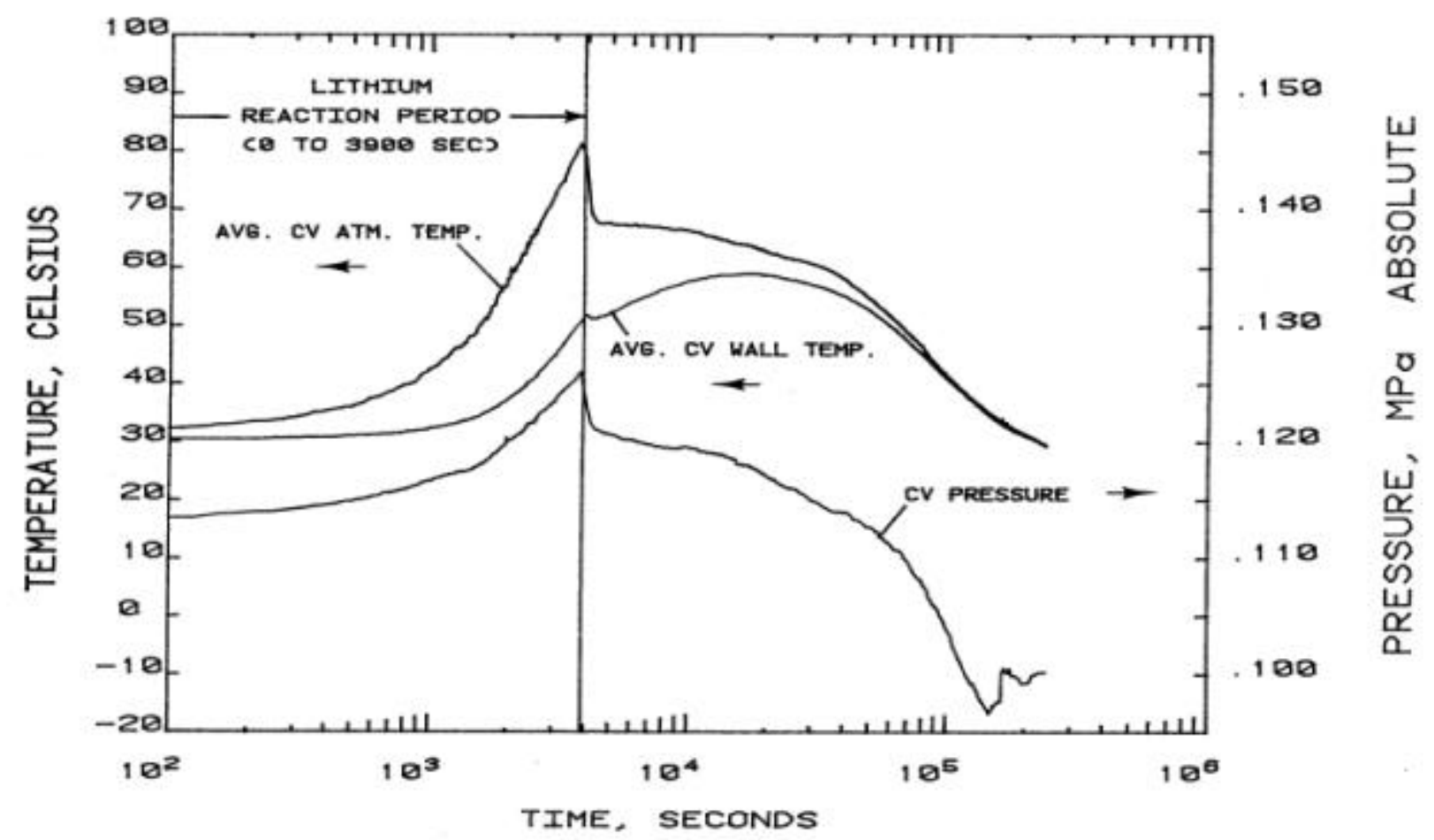

Figure 7. Containment vessel pressure, average atmosphere temperature and average vessel wall temperature during Test LA-5. 


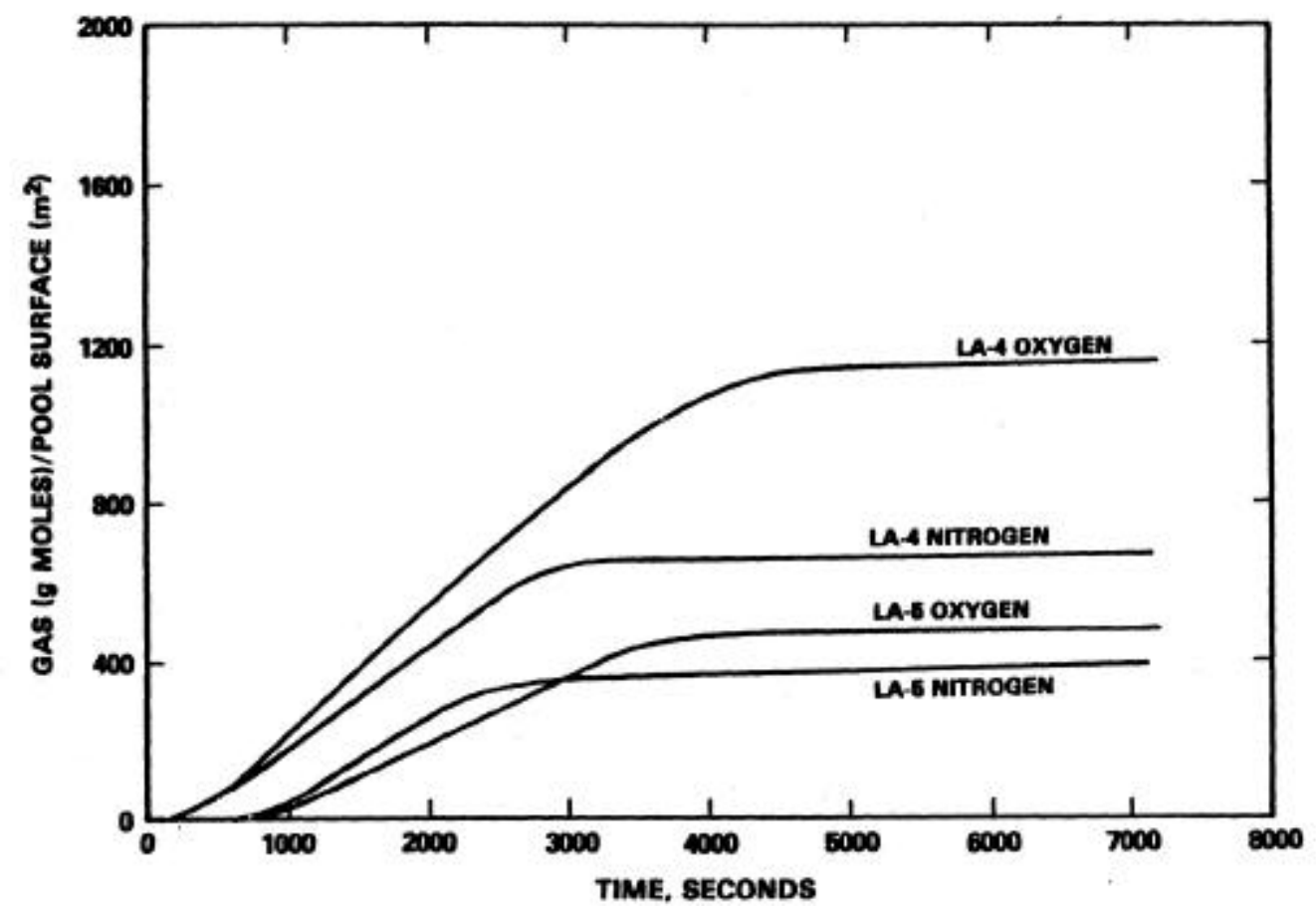

Figure 8. Nitrogen and oxygen consumption during Tests LA-4 and LA-5. 


\subsection{MELCOR Model of the HEDL CSTF}

Figure 9 contains a schematic of the MELCOR HEDL CSTF model developed for the benchmarking studies. As can be seen, this model contains 11 MELCOR control volumes, 15 MELCOR flow paths, and 13 MELCOR heat structures representing the $\mathrm{CV}$ of the CSTF. The model divides the CV into six sections in the axial direction, and two in the radial direction. The cylindrical portion of the $\mathrm{CV}$ was modeled by four axial zones, and the top and bottom head volumes were modeled by the two remaining axial zones. This nodalization allows the air heated by the lithium pool to rise up the axis of $\mathrm{CV}$, and return down the outer radius of the $\mathrm{CV}$ after convective cooling by the $\mathrm{CV}$ walls. The cross-sectional area of the inner zone of cells equals that of the pool surface area in Test LA-5, which is $2 \mathrm{~m}^{2}$. The outer zones have a crosssectional area of $41.8 \mathrm{~m}^{2}$. The height of the control volumes is $3.6 \mathrm{~m}$, except the bottom head volume that has a height of $2.2 \mathrm{~m}$. The MELCOR flow paths have been assigned the same flow areas as that of the corresponding control volumes that these flow paths connect. No form losses were assigned to the vertical flow paths, but form losses of 0.4 were assigned to the radial flow paths to simulate $90^{\circ}$ turns in the convective flow pattern.

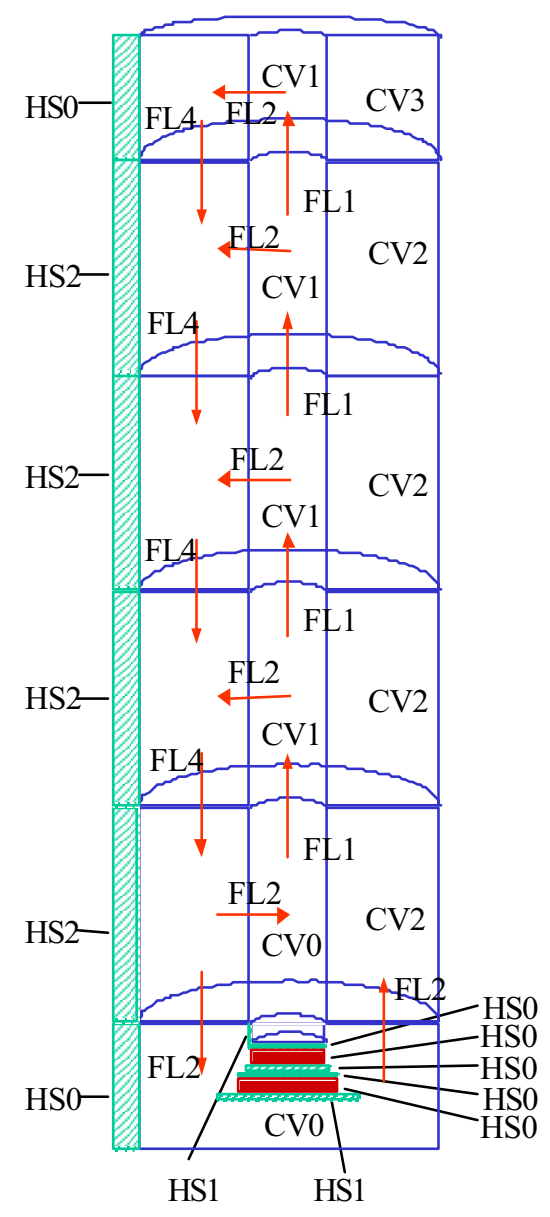

Figure 9. Schematic of MELCOR CSTF containment vessel model.

Heat structures representing the walls of the CV were attached to each of the outer control volumes. The four heat structures representing the walls of the cylindrical portion of the CV have surface areas of $98.5 \mathrm{~m}^{2}$, and thickness of $0.01862 \mathrm{~m}$. The heat structures that represent the top and bottom heads of the vessel have surface areas of $63 \mathrm{~m}^{2}$, with a thickness of $0.02839 \mathrm{~m}$ and $0.01862 \mathrm{~m}$, respectively. These vessel thicknesses were set to give the reported $\mathrm{CV}$ weight, with the top head heat structure sized to include the internal $\mathrm{CV}$ components attached to the top of the $\mathrm{CV}$. Because thermal properties for the CV wall material, called out as SA-212-B carbon steel by Reference [18], were not readily available, the $\mathrm{CV}$ wall material was assumed to be $316 \mathrm{SS}$. The exterior convective boundary condition for these walls was convection to the ambient with a heat 
transfer coefficient of $1.6 \mathrm{~W} / \mathrm{m}^{2}-\mathrm{K}$. This heat transfer coefficient accounted for $25.4-\mathrm{mm}$ layer of fiberglass insulation covering the exterior of the $\mathrm{CV}$, which has a thermal conductivity of $0.047 \mathrm{~W} / \mathrm{m}-\mathrm{K}$ [18], and an assumed air convection coefficient of 10 $\mathrm{W} / \mathrm{m}^{2}-\mathrm{K}$.

The reaction pan/catch pan assembly was modeled by seven heat structures. The bottom and side of the reaction pan were model as two heat structures. The catch pans and firebrick layers were model by the remaining five heat structures. Heat transfer from the side-wall of the reaction pan was by convection to the atmosphere of the control volume, calculated by the standard MELCOR convection package, and by radiant heat loss to the CV lower head (effective emissivity of 0.17 , which is an emissivity of 0.3 per surface assumed [19]). Heat transfer from the bottom of the reaction pan through the catch pan assemble was by gap conduction between heat structures and conduction through heat structures. The gap conductance includes a gap coefficient (typically 10-20 $\mathrm{W} / \mathrm{m}^{2}-\mathrm{K}$, which varied per experiment to match measured pool temperatures during the lithium charging period of a test), and thermal radiation. This gap conductance is scaled by the square root of the gap temperature during a calculation, to reflect the fact that the gap gas conductivity would scale as the square root of temperature. The effective emissivity of the gap was set at 0.3 , which assumes an emissivity value of 0.3 for the SS316 and 1.0 for the firebrick. Temperature dependent material properties of density, specific heat, thermal conductivity, and emissivity for SS316 where obtained from Reference [19]. Temperature dependent material properties for Missouri firebrick were obtained from Reference [20], and those for KAOWOOL from Reference [21].

A final modeling issue that needs to be addressed relates to the MELCOR model for mass and heat transfer at the surface of the lithium pool described in Section 3.2. As can be seen from Equation 34 of Section 3.2, there is a convective and radiative component to the heat transfer between the pool and atmosphere in a MELCOR nonequilibrium control volume. The problem with the radiative component is that it assumes perfect absorption of the thermal radiation by the atmosphere in the volume. This is probably a good assumption for a water-vapor atmosphere, but not for an air atmosphere. Future modifications will be made to this MELCOR model that will more accurately

estimate the quantity of heat being absorbed by the vapor. But for this benchmarking study, the radiative heat transfer component of Equation 34 was set to zero, and a user defined MELCOR control function employed to predict the radiative heat transfer between the pool surface and the $\mathrm{CV}$ walls for the following benchmark studies.

\subsection{Test LA-4 Benchmark Study Results}

Comparisons of MELCOR predictions with data from Test LA-4 are contained in Figures 10 through 17. Figure 10 contains the averaged pool temperature from Test LA4 and MELCOR predicted pool temperatures. As can be seen, excellent agreement was achieved between two MELCOR predictions and test results. The averaged pool temperature of Figure 10 is that of thermocouple locations 2 through 4 of Figure 4 . The pool temperature at $2.54 \mathrm{~cm}$ above the reaction pan floor was not included in this average because this thermocouple resides in a region of the pool that experienced a large thermal gradient. The MELCOR predictions correspond to this average temperature because the 
lithium pool of the MELCOR model was a lumped representation of the pool, that is the pool was not sub-divided into a multiple MELCOR control volumes. The MELCOR results were arbitrarily terminated at 3200 seconds, which is the time at which the reaction pan failed in this test. Two MELCOR predictions have been included. The first case, designated natural convection at the pool interface (NCPI), disallowed forced convection heat transfer at the pool surface. This was accomplished by setting sensitivity coefficient 4407(2) to zero in the user input. The second case, designated forced convection at the pool interface (FCPI), allowed forced convection heat transfer at the pool surface. Because these MELCOR cases gave similar results and because the forced convection heat transfer coefficient is a factor of three larger than the natural convection heat transfer coefficient, it could be concluded that convective heat transfer did not play an important role in Test LA-4. In fact, predictions for this test were not very sensitive to any of the heat transfer modeling assumptions detailed in Section 4.2, for example the gap conductance coefficient between the reaction pan and the firebrick layer beneath the pan. This is probably the consequence of the KAOWOOL and firebrick insulating layers that surround the reaction pan of Test LA-4. As can also be seen, the MELCOR prediction for forced convection at the pool interface gives slightly better pool temperatures than does the case with natural turbulent convection.

Based on MELCOR predictions, the lithium reactions of Test LA-4 produced 170 MJ of energy in the first 3200 seconds of the test. Of this energy, 9 MJ was conducted through the bottom of the reaction pan, $7 \mathrm{MJ}$ was convected from the outer surface of the KAOWOOL to the $\mathrm{CV}$ atmosphere, $5 \mathrm{MJ}$ was radiated from the KAOWOOL outer surface to the CV walls, $20 \mathrm{MJ}$ was convected from the inner surface of the reaction pan to the atmosphere, $5 \mathrm{MJ}$ produced lithium pool vaporization, and $46 \mathrm{MJ}$ was radiated from the surface of the pool to the $\mathrm{CV}$ walls. To obtain the pool surface radiative rate, an emissivity coefficient of 1.0 was used. This value was adopted because: 1) emissivity data could not be found for $\mathrm{Li}_{2} \mathrm{O}$ and $\mathrm{Li}_{3} \mathrm{~N}, 2$ ) it gave the best fit to the data for the above modeling assumptions, and 3) photographs in Reference [18] of the residue from the reaction pan appears to be a "grayish" color, which suggests a high surface emissivity coefficient.

Figures 11 and 12 contain the gmoles per unit area $\left(\mathrm{m}^{2}\right)$ of oxygen and nitrogen gas consumed during Test LA-4. As can be seen, both MELCOR cases examined agreed well with the measured value from the experiment. Of interest here are the results for nitrogen for two reasons. First, the rate of consumption of nitrogen decreases to nearly zero in the data between test times of 2700 seconds and 3200 seconds. Note that this transition occurs prior to the failure of the reaction pan during this experiment. The corresponding temperature range is about $1300 \mathrm{~K}$ to $1350 \mathrm{~K}$. According to Reference [12], two important phenomena occur for lithium nitride $\left(\mathrm{Li}_{3} \mathrm{~N}\right)$ near this temperature range: 1) lithium nitride melts at $1082 \mathrm{~K}$, and 2) the phase equilibrium constant for the lithium-nitrogen reaction becomes 1.0 at a temperature of about $1225 \mathrm{~K}$, suggesting that above this temperature $\mathrm{Li}_{3} \mathrm{~N}$ should start to decompose. Second, to achieve the measured rate of nitrogen consumption the reaction rate equation (Equation 27 for nitrogen) had to be multiplied by a factor of 0.3 . This suggests that only $30 \%$ of the mass diffusing through the gas boundary layer actually reacts with the lithium. In contrast, the measured 
rate of oxygen consumption matched the predicted rate (Equation 27) without the use of a multiplying factor.

Figures 13 and 14 contain comparisons for $\mathrm{CV}$ average atmosphere temperature and average wall temperature, respectively, for Test LA-4. Fair agreement was obtained with the two MELCOR cases examined. The important features of these figures are that the MELCOR prediction for natural convection heat transfer at the pool surface more accurately matches the test data, and that very little heat transfer occurred to the $\mathrm{CV}$ atmosphere and walls during the first 3200 seconds of Test LA-4. The measured CV atmosphere temperature rise was $4 \mathrm{~K}$, and the $\mathrm{CV}$ wall temperature rise was $1.7 \mathrm{~K}$. This compares to a $7 \mathrm{~K}$ and $10 \mathrm{~K}$ rise for the $\mathrm{CV}$ atmosphere temperature and $1.8 \mathrm{~K}$ and $2.0 \mathrm{~K}$ rise for the $\mathrm{CV}$ wall temperature for the MELCOR cases examined.

The energy transferred directly to the CV wall by thermal radiation was about 51 $\mathrm{MJ}$ and that transferred to the $\mathrm{CV}$ atmosphere by convection was $31 \mathrm{MJ}$. If the heat transfer to the atmosphere were to be reduced by $50 \%$ to match the measured atmosphere temperature rise, the pool and $\mathrm{CV}$ wall temperature rise would increase. Therefore, it could be argued that heat of reaction used in this new MELCOR model is about $9 \%$ too high (i.e., 0.5x31 MJ/170 MJ = 0.09). Consequently, a third MELCOR case was examined to test this hypothesis. This case is similar to Case 1 but has a reduced heat of reaction (NCRH). Figures 15 through 17 contain the results of this case, compared to Test LA-4 data. As can be seen, excellent agreement was obtained for this case. It could be argued that a similar result could have been obtained by increasing the heat transfer through the bottom of the reaction pan and catch pan assembly. It is unfortunate that measured catch pan temperatures for this test where not reported, because this would help answer this point. However, for this argument to be correct, the heat transfer through this structure would have to be increased by a factor of $170 \%$ since the predicted energy flow through the bottom of the reaction pan was only $9 \mathrm{MJ}$ for this test. The same could be said about increasing the radial heat flow through the side-wall of the reaction pan. 


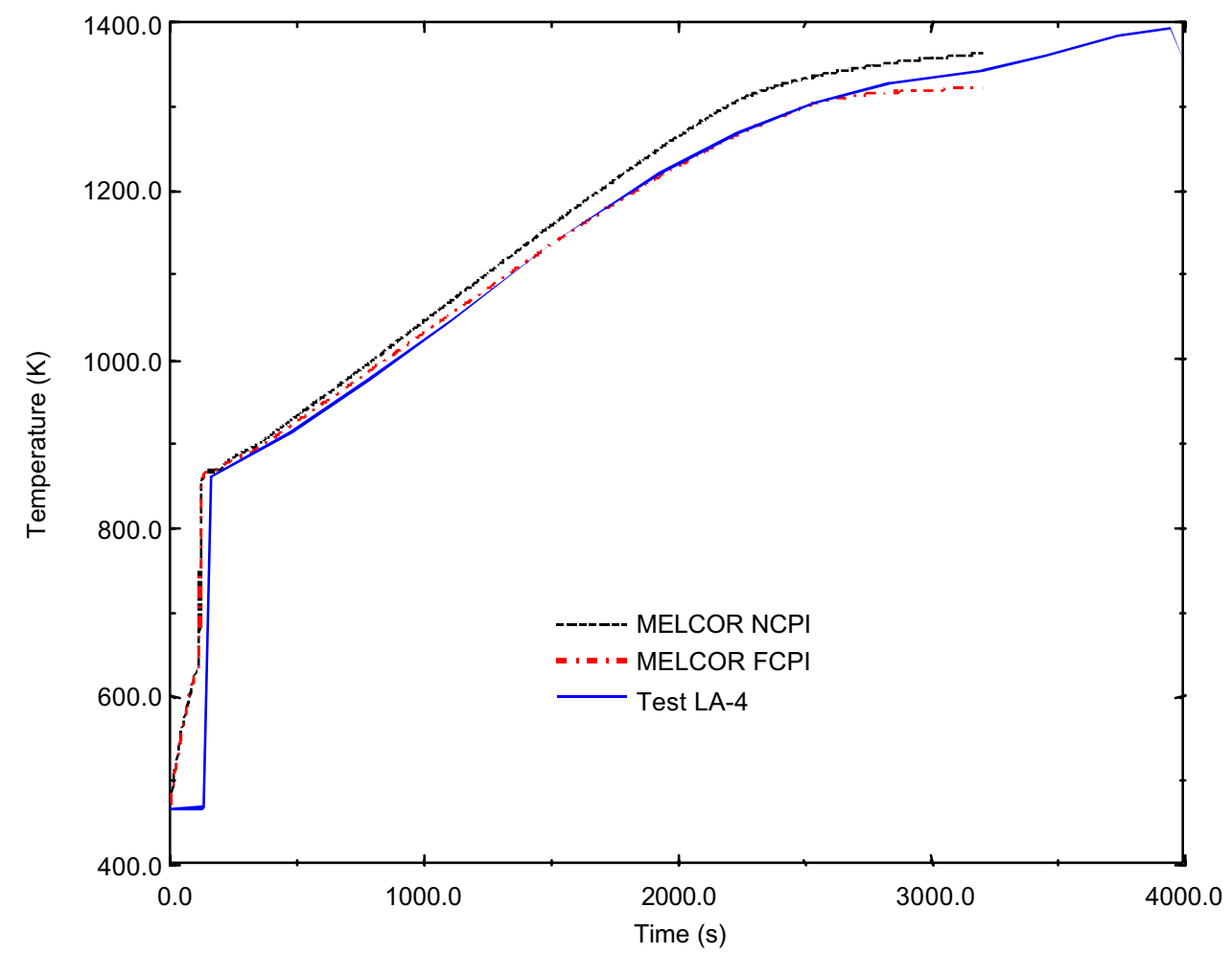

Figure 10. Comparison of MELCOR predicted pool temperature with data from Test LA-4.

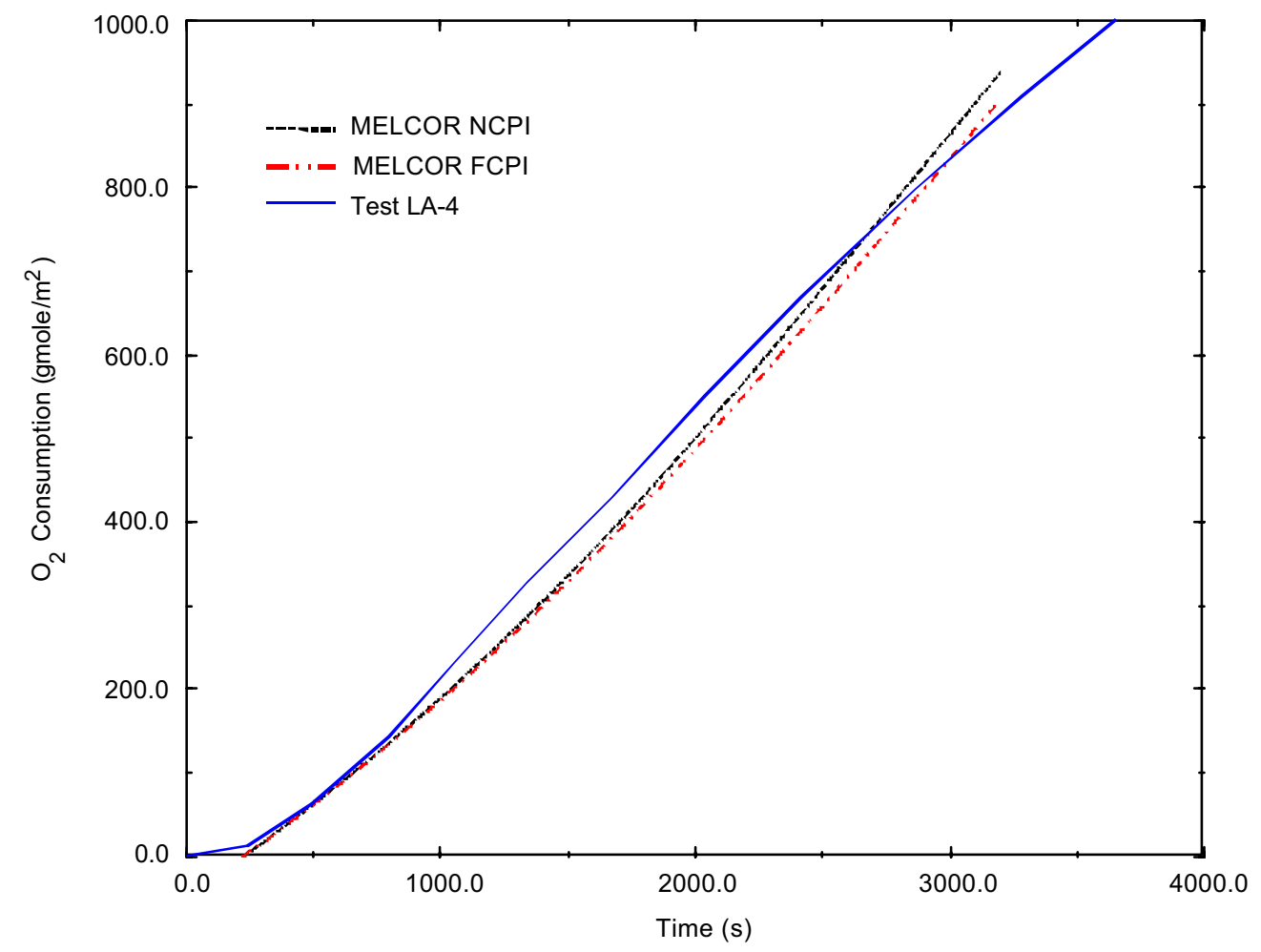

Figure 11. Comparison of MELCOR predicted oxygen consumption with that measured during Test LA-4. 


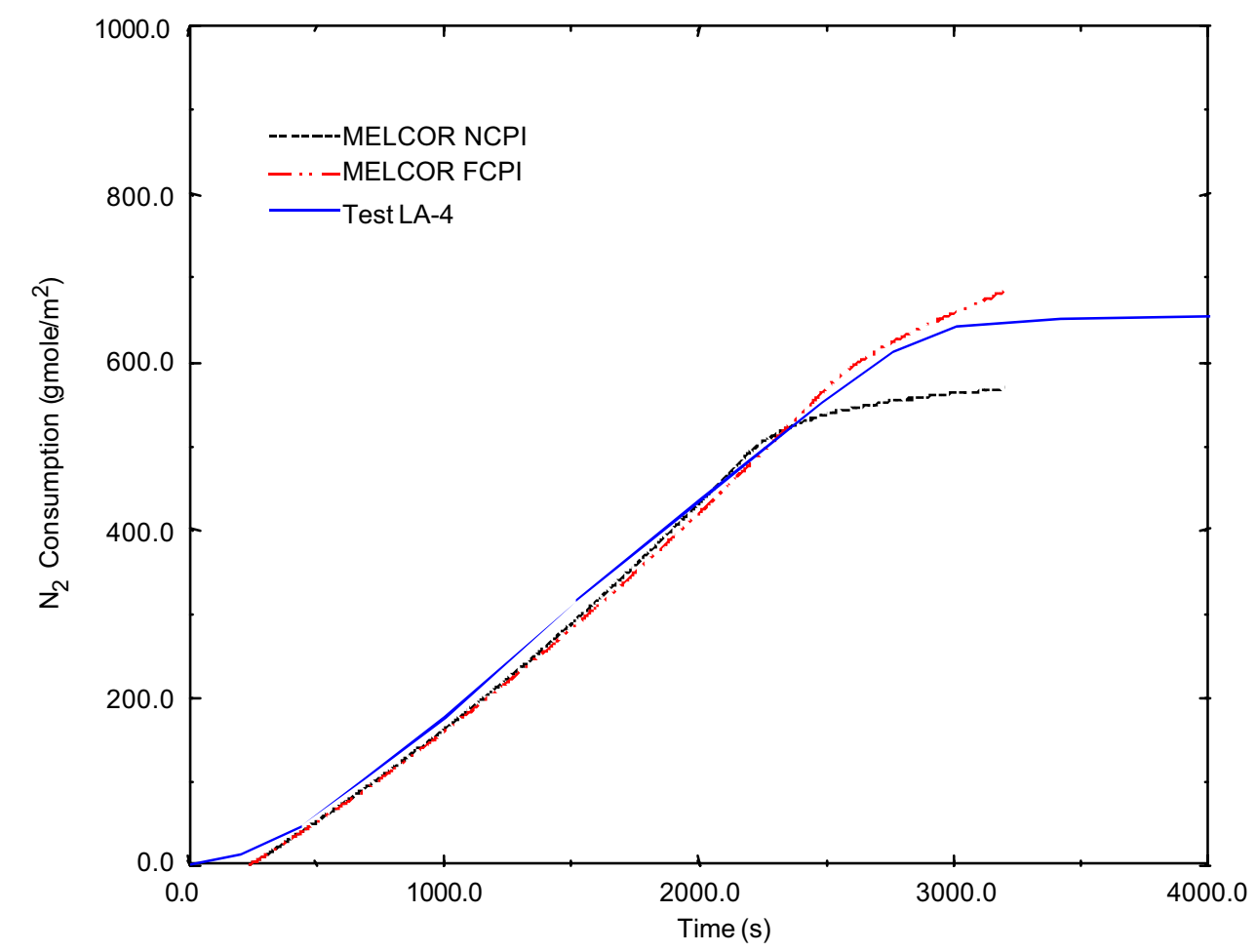

Figure 12. Comparison of MELCOR predicted nitrogen consumption with that measured during Test LA-4.

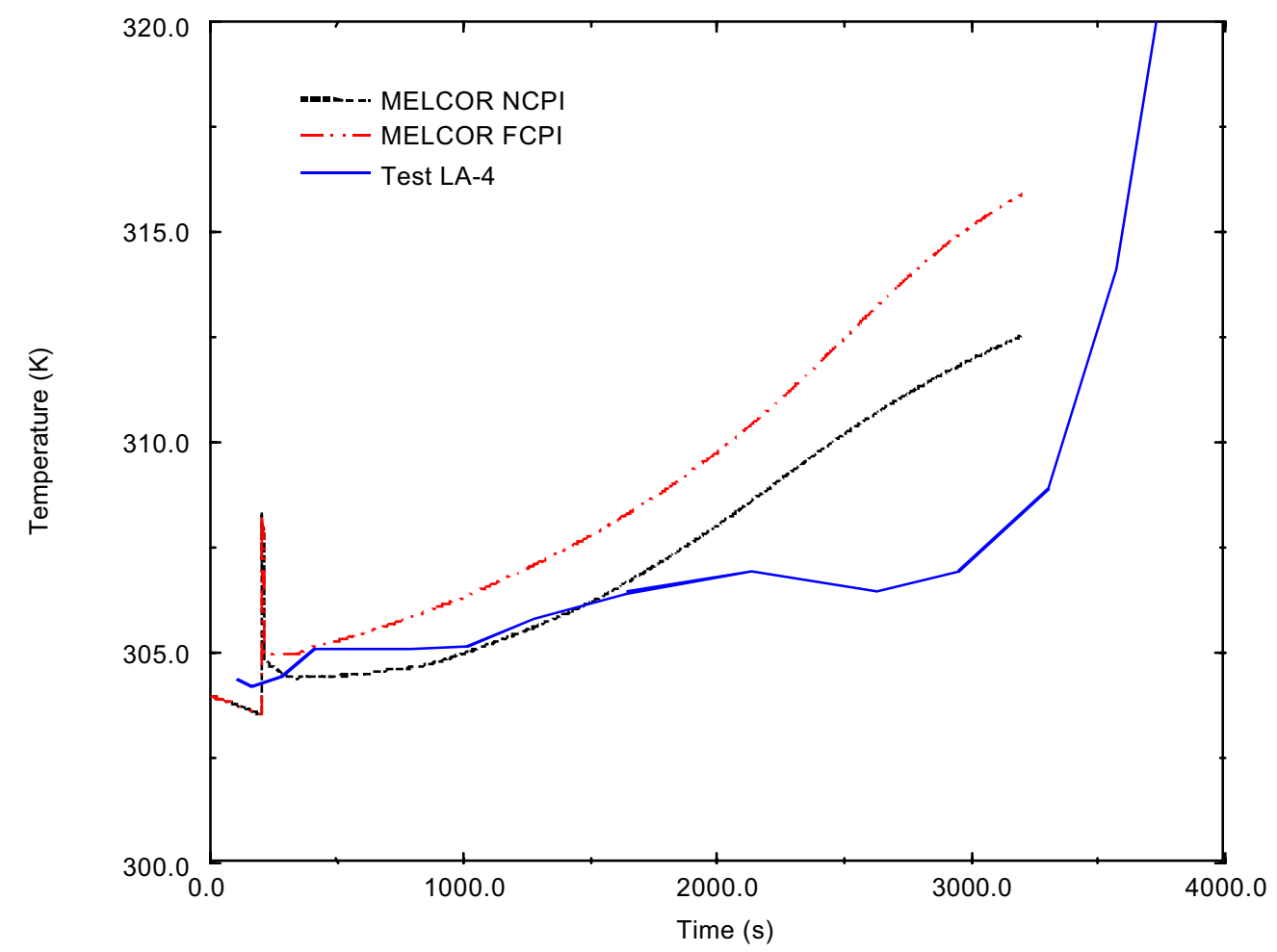

Figure 13. Comparison of MELCOR predicted CV atmosphere temperature with that measured during Test LA-4. 


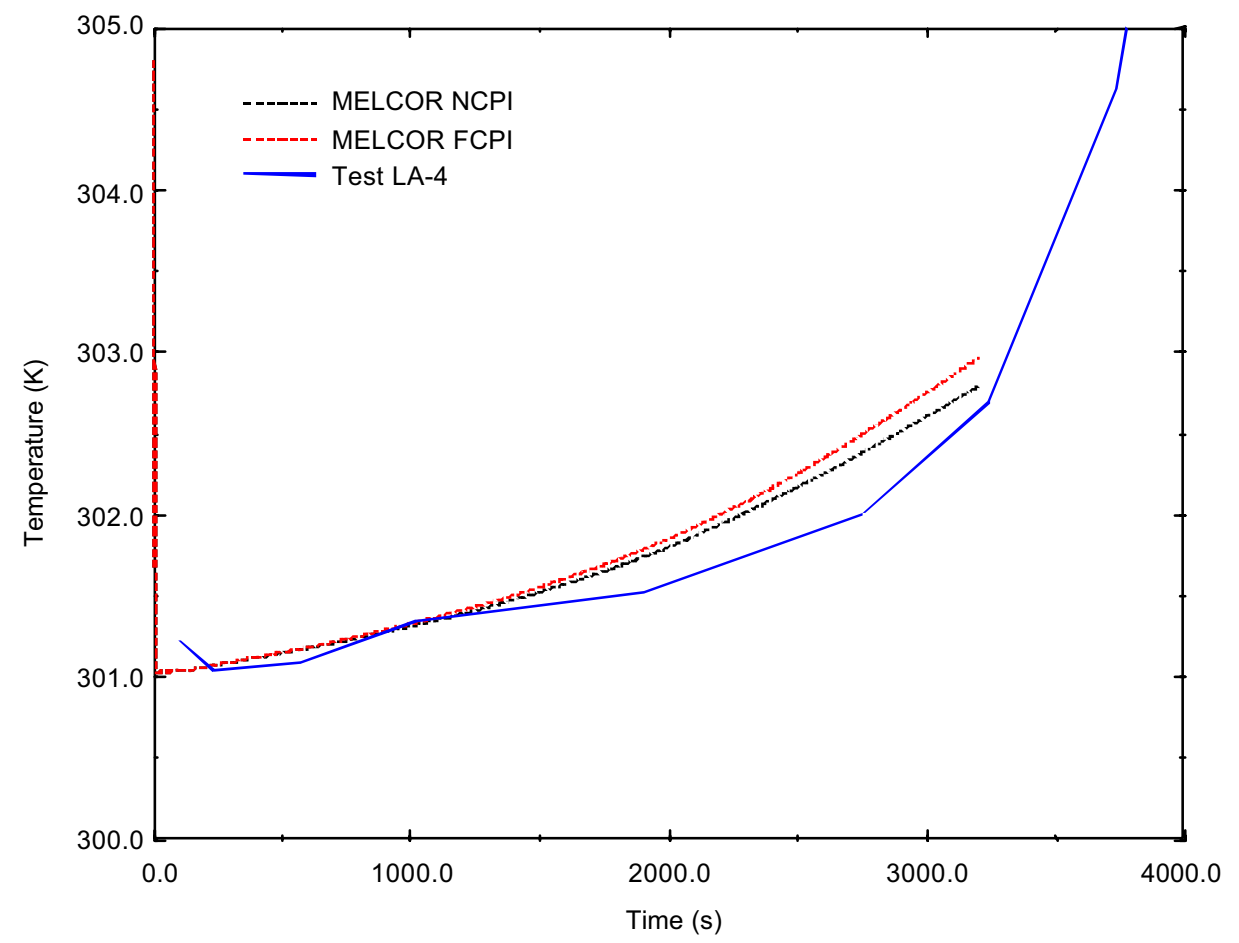

Figure 14. Comparison of MELCOR predicted CV wall temperature with that measured during Test LA-4.

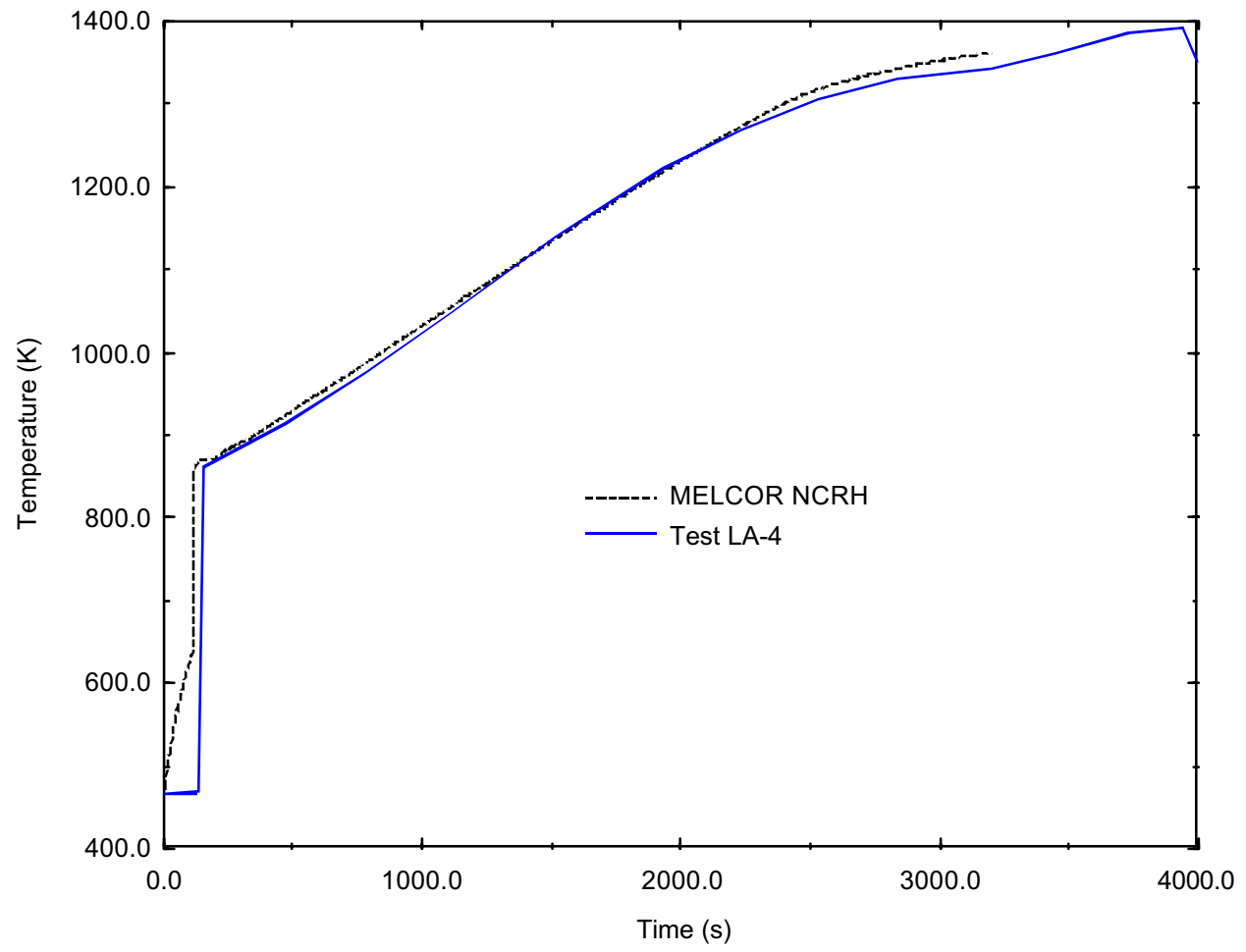

Figure 15. Comparison of MELCOR reduced heat of reaction case predicted lithium pool temperature with that measured during Test LA-4. 


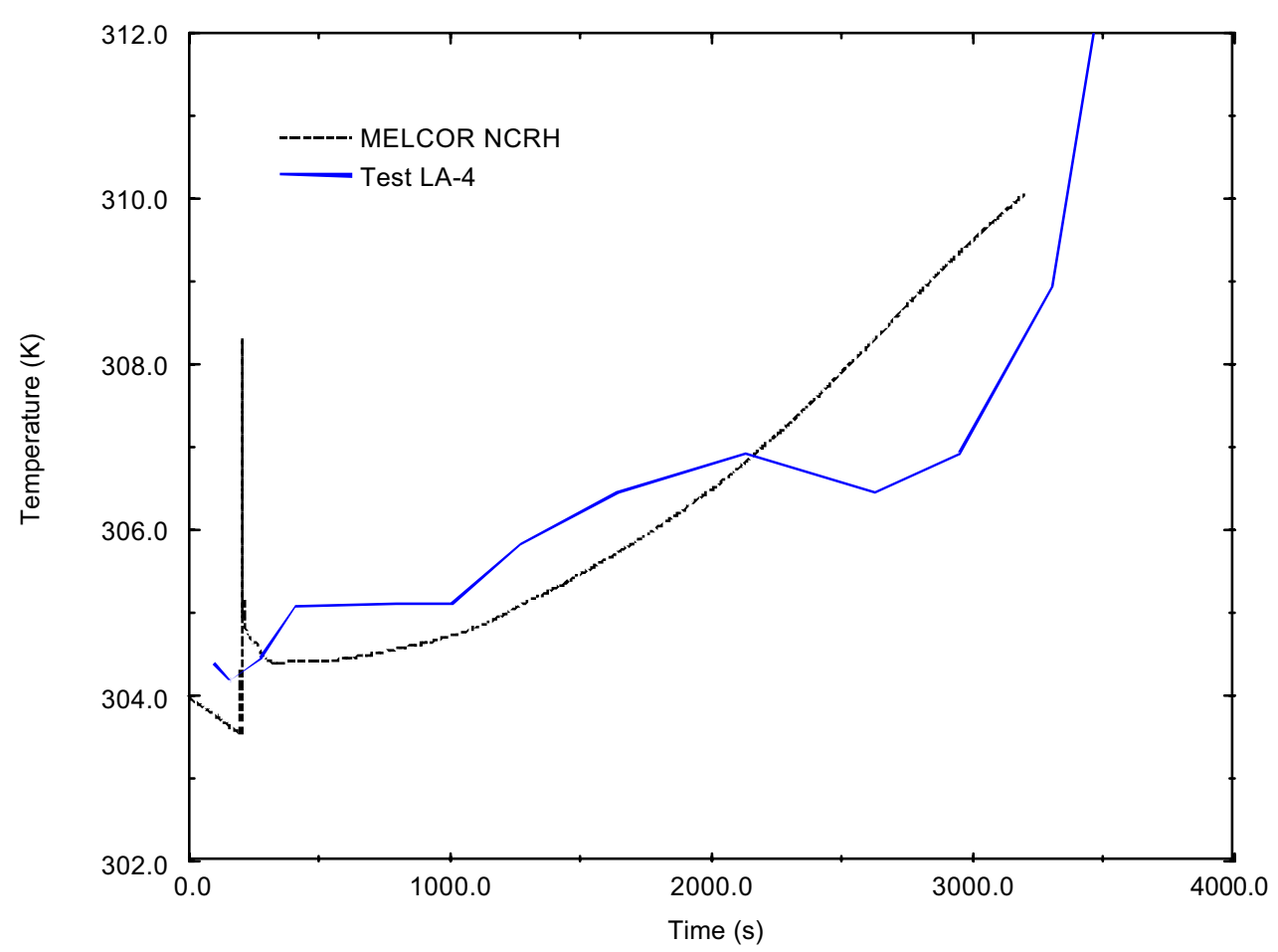

Figure 16. Comparison of MELCOR reduced heat of reaction case predicted CV atmosphere temperature with that measured during Test LA-4.

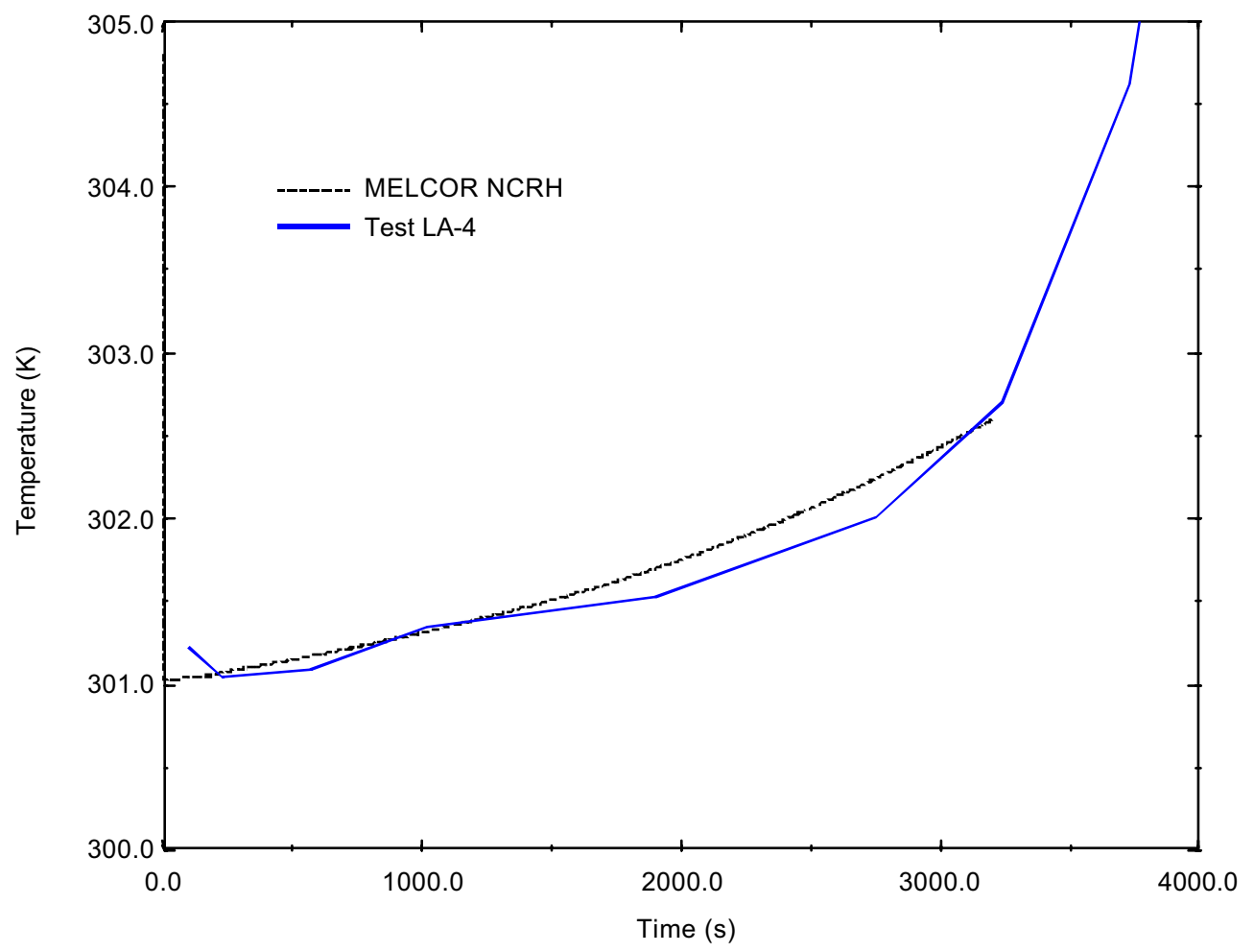

Figure 17. Comparison of MELCOR reduced heat of reaction case predicted CV wall temperature with that measured during Test LA-4. 


\subsection{Test LA-5 Benchmark Study Results}

Results for Test LA-5 appear in Figures 18 through 23. Figure 18 contains a comparison of Test LA5 average pool temperature from thermocouples 1 and 2 (note Figure 3) with MELCOR predictions. The same three cases examined for Test LA4 were examined for Test LA-5, which are: 1) natural convection at the pool atmosphere interface (NCPI), 2) forced convection at the pool atmosphere interface (FCPI), and 3) natural convection at the pool atmosphere interface plus a reduced heat of reaction (NCRH). The comparison for all three cases is very good. However, to follow the measured temperature before 900 seconds and after 1700 seconds three modeling changes had to be made to the MELCOR model used for analyzing Test LA-4. The first change dealt with the difference in reaction pan dimensions between Test LA-4 and Test LA-5, and removal of the KOAWOOL insulation from the reaction pan side-wall. The second modeling change affected the rate at which the lithium reacts with oxygen and nitrogen during the first 900 seconds. As reported by Reference [18]: "During the initial 900 seconds, localized flames were observed as small, 'popcorn kernel'-like fires on the surface of the pool. Lithium appeared to wick up on these "kernels," burn and slowly grow in diameter to cover the pool surface." To simulate the growth of the reaction zone an Arrhenius type reaction relationships were derived from the oxygen and nitrogen consumption data for Test LA-5 during this period of time. These relationships are:

$\Gamma_{\mathrm{O} 2}=1.8 \times 10^{6} \mathrm{e}^{-15360 / \mathrm{T}}$

for oxygen, where $\Gamma_{\mathrm{O} 2}$ is the oxygen consumption rate $\left(\mathrm{kg} / \mathrm{m}^{2}-\mathrm{s}\right)$, and $\mathrm{T}$ is the pool temperature $(\mathrm{K})$, and for nitrogen

$\Gamma_{\mathrm{N} 2}=5.8 \times 10^{8} \mathrm{e}^{-18780 / \mathrm{T}}$

where $\Gamma_{\mathrm{N} 2}$ is the nitrogen consumption rate $\left(\mathrm{kg} / \mathrm{m}^{2}-\mathrm{s}\right)$. As such, these relationships compensate for the inability of a one-dimensional heat conduction model to accurately represent a three-dimensional heat conduction problem. The final modeling change dealt with the adopted pool surface emissivity. For Test LA4 a constant value of 1.0 was used. However, for Test LA-5 an emissivity that varied with temperature had to be used to match test data. The emissivity as a function of pool temperature used appears in Figure 19.

Figures 20 and 21 contain the gmoles per unit area $\left(\mathrm{m}^{2}\right)$ of oxygen and nitrogen gas consumed during Test LA-5. As can be seen, the MELCOR cases agree well with the test data. The consumption of nitrogen for Test LA-5 is similar to that of Test LA-4, that is the measured rate of nitrogen consumption occurrs at $30 \%$ of the predicted rate from Equation 27 for nitrogen. However, there is a difference in the temperature at which the reaction starts to cease. In Test LA-5 this temperature was $1200 \mathrm{~K}$ (i.e., pool temperature a 2250 seconds), compared to $1300 \mathrm{~K}$ for Test LA-4. It also appears that the temperature range over which the decrease occurs is larger for Test LA-5. To match the measured oxygen consumption for test LA-5, the predicted rate of consumption had to be multiplied by a factor of 0.6. This differed from Test LA-4 that did not require any 
multiplying factor applied to Equation 27. It is also of interest to note that the lithiumoxygen reaction starts to decrease before the termination of Test LA-5 (i.e., at a time of 3200 seconds and a temperature of $1350 \mathrm{~K}$ ).

Figures 22 and 23 contain comparisons of average $\mathrm{CV}$ atmosphere and wall temperatures for Test LA-5. Fairly good agreement was obtained with the MELCOR cases examined. Cases 2 and 3, which are forced convection heat transfer at the pool interface (FCPI) and natural convection at the pool interface plus a reduction in heat of reaction $(\mathrm{NCRH})$, bracket the measured $\mathrm{CV}$ atmosphere and $\mathrm{CV}$ wall temperature rise. However, Case 1, which is natural convection at the pool interface (NCPI), appears to more accurately match both temperatures. The measured CV atmosphere temperature rise is $50 \mathrm{~K}$, while the predicted rise for Cases 1 through 3 is $48 \mathrm{~K}, 60 \mathrm{~K}$, and $40 \mathrm{~K}$, respectively. Similarly the measure $\mathrm{CV}$ wall temperature rise is $20 \mathrm{~K}$, while the predicted rise for Cases 1 through 3 is $17 \mathrm{~K}, 22 \mathrm{~K}$, and $15 \mathrm{~K}$, respectively.

The energy balance for Test LA-5 is that of the $1410 \mathrm{MJ}$ of energy liberated, $410 \mathrm{MJ}$ was radiated from the pool surface to the $\mathrm{CV}$ walls, $210 \mathrm{MJ}$ was conducted through the bottom of the reaction pan into the catch pan assembly, $73 \mathrm{MJ}$ was convected to the atmosphere from the reaction pan side wall, $115 \mathrm{MJ}$ was radiated from the reaction pan side-wall, and $155 \mathrm{MJ}$ produced lithium vaporization at the pool surface. This division of energy suggests a shift in importance of heat transfer path between Test LA-4 and Test LA-5 from the side-wall of the reaction pan to the bottom of the reaction pan. For Test LA-5 the energy split was $15 \%$ through the bottom of the reaction pan, and $13 \%$ through the side-wall of the reaction pan. For Test LA-4, this energy split was 5.3\% and $18.8 \%$, respectively. Radiation from the pool surface accounted for $29 \%$ of the energy transferred in Test LA-5 and $27 \%$ in Test LA-4. This is interesting given the dramatic difference in the modeling assumptions used regarding pool surface emissivity between Test LA-4 and Test LA-5. The fraction of energy produced by the lithium-nitrogen reaction for Test LA-5 was $45 \%$ of the total, compared to only $33 \%$ for Test LA-4. This is due to the lower lithium-oxygen reaction rate measured for Test LA-5. 


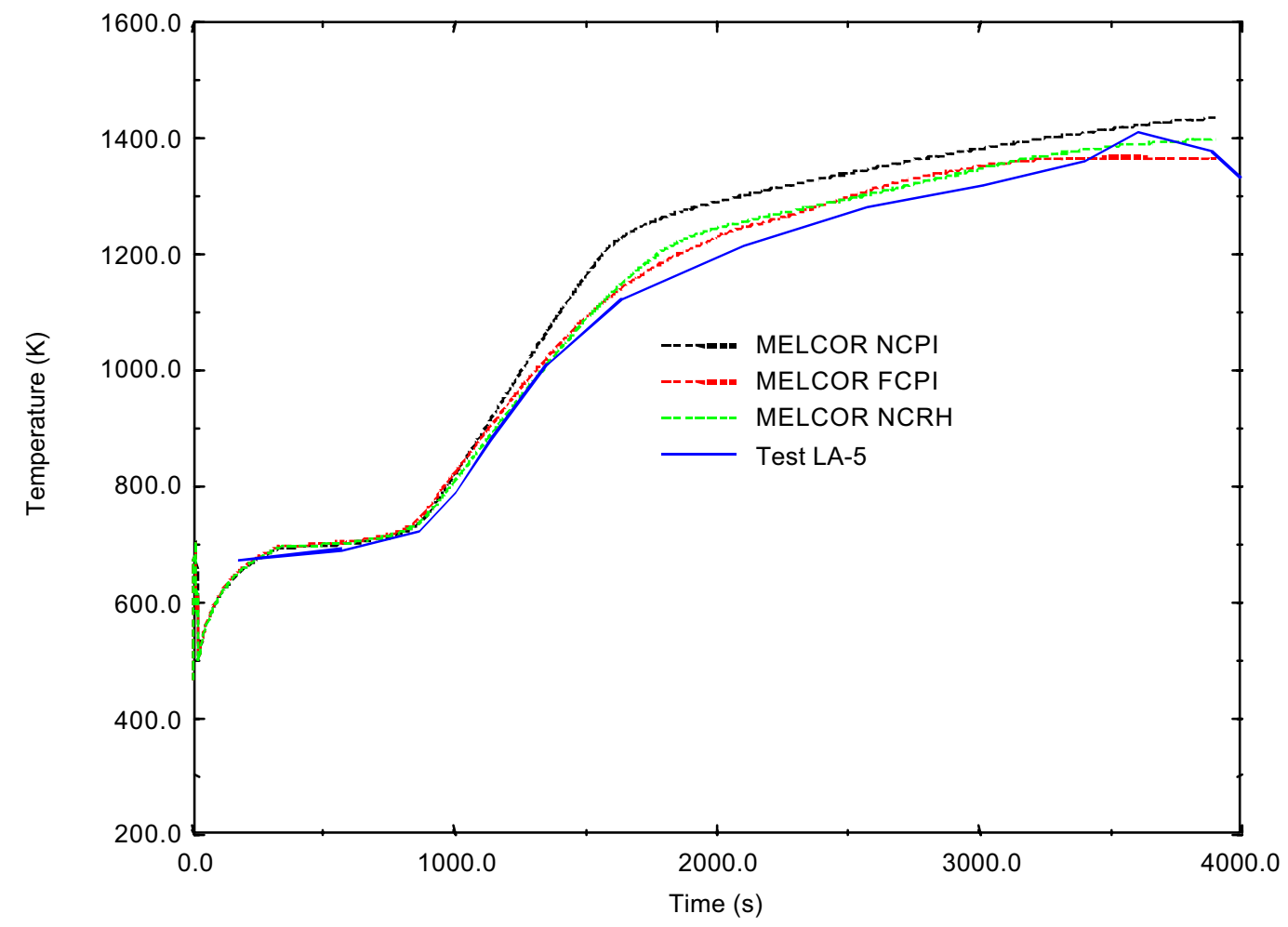

Figure 18. Comparison of MELCOR predicted pool temperature with data from Test LA-5.

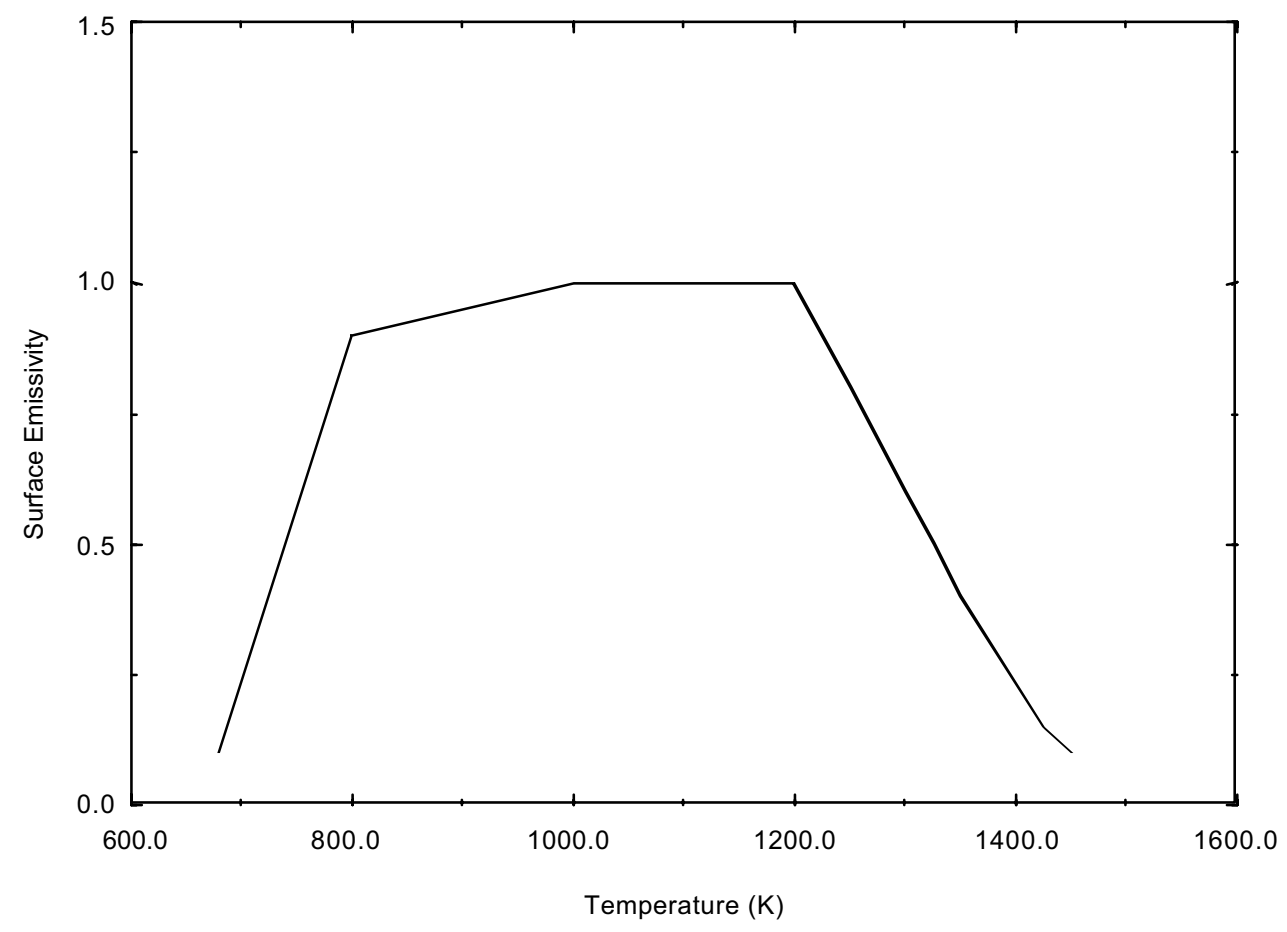

Figure 19. Pool surface emissivity use by MELCOR to match pool temperature data from Test LA-5. 


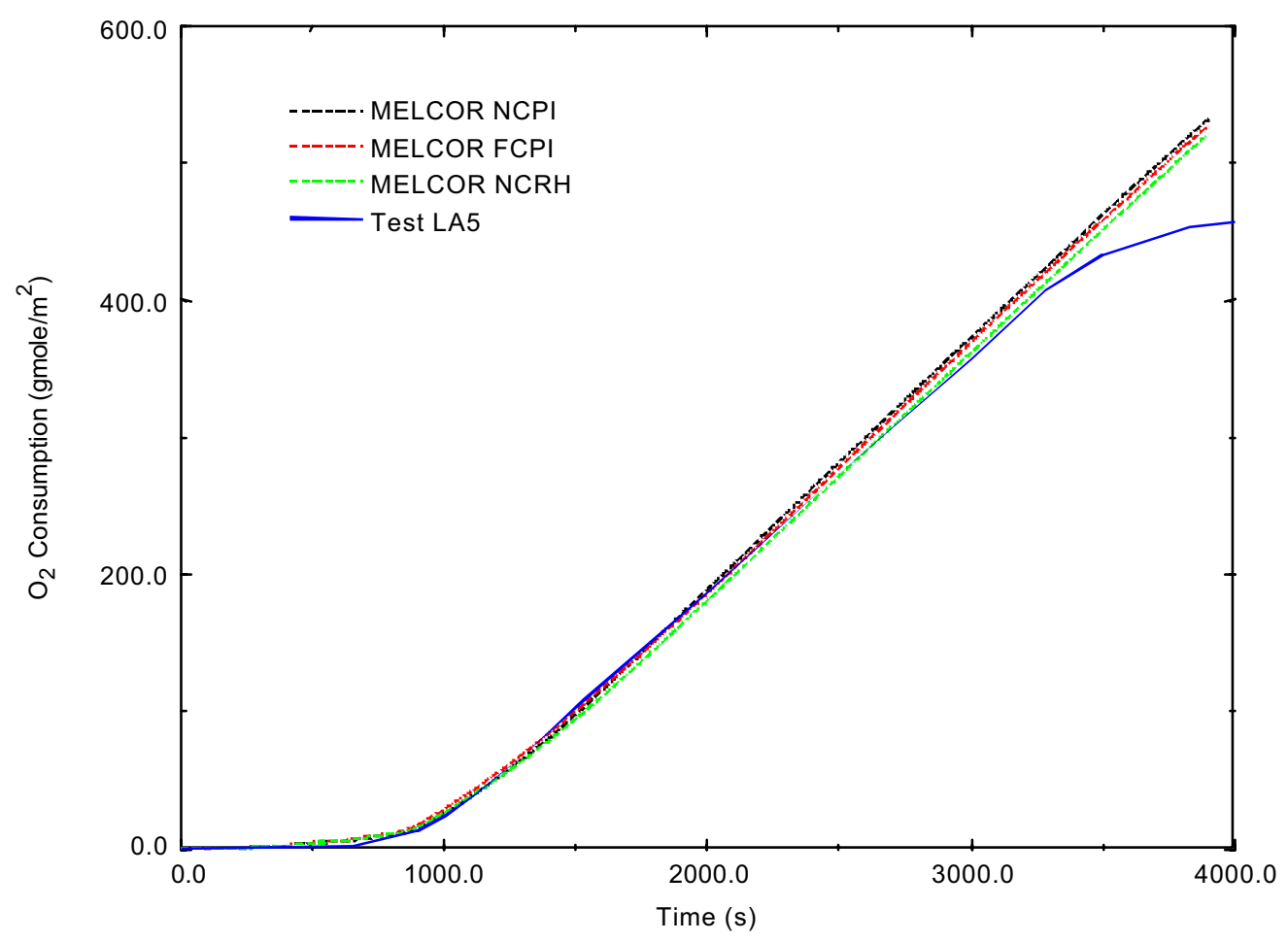

Figure 20. Comparison of MELCOR predicted oxygen consumption with that measured during Test LA-5.

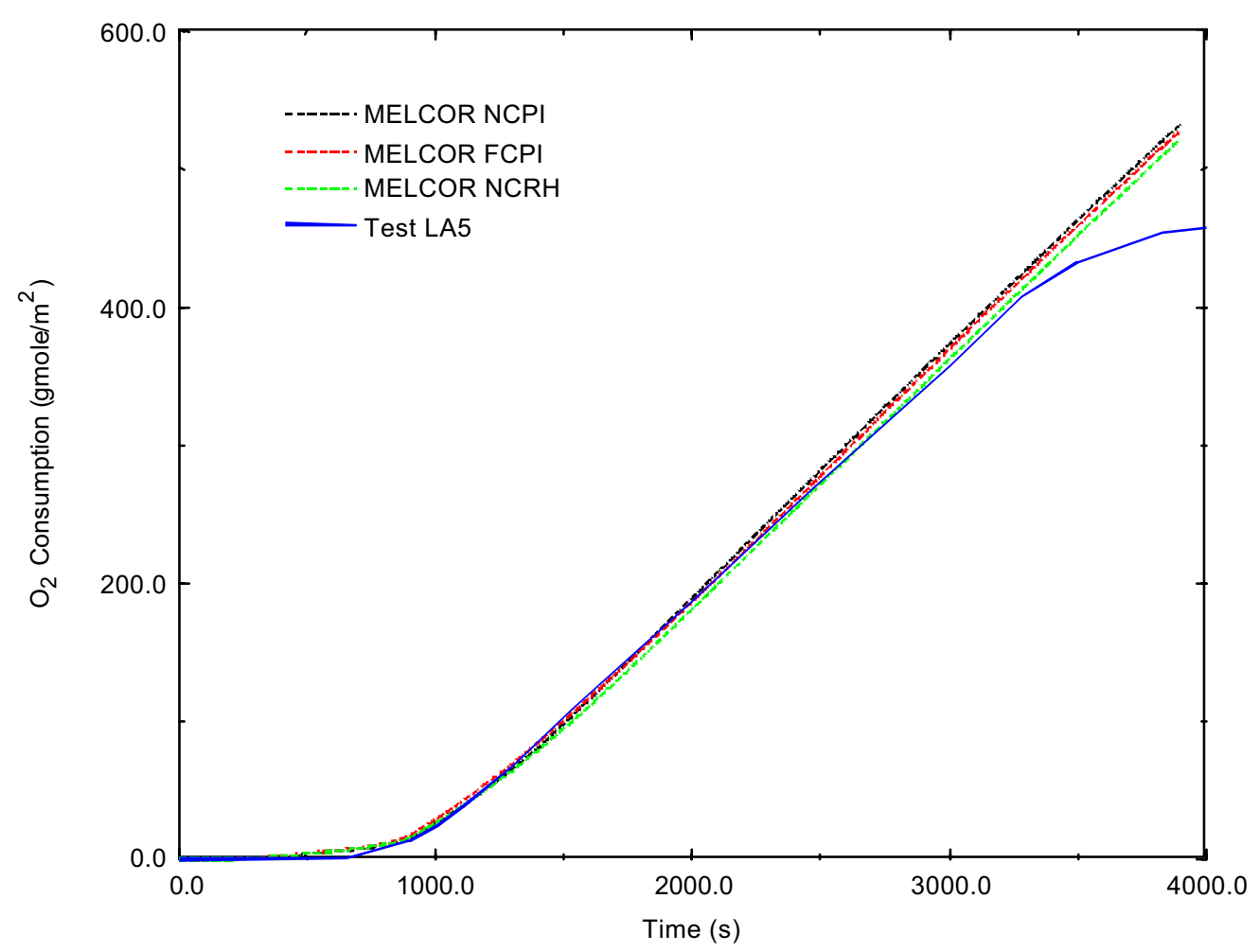

Figure 21. Comparison of MELCOR predicted nitrogen consumption with that measured during Test LA-5. 


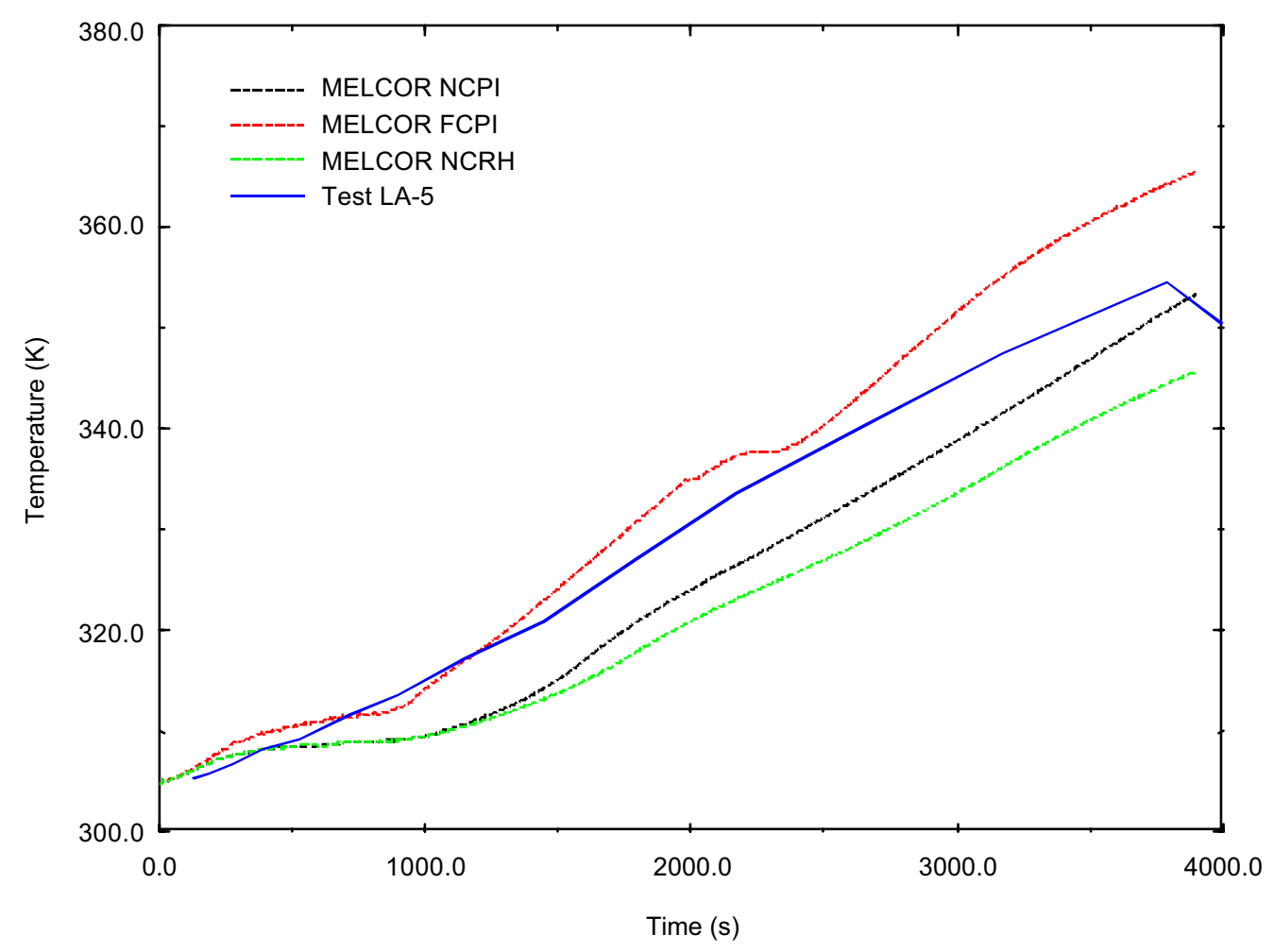

Figure 22. Comparison of MELCOR predicted CV atmosphere temperature with that measured during Test LA-5.

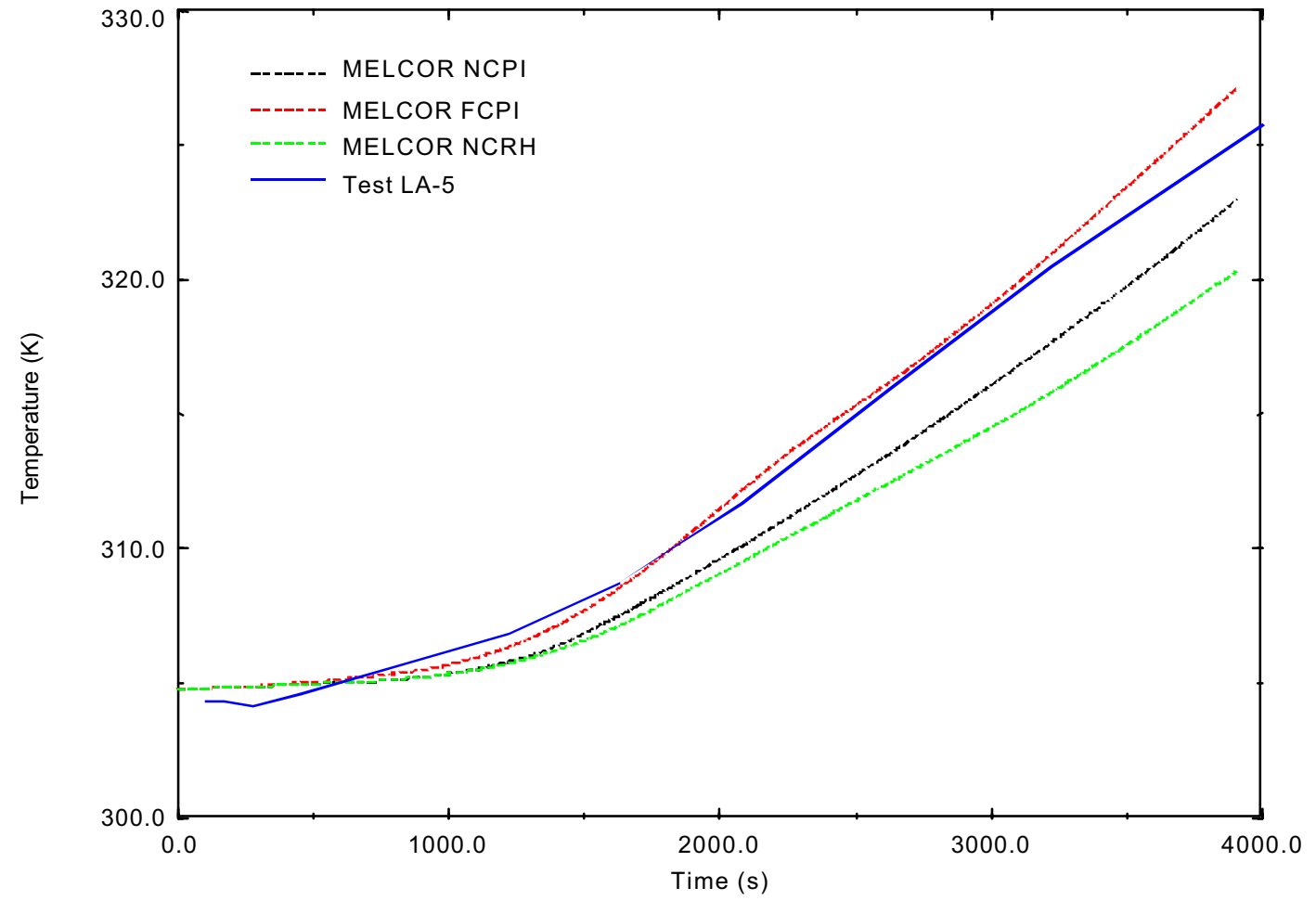

Figure 23. Comparison of MELCOR predicted CV wall temperature with that measured during Test LA-5. 


\section{CONCLUSIONS AND RECOMENDATIONS}

This report documents the effort required to incorporate a new lithium-air fire model in the MELCOR code. This effort includes the introduction of a lithium Equationof-State accomplished by modifying MELCOR to access the Fusion Safety fluid property database, and by adding subroutines to MELCOR that predict the rate at which lithium reacts with air. These modifications not only allow the Fusion Safety group at the INEEL to examine safety issue of MFE and IFE reactor designs that propose liquid lithium as a coolant, but for other liquid metal and molten salt coolant designs as well.

Two lithium-air reaction tests conducted at the HEDL were selected to benchmark this new lithium capability in MELCOR. These tests were conducted in a large containment vessel. Lithium pool temperature, vessel atmosphere, vessel wall, and oxygen and nitrogen consumption were measured. The two lithium-air spill tests examined were designated Tests LA-4 and LA-5. Test LA-4 was designated as a deep pool spill test, where $43 \mathrm{~kg}$ of liquid lithium at a temperature of $600{ }^{\circ} \mathrm{C}$ was transferred into a reaction pan, resulting in a lithium pool with a diameter to depth ratio of 0.89 . Test LA-5 was designated as a shallow pool spill test, where $100 \mathrm{~kg}$ of liquid lithium at a temperature of $500{ }^{\circ} \mathrm{C}$ was transferred into a reaction pan, resulting lithium pool diameter to depth ratio of 16 .

Three MELCOR cases where compared to data from Test LA-4 and LA-5. Case 1 disabled the forced convection heat transfer option between the pool and the atmosphere of non-equilibrium MELCOR control volume, resulting in only natural convective heat transfer being predicted between the pool and the atmosphere. The second case was the standard pool to atmosphere heat transfer model in MELCOR which accepts the greater heat transfer coefficient predicted from the heat transfer regimes of forced convection, turbulent natural convection, and laminar natural convection heat transfer. The third case was the same as Case 1, but the heat of reaction of the lithium-air reactions was reduced by $9 \%$. Based on the results obtained, the use of the standard MELCOR pool-atmosphere interface heat transfer model (Case 2) is not recommended for use in conjunction with the new MELCOR lithium fire capability for three reasons. First, the use of forced convection (Equation 35) for mass transfer at the pool surface is not consistent with the used of turbulent natural convection (Equation 25) for oxygen and nitrogen mass transport at the surface of the pool. Second, the forced convection correlation depends on predicted atmosphere velocity. This velocity depends on the level of modeling detail the user undertakes in modeling the natural convective flow patterns above the pool, a calculation for which MELCOR is not well suited. Third, overall the results of Case 1 were a better match to measured pool temperature, $\mathrm{CV}$ atmosphere temperature, and $\mathrm{CV}$ wall temperature for these tests. While Case 3 gave better results for Test LA-4 and for the pool temperature for Test LA-5, but this was not the case for $\mathrm{CV}$ atmosphere and wall temperature measurements for Test LA-5. Since heat conduction through the reaction pan is a more dominate heat transfer path for Test LA-5 and because measurements of catch pan temperatures were not reported by Reference [18], the adoption of the heat of reaction multiplier from Case 3 can not be recommended at this time for inclusion in the lithium fire model. 
In order to match the nitrogen consumption data for Tests LA-4 and LA-5, the proposed model (Equation 27 for nitrogen) had to be multiplied by a factor of 0.3 . The oxygen consumption rate for Test LA-4 did not require a multiplier to match the data, but the consumption rate for LA-5 required a multiplier of 0.6. For both tests the nitrogen reaction ceased prior to the end of the test. In Test LA-4 the lithium-nitrogen reaction began to cease above $1300 \mathrm{~K}$, and for Test LA-5 the reaction began to cease above $1200 \mathrm{~K}$. The oxygen reaction in Test LA-4 did not show an indication of ceasing during the test, but in Test LA-5 the reaction began to cease above a temperature of $1350 \mathrm{~K}$. The reason for the nitrogen rate limit is unclear but it is not believed to be due to the existence of a film or crust on the pool surface for two reasons. First, oxygen did not require a rate limit to match the data from Test LA-4, and the binary diffusion coefficients for oxygen and nitrogen vary by less than a percent and not by a factor of three. Second, there is no difference in the magnitude of the rate limit for nitrogen between Test LA-4 and Test LA-5. It is possible that the 70\% reduction in lithiumnitrogen reaction is due to surface kinetics, that is by the rate at which liquid lithium will actually react with nitrogen. However, a plausible explanation for the oxygen rate limit in Test LA-5 is the existence of a film or crust. A thin crust could result in the $40 \%$ reduction in the arrival rate of oxygen to the liquid lithium surface between Test LA-4 and Test LA-5, but at the same time not dramatically affect the rate of nitrogen consumption which is limited by surface kinetics and not nitrogen rate of arrival. However, whether a thin crust formed during the course of events in Test LA-5 or a thick patchy crust formed during the first 900 seconds of this test can not be determined. These tests also indicated that the nitrogen reaction decreases after reaching $1300 \mathrm{~K}$ in Test LA-4 and $1200 \mathrm{~K}$ in test LA-5. For Test LA-4 this decrease is believed to be due to the fact that the thermochemical conditions of this test above $1300 \mathrm{~K}$ were no longer favorable to the formation of $\mathrm{Li}_{3} \mathrm{~N}$. In Test $\mathrm{LA}-5$, this decrease could be due to the build up of a crust on the pool surface. Because these conclusions are speculative and because of the lack of reproducible data, it was decided that a heuristic approach will be taken for simulating the above phenomena in this new MELCOR capability at this time. This approach assumes that the consumption rates scale as the pool diameter to depth ratio. That is, based on the results obtained empirically from the benchmarking studies in Section 4.3 and 4.4, the rate lithium-oxygen reaction rate (Equation 27) becomes:

$\Gamma_{\mathrm{O} 2}=\mathrm{f}_{\mathrm{O} 2} \mathrm{~K}_{\mathrm{m}_{\mathrm{O} 2}} \rho_{\mathrm{O} 2}$

where the rate limiting factor $\varphi$ is defined as

$\varphi_{\mathrm{O} 2}=1.0-0.4(\mathrm{D} / \mathrm{h}-0.89) / 15.11$

For nitrogen, this equation becomes:

$\Gamma_{\mathrm{N} 2}=\mathrm{f}_{\mathrm{N} 2} \mathrm{~K}_{\mathrm{m}_{\mathrm{N} 2}} \rho_{\mathrm{N} 2}$

where the rate limiting factor $\varphi$ is defined as 
$\varphi_{\mathrm{N} 2}=0.3 \mathrm{e}^{-\delta \mathrm{T} / \tau}$

and where

$$
\begin{aligned}
& \delta \mathrm{T}=\max \left(0.0, \mathrm{~T}-\mathrm{T}_{\mathrm{I}}\right) \\
& \mathrm{T}=\text { lithium pool temperatu re }(\mathrm{K}) \\
& \mathrm{T}_{\mathrm{I}}=1300.0-100.0(\mathrm{D} / \mathrm{h}-0.89) / 15.11(\mathrm{~K}) \\
& \tau=25.0+25.0(\mathrm{D} / \mathrm{h}-0.89) / 15.11(\mathrm{~K})
\end{aligned}
$$

Regarding aerosols, the fraction of $\mathrm{Li}_{2} \mathrm{O}$ and $\mathrm{Li}_{3} \mathrm{~N}$ produced that will be suspended as an aerosol is:

$\varphi_{\mathrm{s}}=0.1-0.066(\mathrm{D} / \mathrm{h}-0.89) / 15.11$

The pool diameter to depth ratio $(\mathrm{D} / \mathrm{h})$ in a given control volume is calculated by MELCOR during the course of an analysis.

The final recommendation that needs to be addressed is pool radiant heat transfer. For the benchmark studies the radiant heat transfer rate was specified by user defined control functions that removed heat from the pool and deposited this heat on the walls of the CV. It will be up to the user to replicate this modeling approach. The pool emissivity used for different pool configurations, that is shallow verses deep pools, are reported in Sections 4.3 and 4.4. The physical explanation for a variable emissivity in Test LA-5 is not clear. There are least two possible explanations. First, it could be that after the nitrogen reaction ceases in Test LA-5 that only $\mathrm{Li}_{2} \mathrm{O}$ is produced, causing a change in surface emissivity. Reference [22] states that $\mathrm{Li}_{3} \mathrm{~N}$ has a black-gray appearance while $\mathrm{Li}_{2} \mathrm{O}$ has a white appearance. Second, it could also be that the surface emissivity does not change but a crust develops which adds resistance to heat flow from the pool surface, and drops the surface temperature below the measured pool temperature. For example, at 3900 seconds in Test LA-5 the surface radiant heat flux is about $3.2 \times 10^{4} \mathrm{~W} / \mathrm{m}^{2}$, the pool temperature is $1420 \mathrm{~K}$, and the wall temperature is $311 \mathrm{~K}$. These conditions could also exist for a surface emissivity of 1.0 if a $3.0 \mathrm{~cm}$ crust had developed on the pool surface with a surface temperature of $871 \mathrm{~K}$. This crust thickness was estimated by using a thermal conductivity for a $\mathrm{Li}_{2} \mathrm{O}$ reported by Reference [23] of $1.73 \mathrm{~W} / \mathrm{m}-\mathrm{K}$.

The modifications described in this report are intended as initial models for addressing lithium-air reaction safety concerns for future fusion reactors. Given the importance of this issue to the use of lithium in fusion reactors and the nature of these models recommend here, additional theoretical and experimental work must be undertaken to improve the recommendations presented in this section. 


\section{References}

1. R. M. Summers, et al., MELCOR 1.8.0: A Computer Code for Nuclear Reactor Severe Accident Source Term and Risk Assessment Analyses, NUREG/CR-5531 and SAND90-0364, USNRC Report, Sandia National Laboratory, January 1991.

2. Keenen, Keyes, Hill, and Moore, 1969, Steam Tables, John Wiley \& Sons, Inc.

3. K. E. Carlson, P. A. Roth, and V. H. Ransom, ATHENA Code Manual, Volume 1 and 2, EGG-RTH-7397, September 1986.

4. J. E. Tolli, New Fluids Capability for the RELAP5 Based Integrated Code, unpublished EG\&G technical report, Idaho National Engineering Laboratory, September 1989.

5. J. E. Tolli, Overview of Property Formulations for Helium, Nitrogen, Lithium, and Lithium-lead in ATHENA/MOD1 with Comparison of Calculated Properties to Measured Properties, EGG-FSP-10245, Idaho National Engineering Laboratory, April 1992.

6. RELAP5/MOD3 Code Manual, NUREG/CR-5535, INEL-95/0174, Idaho National Engineering Laboratory, August 1995.

7. R. O. Gauntt, et al., MELCOR Computer Code Reference Manuals, Version 1.8.4, NUREG/CR-6119, Vol.2, Rev 1., SAND07-2398, July 1997.

8. Brad Merrill, Richard L. Moore, Steve T. Polkinghorne, and David A. Petti, "Modifications to the MELCOR Code for Application in Fusion Accident Analyses," 5th International Symposium on Fusion Nuclear Technology, Rome, Italy, September 19-24, 1999.

9. G. J. Van Wylen, R. E. Sonntag, 1965, Fundamentals of Classical Thermodynamics, John Wiley \& Sons, Inc., pg. 336.

10. Ibid, pg. 337.

11. J. G. Collier, Convective Boiling and Condensation, McGraw-Hill, New York, pg. 316, 1972.

12. A. Roine, "Outokumpu HSC Chemistry for Windows, Chemical Reaction and Equilibrium Software with Extensive Thermochemical ${ }^{\circledR}$ Database," Version 4.0, Outokumpu Research Oy, P.O. Box 60, FIN-28-101 Pori, Finland, June 30, 1999.

13. J. R. Welty, C. E. Wicks, and R. E. Wilson Fundamentals of Momentum, Heat and Mass Transfer, John Wiley \& Sons, Inc., New York, 1969, pp. 534-558.

14. J. G. Collier, J. R. Thome, Convective Boiling and Condensation, $3^{\text {rd }}$ edition, Claredon Press, Oxford, 1994, pg. 442.

15. T. T. Utschig and M. L. Corradini, "Lithium Safety in Fusion Systems (ITER)," 5 th International Symposium on Fusion Nuclear Technology, Rome, Italy, September 1924, 1999.

16. R. C. Reid, J. M. Prausnitz, and B. E. Poling, The Properties of Gases and Liquids, Fourth Edition, McGraw-Hill, Inc., New York, 1987, pg. 587.

17. J. R. Welty, C. E. Wicks, and R. E. Wilson, Fundamentals of Momentum, Heat and Mass Transfer, John Wiley \& Sons, Inc., New York, 1969, pg. 460.

18. D. W. Jeppson, Results and Code Prediction Comparisons of Lithium-air Reaction and Aerosol Behavior Tests, HEDL-TME 85-25, Hanford Engineering Development Laboratory, March 1986. 
19. H.-W. Bartels, et al., Safety Analysis Data List-2 (SADL-2), S 81 RI 97-05004 W1.1, version 2,1, Section 4, ITER San Diego JWS, June 30, 1997.

20. J. R. Welty, C. E. Wicks, and R. E. Wilson, Fundamentals of Momentum, Heat and Mass Transfer, $2^{\text {nd }}$ Edition, John Wiley \& Sons, Inc., New York, 1969, pg. 730.

21. Sunwacork Insulation, KAOWOOL Physical Properties, Sunwacork Webpage, www.sunwacork.com.jk/hewpage8.htm, January 2000.

22. R. C. Weast, CRC Handbook of Chemistry and Physics, Florida:CRC Press, Inc., Boca Raton, 1979.

23. Y. S. Touloukian, Thermal Conductivity: Nonmetallic Solids, Vol. 2, IFI/Plenum, New York, 1970. 
Appendix A

FORTRAN Listing of MELCOR

Modifications to Allow MELCOR to Access the

Fusion Safety Fluid Property Database 
SUBROUTINE H2O1PH

C

C

C

$\mathrm{C} *$

C

C

C

C

C

C

C

C

C

C

C

C

C

C

C

C

C

C

C

C

C

C

C

C

C

C$$
\mathrm{C}
$$

C

C

C

$\mathrm{C}$

*

$\mathrm{C}$

C

C

C

C

C

C

C

C

C
EVALUATE EOS (SINGLE PHASE - LIQUID OR VAPOR)

SLT 5/19/84

DATA FROM

ATHENA FLUID PROPERTY PACKAGE

INPUT VARIABLES IN COMMON BLOCK H2OCB1

T=TEMPERATURE IN $\mathrm{K}$

RHO=DENSITY IN KG/M3

OUTPUT VARIABLES IN COMMON BLOCK H2OCB1

$\mathrm{P}=\mathrm{PRESSURE}$ IN PA $(=\mathrm{NT} / \mathrm{M} 2)$

$E=E N E R G Y$ IN JOULES/KG

$\mathrm{S}=$ ENTROPY IN JOULES/ $(\mathrm{KG}-\mathrm{K})$

H=ENTHALPY IN JOULES/KG

$\mathrm{CV}=\mathrm{SPECIFIC} \mathrm{HEAT} \mathrm{IN} \mathrm{JOULES/}(\mathrm{KG}-\mathrm{K})$

DPT=PRESSURE DERIVATIVE WRT TEMPERATURE PA/K

DPR=PRESSURE DERIVATIVE WRT DENSITY PA-M3/KG

DHT=ENTHALPY DERIVATIVE WRT TEMPERATURE JOULES/ $(\mathrm{KG}-\mathrm{K})$

IERR $=E R R O R$ INDICATOR FLAG

$=0$ NO ERROR

$=1 \mathrm{~T}$ TOO HIGH (.GT.TMAX) - NOT ERROR, USE JANAF DATA

$=2 \mathrm{~T}$ TOO LOW (.LT.TMIN)

$=-1$ RHO TOO HIGH FOR GIVEN T

$=-2$ RHO TOO LOW (.LE.0)

$=-3$ IN UNPHYSICAL REGION WITH DPR.LT.O

DO CALCULATION OF $Q$ AND $Q R=D Q / D R$ IN DOUBLE PRECISION

ON SHORT-WORD MACHINES TO AVOID CANCELLATION IN P

COMMON / H2OCB1/ P, E, S, H, CV, DPT, DPR, DHT, T, RHO, IERR

COMMON /H2OCB2/ CLEST, CL1PH, CL2PH, CLSAT, CNTIT1, CNTIT2, CNFAL

1 , TLEST, TL1PH, TL2PH, TLSAT

COMMON /H2OCB3/ KUNIT

COMMON /H2OCB4/ TSATOR, KPASE

COMMON /H2OCBP/ ANSPH, RVAP, RLIQ, AMV, AML, ALPHA

THE NEXT COMMON BLOCK CONTAINS THE INTERNAL ENERGY AND ENTROPY INTEGRATION CONSTANTS IN MKS UNITS

PARAMETER (RLICE $=991.064148 \mathrm{D} 0, \mathrm{RVICE}=4.83837730 \mathrm{D}-3)$

PARAMETER (ELICE $=-2.230824 \mathrm{D} 3, \quad \mathrm{EVICE}=2.0691669 \mathrm{D} 6)$

COMMON / EOSPARM / TCRIT, RCRIT, PCRIT, TSATO, TSINV, CVLFUS 


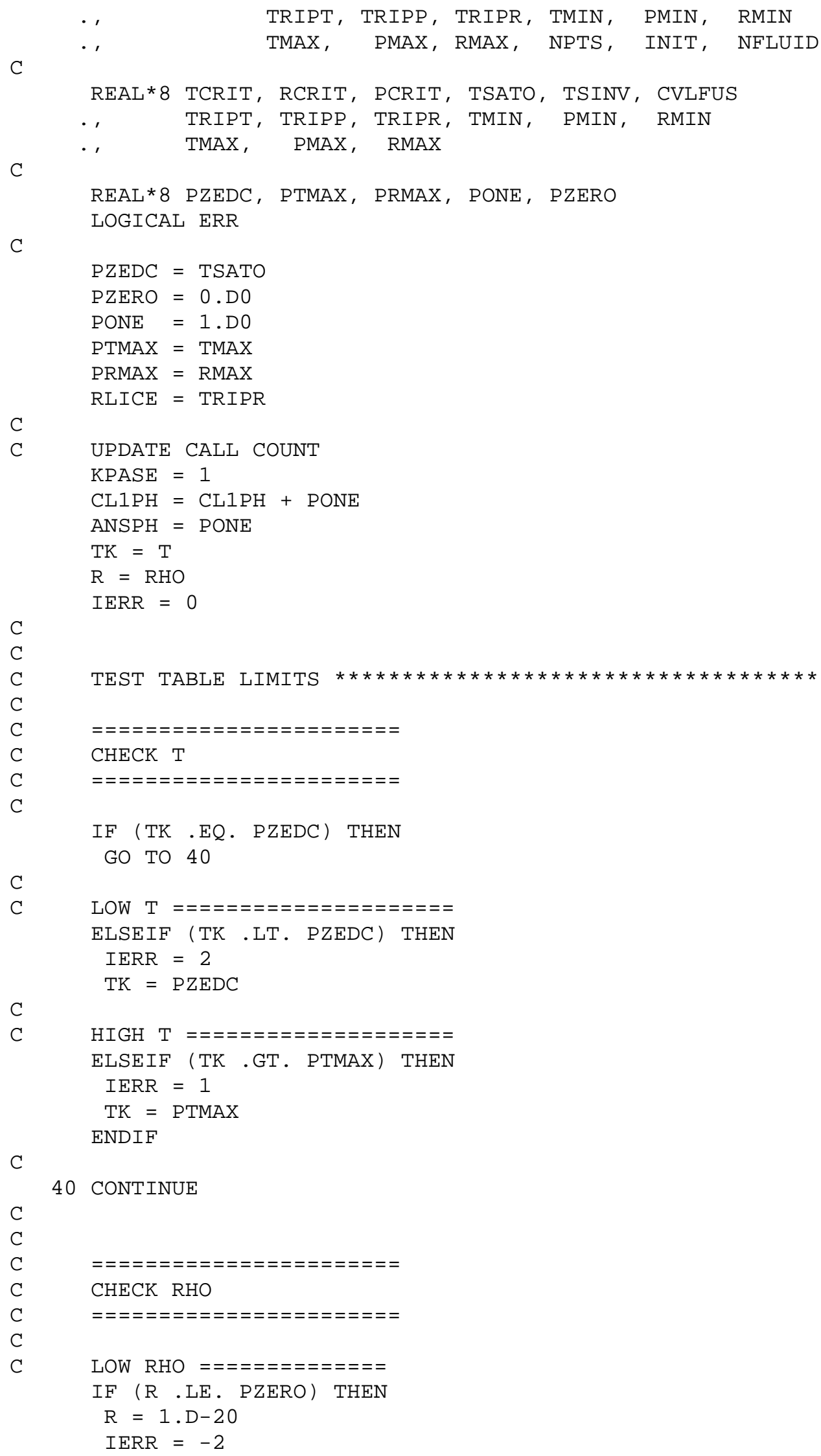


C

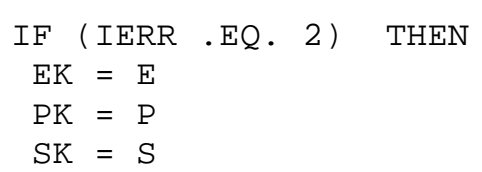

C

$\mathrm{TKM} 1=\mathrm{TK}-1$.

C

C

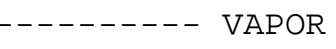

IF (R.LT.RLICE) THEN

$\mathrm{P}=\mathrm{PK}+\mathrm{DPT}$ * $(\mathrm{T}-\mathrm{TK})$

$\mathrm{E}=\mathrm{EK}+\mathrm{CV}^{\star}(\mathrm{T}-\mathrm{TK})$

$\mathrm{S}=\mathrm{SK}+\mathrm{CV} \mathrm{C}^{\star} \mathrm{LOG}(\mathrm{T} / \mathrm{TK})$

C

ELSE

C -------- $\mathrm{ICE}$

$\mathrm{DPT}=\mathrm{PK} / \mathrm{TK}$

$\mathrm{P}=\mathrm{PK}+\mathrm{DPT}$ * $(\mathrm{T}-\mathrm{TK})$

IF (T.GT.TKM1) THEN

$\mathrm{CV}=\mathrm{CVLFUS}$

$\mathrm{E}=\mathrm{EK}+\mathrm{CV} *(\mathrm{~T}-\mathrm{TK})$

$\mathrm{S}=\mathrm{SK}+\mathrm{CV}$ $\mathrm{LOG}(\mathrm{T} / \mathrm{TK})$

ELSE

$\mathrm{E}=\mathrm{EK}-\mathrm{CVLFUS}+\mathrm{CV} *(\mathrm{~T}-\mathrm{TKM} 1)$

$\mathrm{S}=\mathrm{SK}+\mathrm{CV} \star \mathrm{LOG}(\mathrm{T} / \mathrm{TKM} 1)$

+ CVLFUS ${ }^{*} \mathrm{LOG}(\mathrm{TKM} 1 / \mathrm{TK})$

C ENDIF

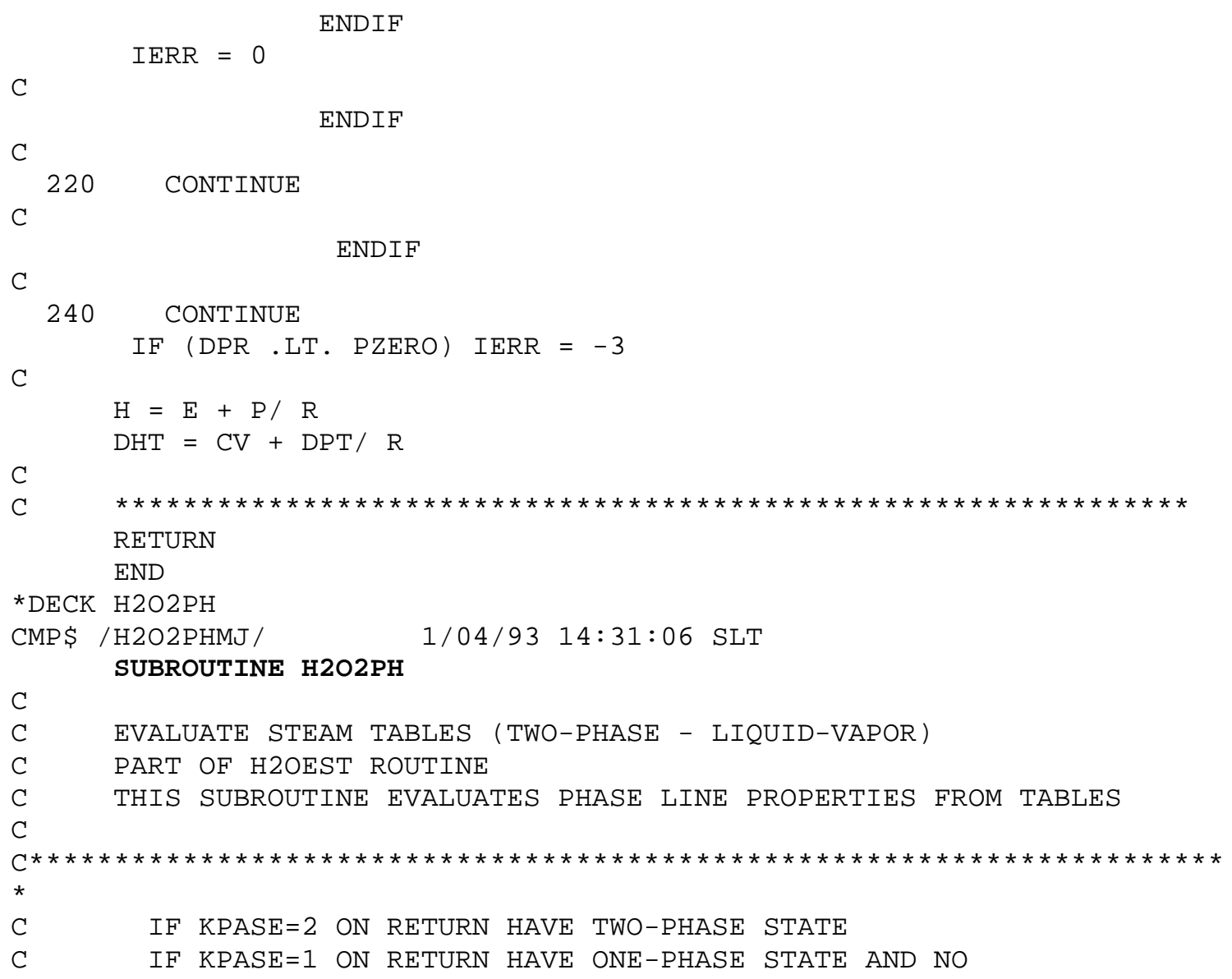

C

C EVALUATE STEAM TABLES (TWO-PHASE - LIQUID-VAPOR)

C PART OF H2OEST ROUTINE

C THIS SUBROUTINE EVALUATES PHASE LINE PROPERTIES FROM TABLES

C 


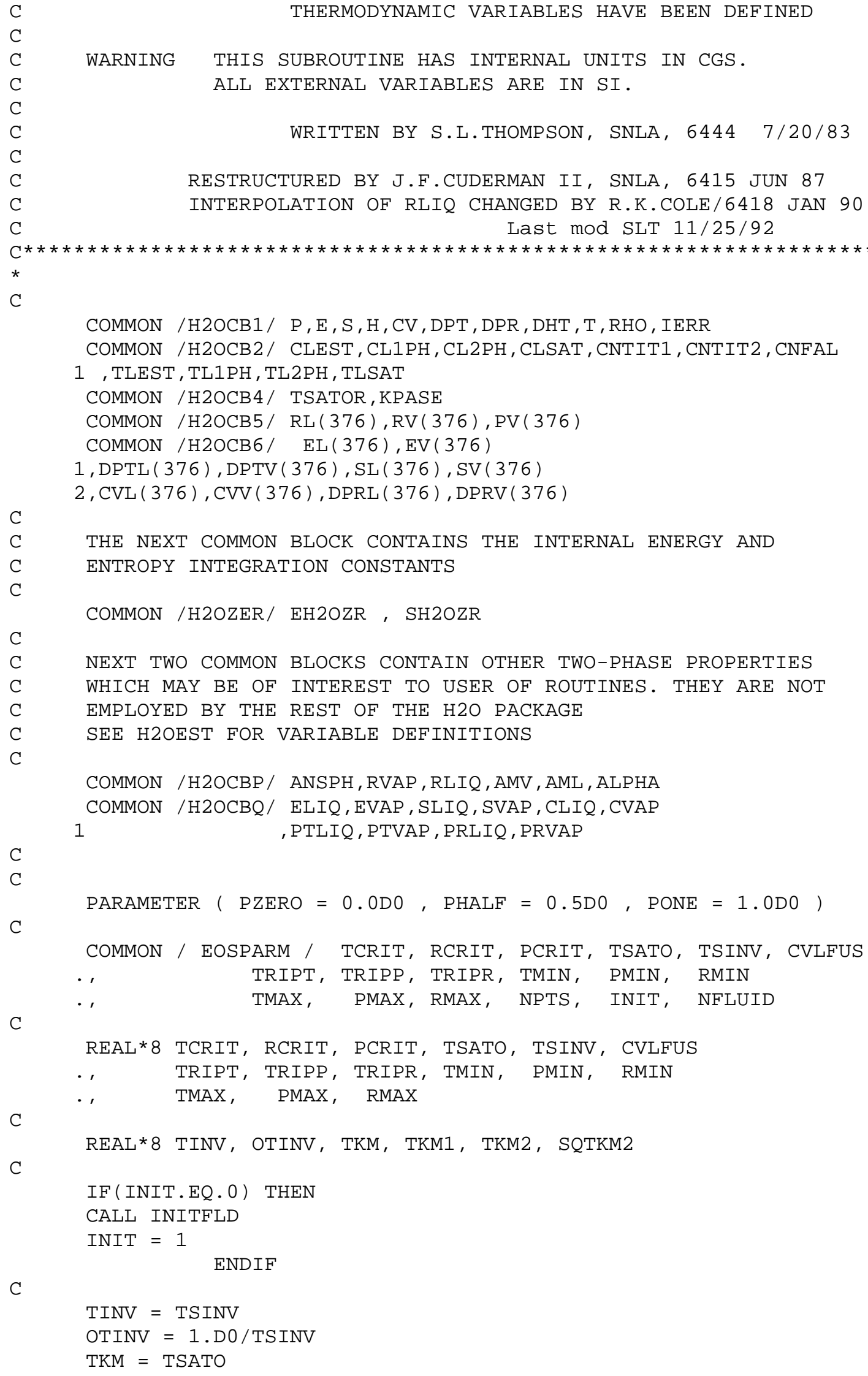




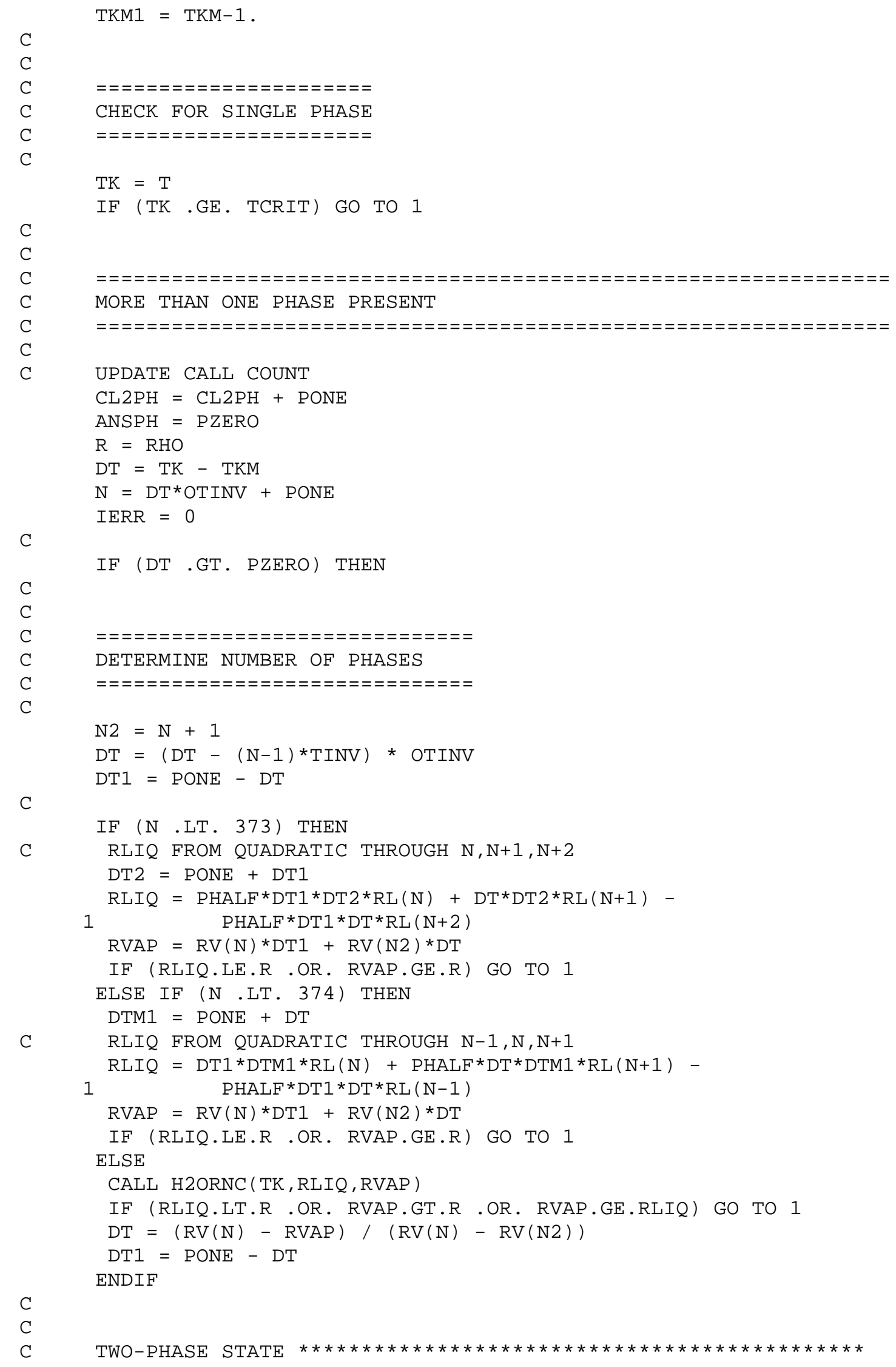




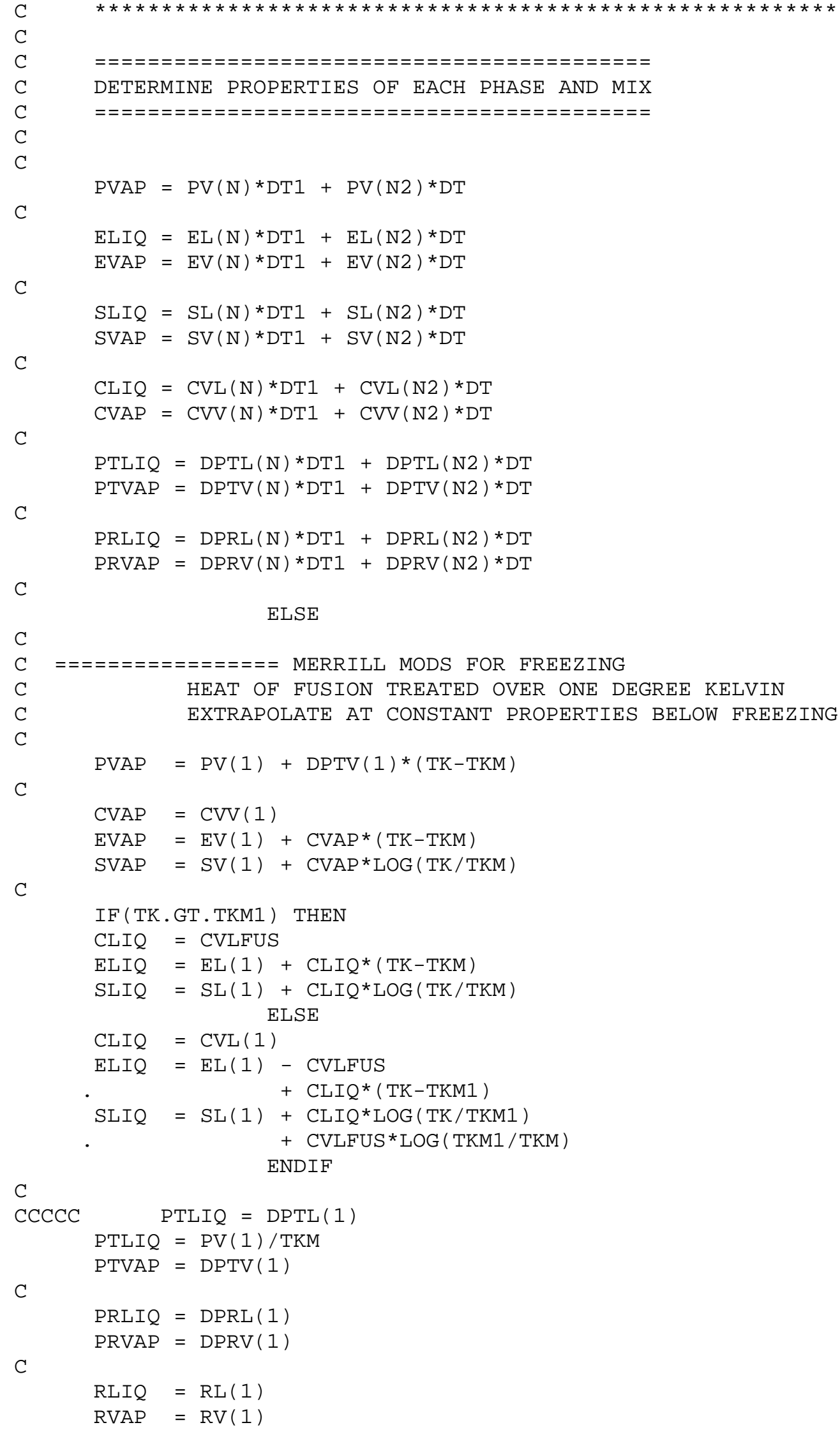

$\mathrm{C}$ 


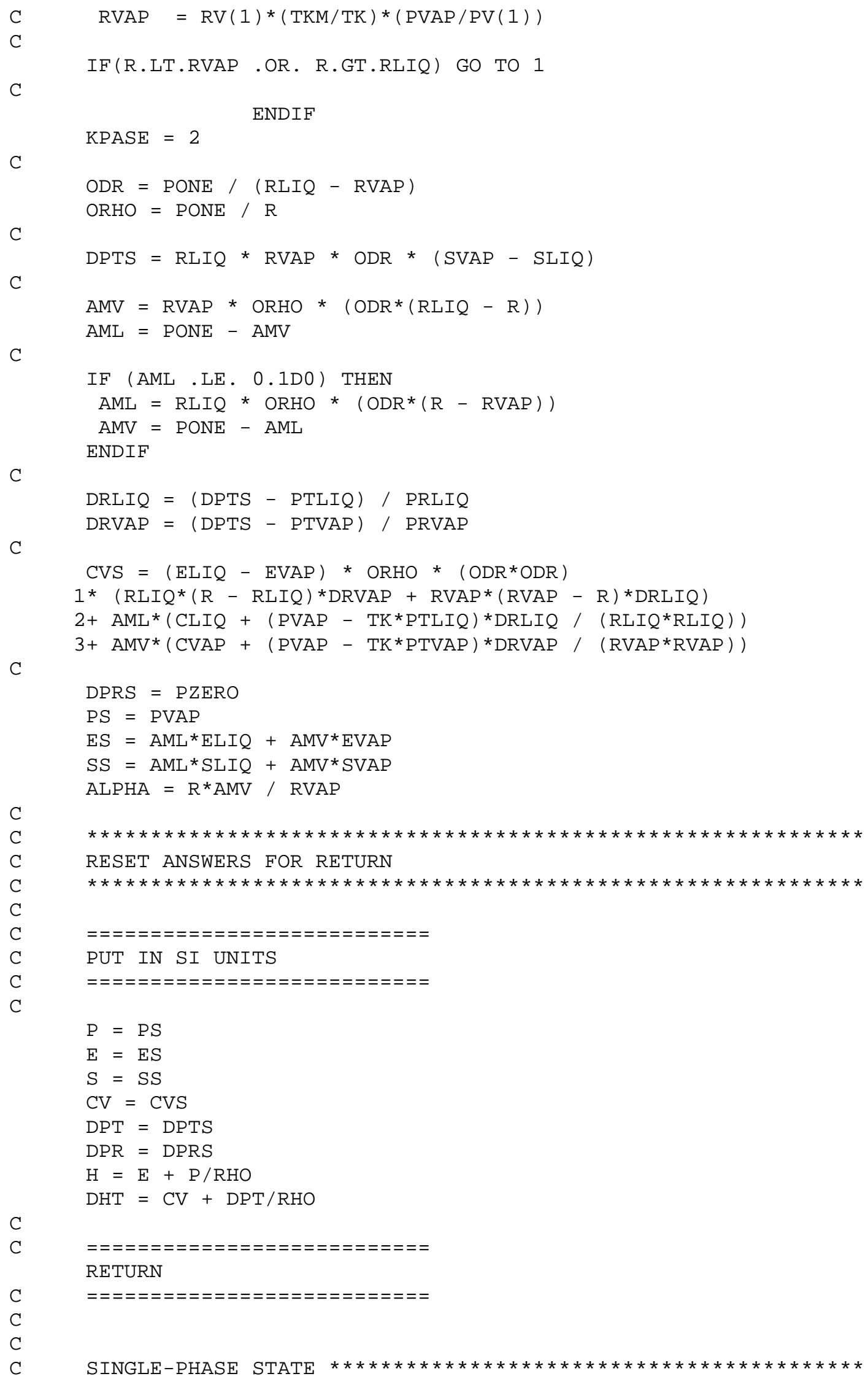


C

C

1 CONTINUE

$\mathrm{KPASE}=1$

C

C

C

C

C

*DECK MPPRP 1

C

C

C

C

C

C

C

C

C

c

C

C

C

C

C

C

C

C

C

WRITTEN FOR MATERIAL PROPERTIES BY JOHN ORMAN

SAVE

EXTERNAL MPPRPL

C

* INCLUDE BLANK

$\mathrm{C}$

C

C

C

C

C

C

C

C

C

C

C

C

C

C

C

C

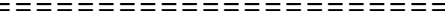

RETURN

END

SUBROUTINE MPPRP1 (IDMAT, X1, X2, Y, JERROR)

THIS GROUP OF MATERIAL PROPERTIES SUBROUTINE CALCULATES

THE PROPERTIES FOR VARIOUS MATERIALS.

WRITTEN BY JOHN ORMAN FOR MELCOR 4/15/85

INPUT :

IDMAT - MATERIAL ID NUMBER

X1 - FIRST INDEPENDENT VARIABLE

X2 - SECOND INDEPENDENT VARIABLE

OUTPUT :

Y - DEPENDENT VARIABLE OF MATERIAL IDMAT

JERROR - ERROR FLAG, $=0$ IF INPUT PARAMETERS O.K.

\section{MAIN DATABASE COMMON BLOCKS}

NUM $* * *=$ DIMENSION OF ARRAY

NED $* * *=$ PHYSICS PACKAGES WORKING + SCRATCH STORAGE

IXXXCS $=$ POINTER TO START OF SCRATCH STORAGE

$I * \star \star E S=$ POINTER TO START OF EDIT PACKAGE SCRATCH STORAGE

XREALX, INTEGE, LOGICA, CHARAC STORAGE ARRAYS

NUMREL = MAXIMUM NUMBER OF REALS

PARAMETER (NUMREL $=500000)$

PARAMETER (NUMINT $=50000)$

PARAMETER (NUMLOG $=5000)$

PARAMETER (NUMCHR $=30000)$

CORRECT 8-BYTE BOUNDARY ON THOSE MACHINES THAT CARE .NE. 0 IF INPUT PARAMETERS OFF-SCALE

REL $=$ REALS, INT = INTEGERS, CHR = CHARACTERS, LOG = LOGICALS

(DIMENSION OF XREALX)

NUMINT = MAXIMUM NUMBER OF INTEGERS (DIMENSION OF INTEGE)

NUMLOG = MAXIMUM NUMBER OF LOGICALS (DIMENSION OF LOGICA)

NUMCHR = MAXIMUM NUMBER OF CHARACTER 8 VARIABLES (DIM OF CHARAC)

DECLARING DREALX IN COMMON ENSURES THAT STORAGE BEGINS AT THE 


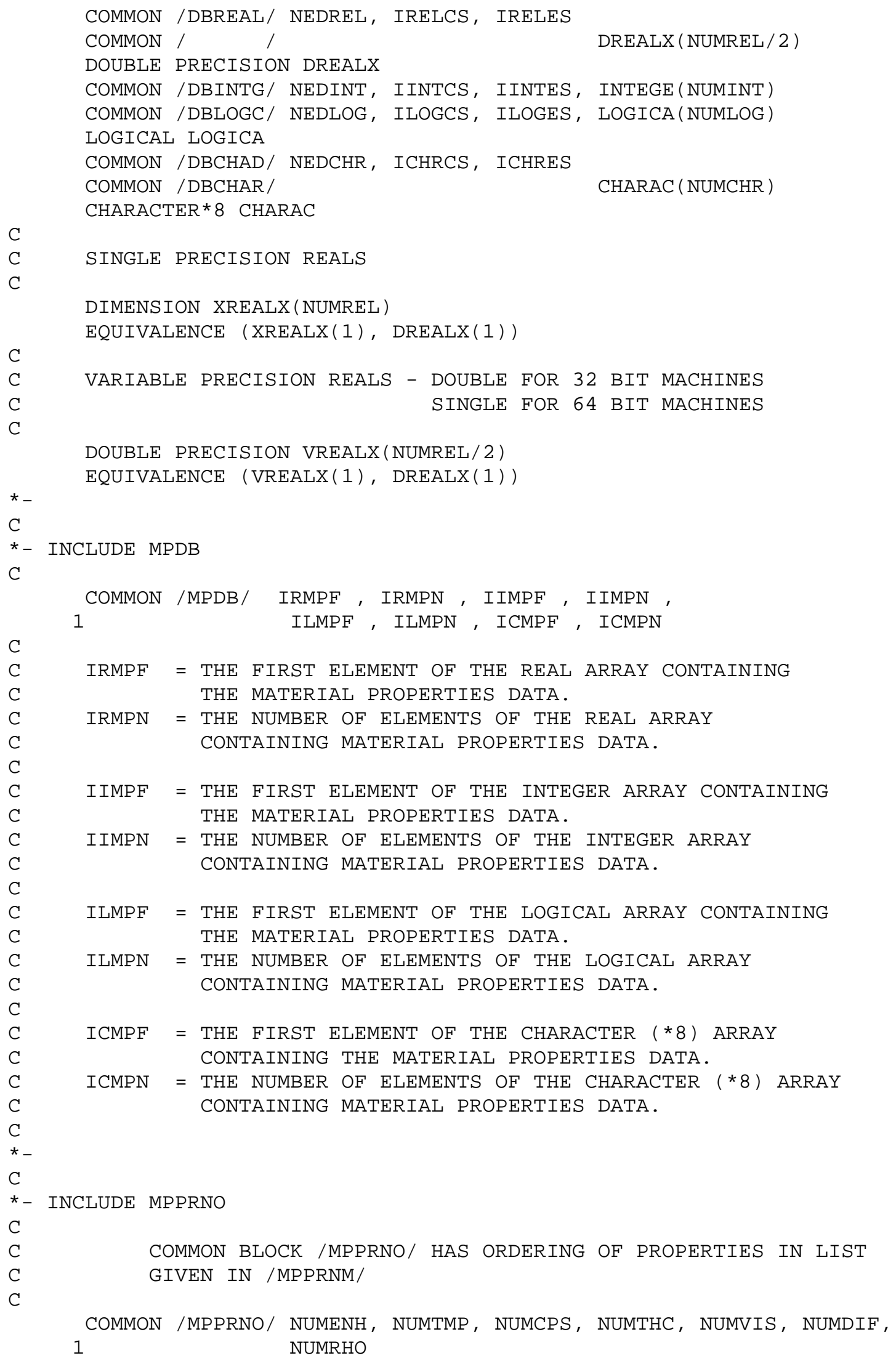




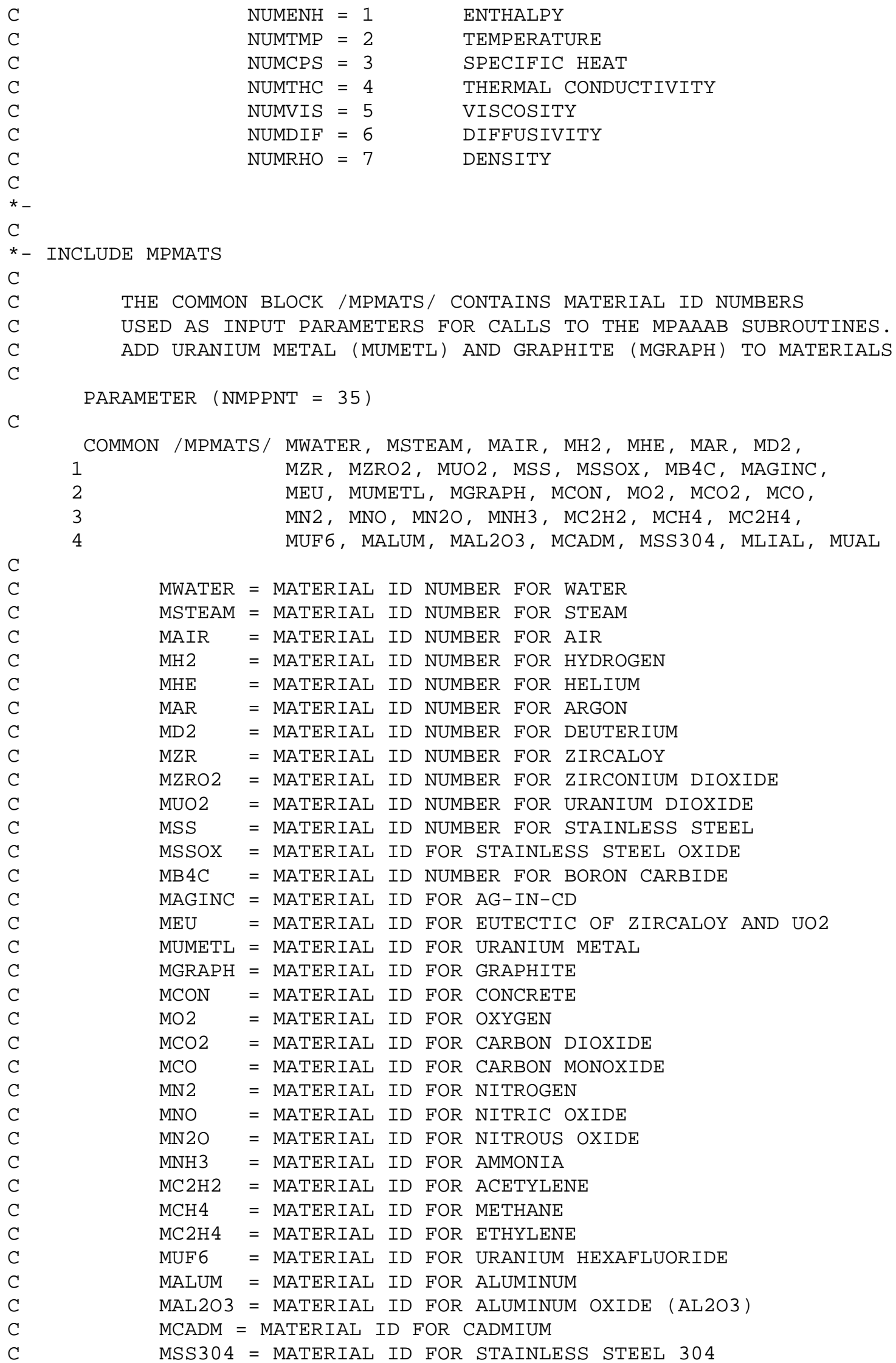




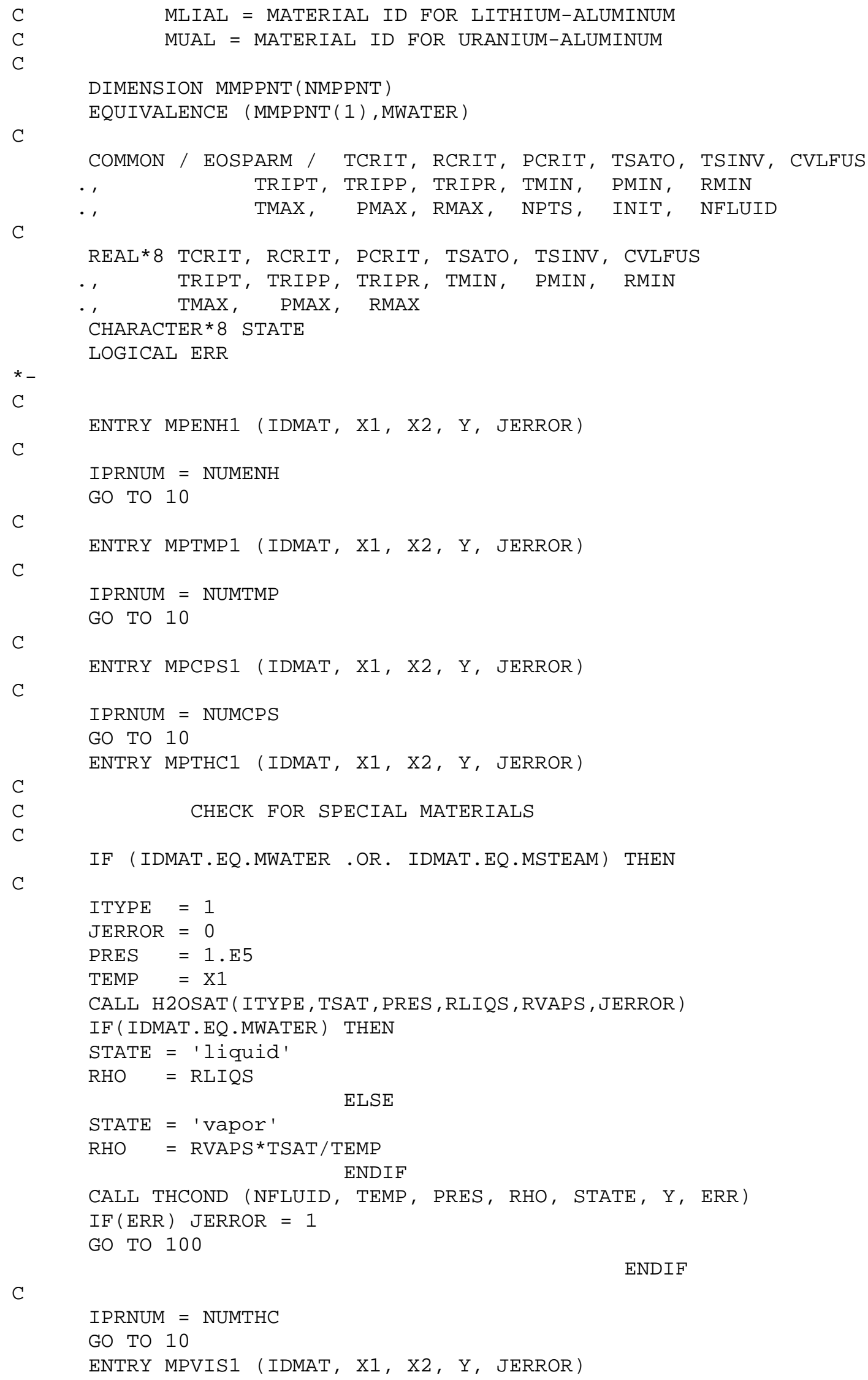


C

C

IF (IDMAT.EQ.MWATER .OR. IDMAT.EQ.MSTEAM) THEN

$\operatorname{ITYPE}=1$

$\mathrm{JERROR}=0$

$\mathrm{PRES}=1 . \mathrm{E} 5$

TEMP $\quad=\mathrm{X} 1$

CALL H2OSAT (ITYPE, TSAT, PRES, RLIQS, RVAPS, JERROR)

IF (IDMAT.EQ.MWATER) THEN

STATE = 'liquid'

RHO $=$ RLIQS

ELSE

STATE = 'vapor'

RHO $=$ RVAPS*TSAT $/$ TEMP

ENDIF

CALL VISCOS (NFLUID, TEMP, PRES, RHO, TSAT, STATE, Y, ERR) $\mathrm{IF}(\mathrm{ERR}) \quad \mathrm{JERROR}=1$

GO TO 100

C

IPRNUM $=$ NUMVIS

GO TO 10

ENTRY MPDIF1 (IDMAT, X1, X2, Y, JERROR)

C

IPRNUM $=$ NUMDIF

GO TO 10

ENTRY MPRHO1 (IDMAT, X1, X2, Y, JERROR)

C

C

$\mathrm{C}$

IF (IDMAT .EQ. MSTEAM) THEN

C

C

CALL MPRHSM (X1, X2, Y, JERROR)

GO TO 100

ENDIF

C

IF (IDMAT .EQ. MAIR) THEN

CALL MPRHAI (X1, X2, Y, JERROR)

C

GO TO 100

ENDIF

C

IPRNUM $=$ NUMRHO

GO TO 10

C

10 CONTINUE

C

C

C

C

C

C
ENDIF 
C

CALL MPPRPL(IDMAT, IPRNUM, X1，X2，Y， JERROR，

1 IRMPN , XREALX(IRMPF) ,

2 IIMPN, INTEGE (IIMPF) ,

3 ILMPN, LOGICA (ILMPE),

4 ICMPN, CHARAC (ICMPF),

5 NSCR, XREALX(IRELCS) )

$\mathrm{C}$

100 CONTINUE

C

RETURN

END

*DECK MPVIS

SUBROUTINE MPVIS( EPS, SIG, XMOLW, TEMP, CEVISC)

C

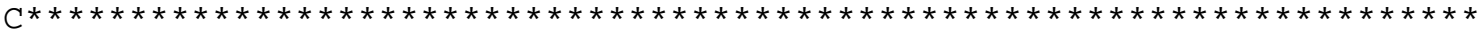

C

$c$

C

C

C

C

C

C

C

C

C

C

$\mathrm{C}$

$\mathrm{C}$

C

EVALUATES CHAPMAN-ENSKOG VALUES FOR GAS TRANSPORT PROPERTIES

ENTRY MPVIS RETURNS VALUE FOR VISCOSITY

ENTRY MPDIF RETURNS VALUE FOR BINARY DIFFUSIVITY

TABLES COPIED FROM TABLE B-2 IN BIRD, STEWART AND LIGHTFOOT, 'TRANSPORT PHENOMENA', WILEY, (1960)

ATTRIBUTED TO HIRSCHFELDER, BIRD, AND SPOTZ

CHEM. REVS. 44, 205 (1949)

EXTRAPOLATION USED ABOVE KT/EPS=100. GIVES BETTER THAN .1 PERCENT FIT TO ALL DATA ABOVE KT/EPS=10.

EXTRAPOLATION USED BELOW KT/EPS=0.3 GIVES BETTER THAN .5 PERCENT FIT TO ALL DATA BELOW KT/EPS=0.5

CODED BY R.K. COLE, JR, SANDIA, NOVEMBER

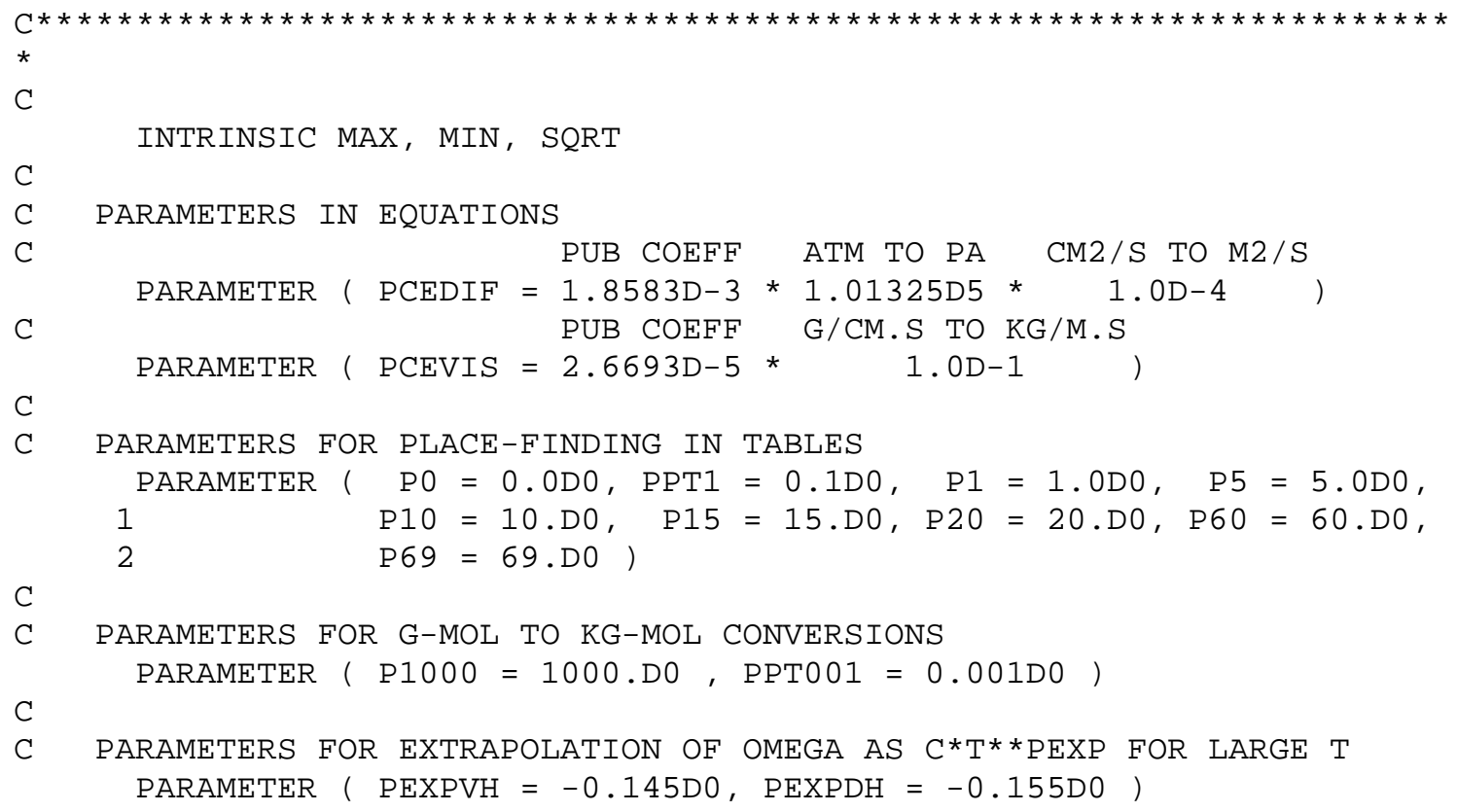




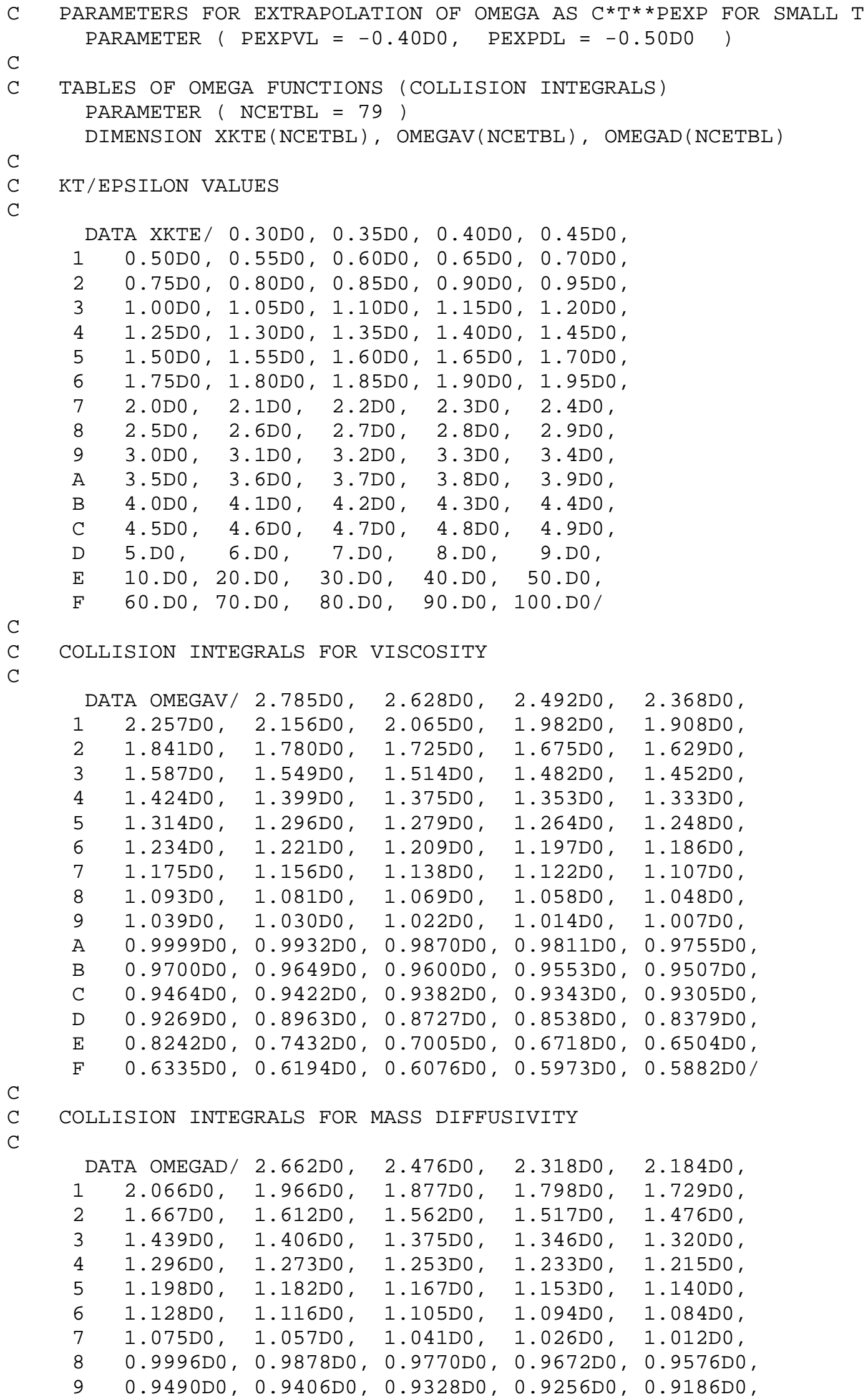




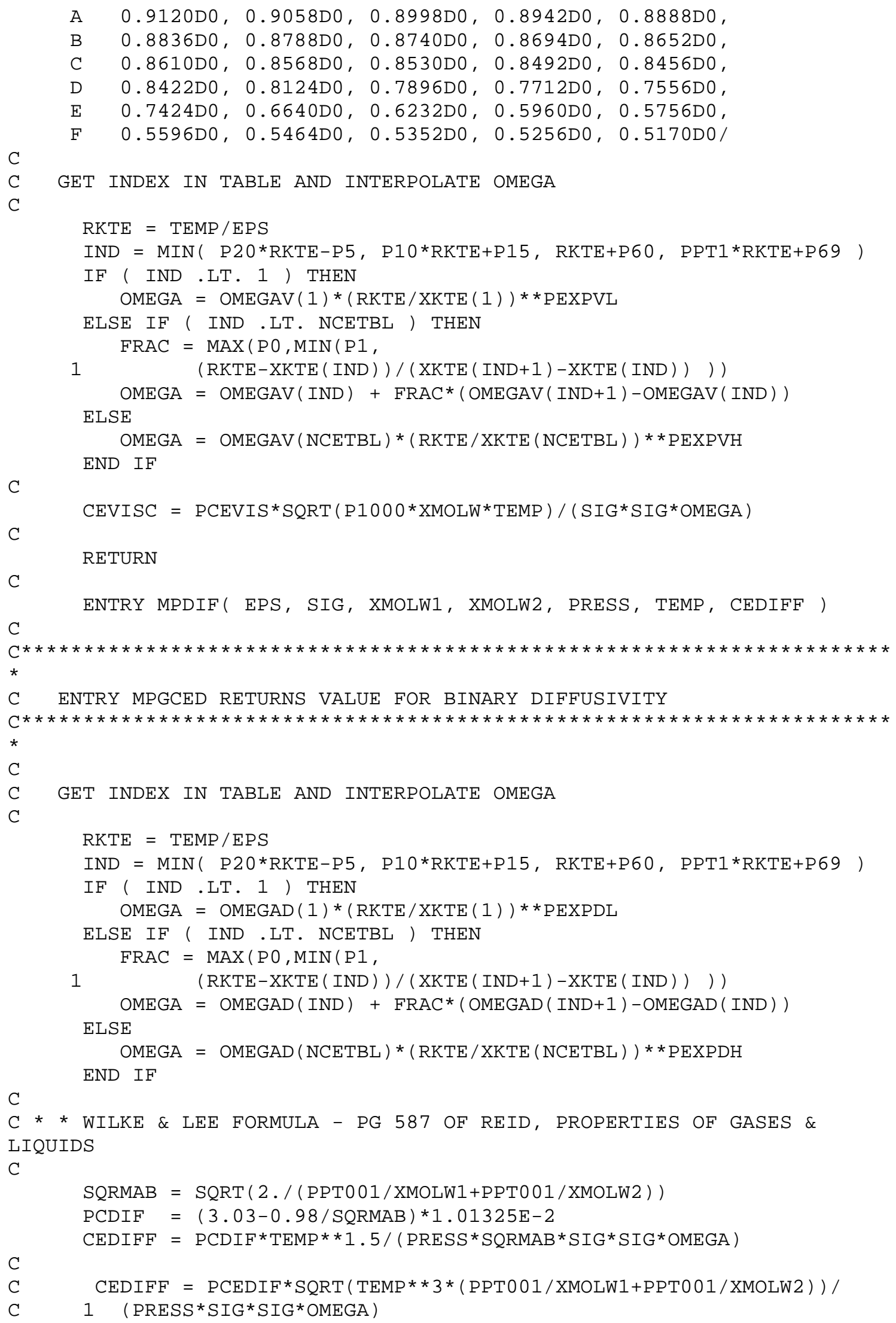




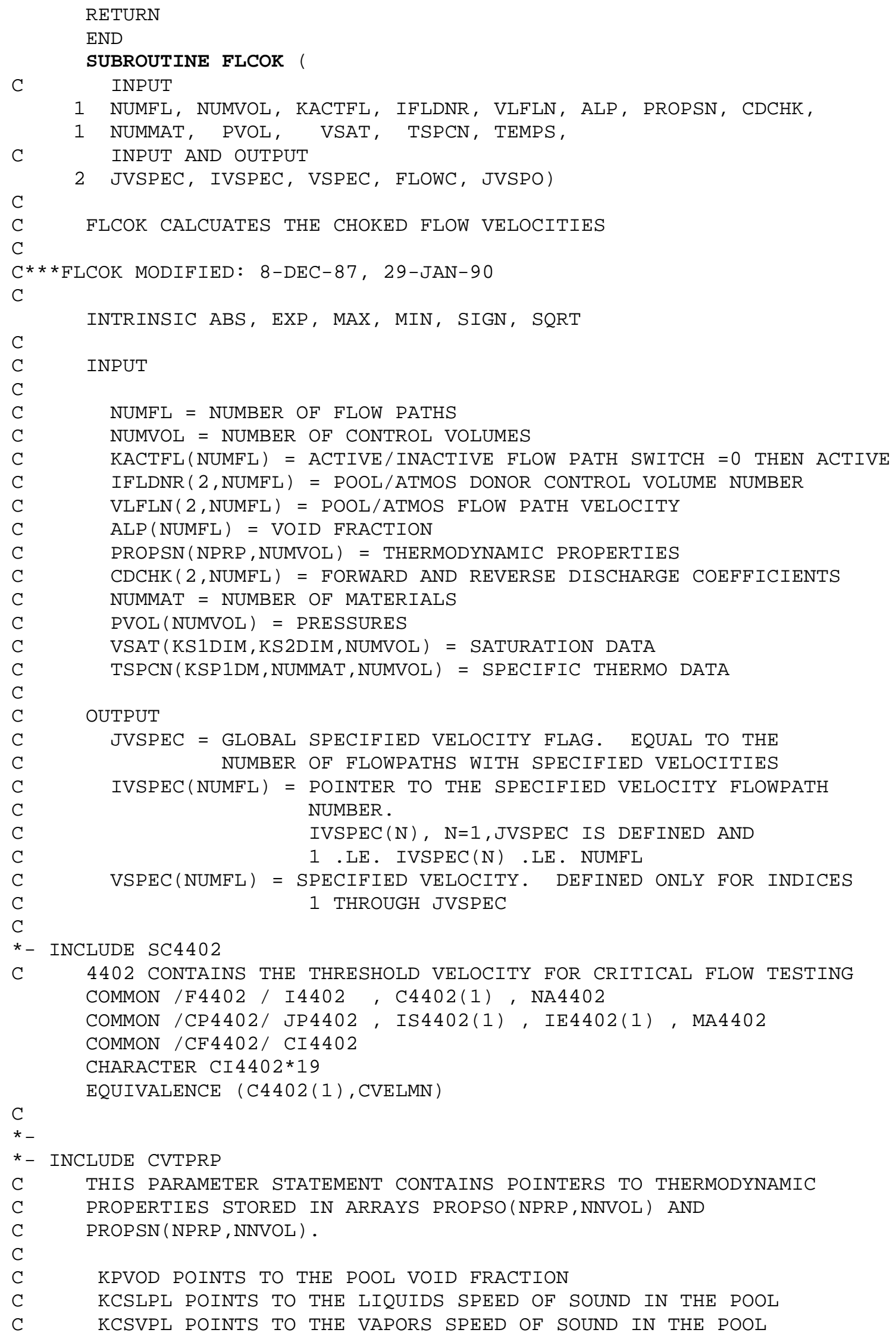




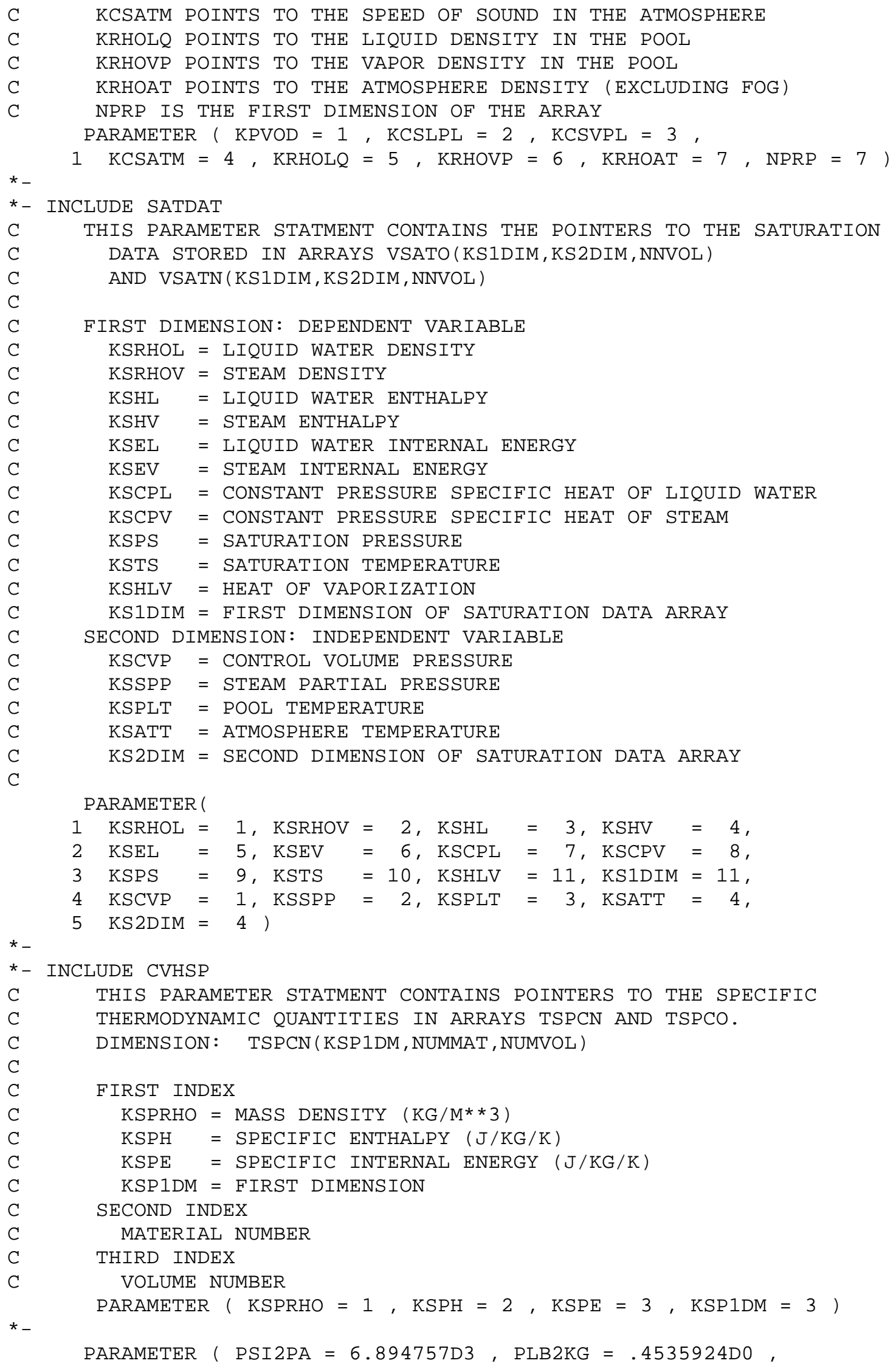




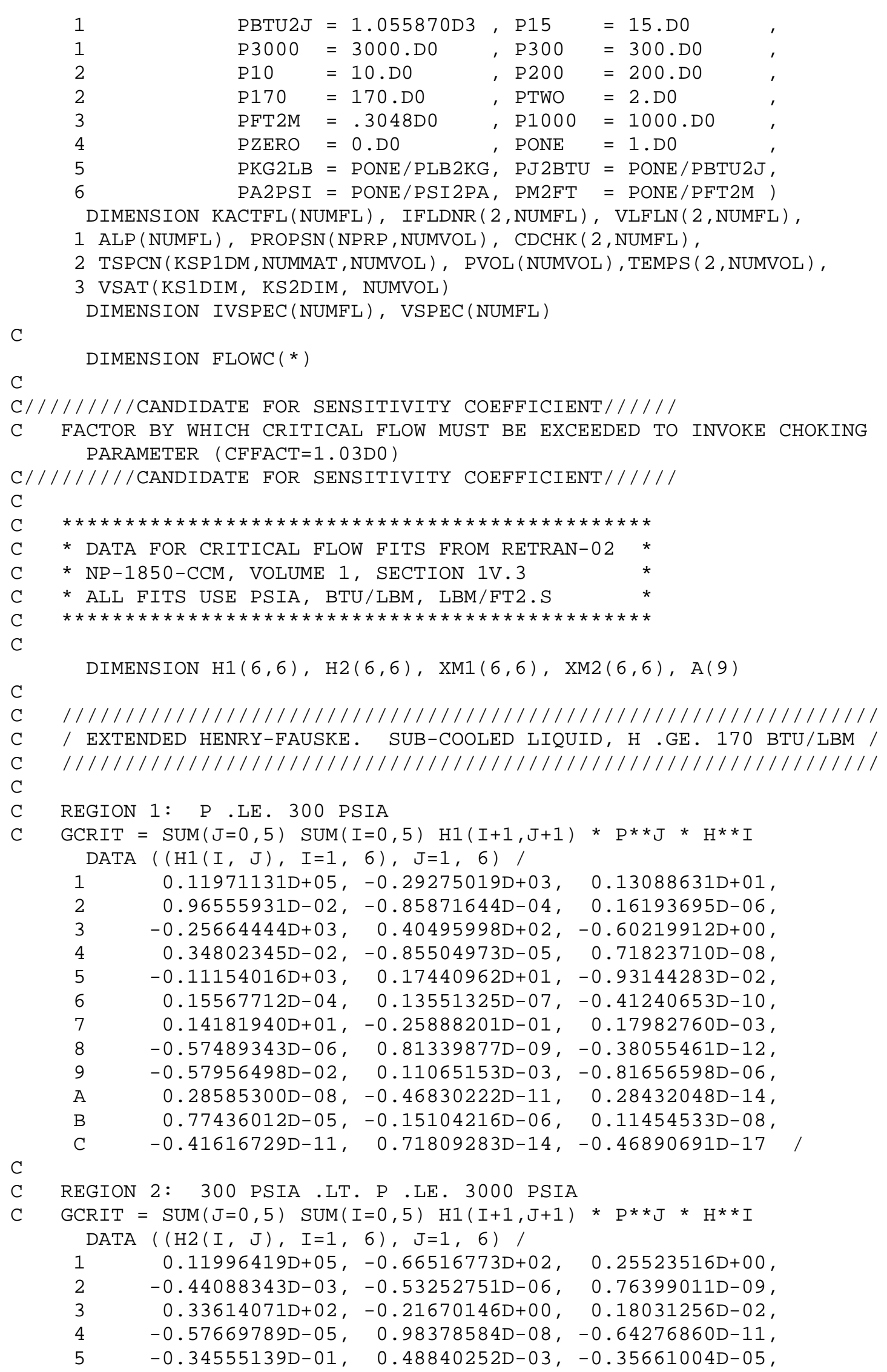

C

C REGION 2: 300 PSIA .LT. P .LE. 3000 PSIA

C $\operatorname{GCRIT}=\operatorname{SUM}(J=0,5) \quad \operatorname{SUM}(I=0,5) \mathrm{H} 1(I+1, J+1) * P \star \star J * H * \star I$

$\begin{array}{lrrrr}\text { DATA } & ((\mathrm{H} 2(\mathrm{I}, \mathrm{J}), \mathrm{I}=1,6), \mathrm{J}=1,6) / & \\ 1 & 0.11996419 \mathrm{D}+05, & -0.66516773 \mathrm{D}+02, & 0.25523516 \mathrm{D}+00, \\ 2 & -0.44088343 \mathrm{D}-03, & -0.53252751 \mathrm{D}-06, & 0.76399011 \mathrm{D}-09, \\ 3 & 0.33614071 \mathrm{D}+02, & -0.21670146 \mathrm{D}+00, & 0.18031256 \mathrm{D}-02, \\ 4 & -0.57669789 \mathrm{D}-05, & 0.98378584 \mathrm{D}-08, & -0.64276860 \mathrm{D}-11, \\ 5 & -0.34555139 \mathrm{D}-01, & 0.48840252 \mathrm{D}-03, & -0.35661004 \mathrm{D}-05,\end{array}$




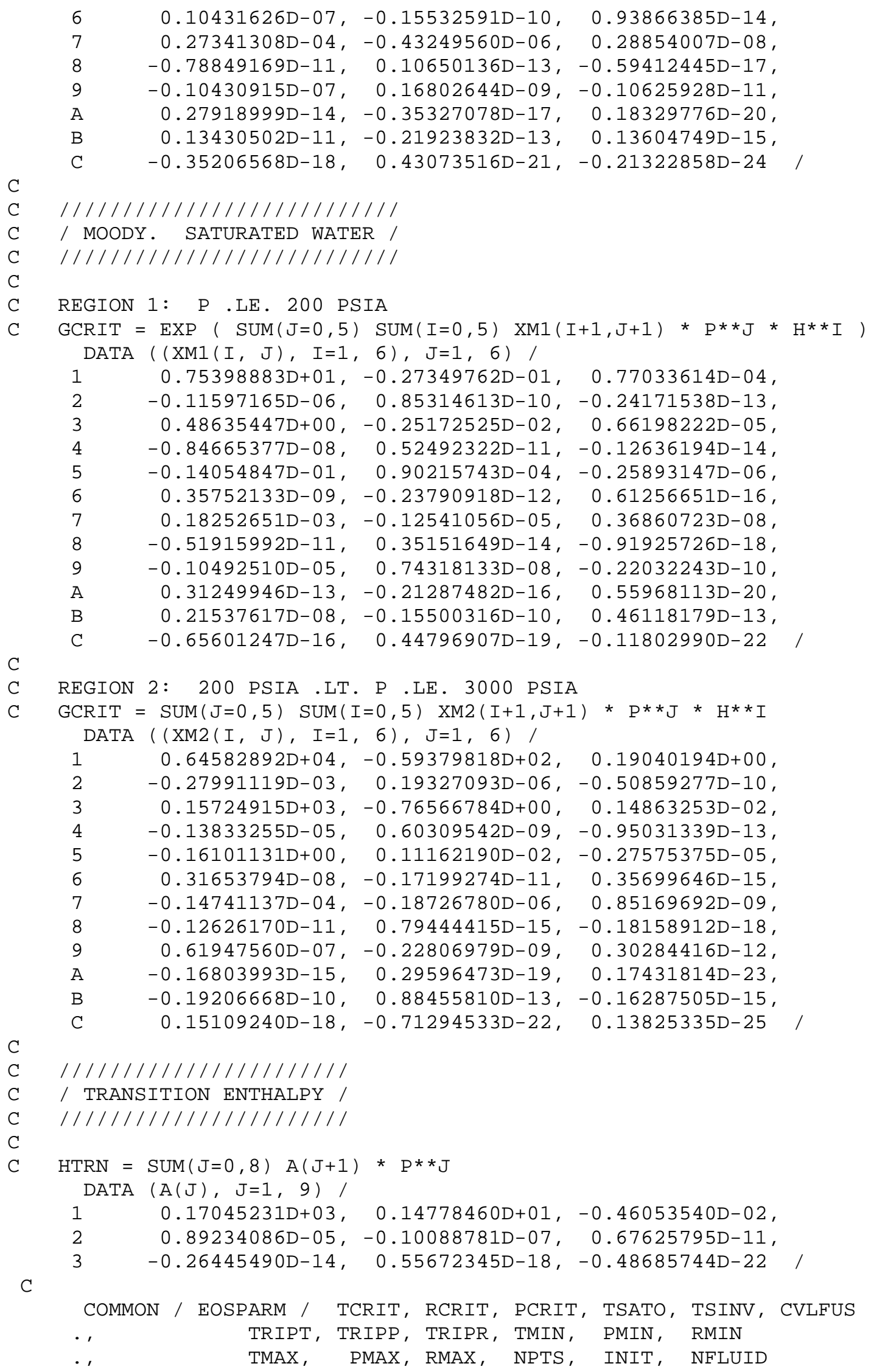




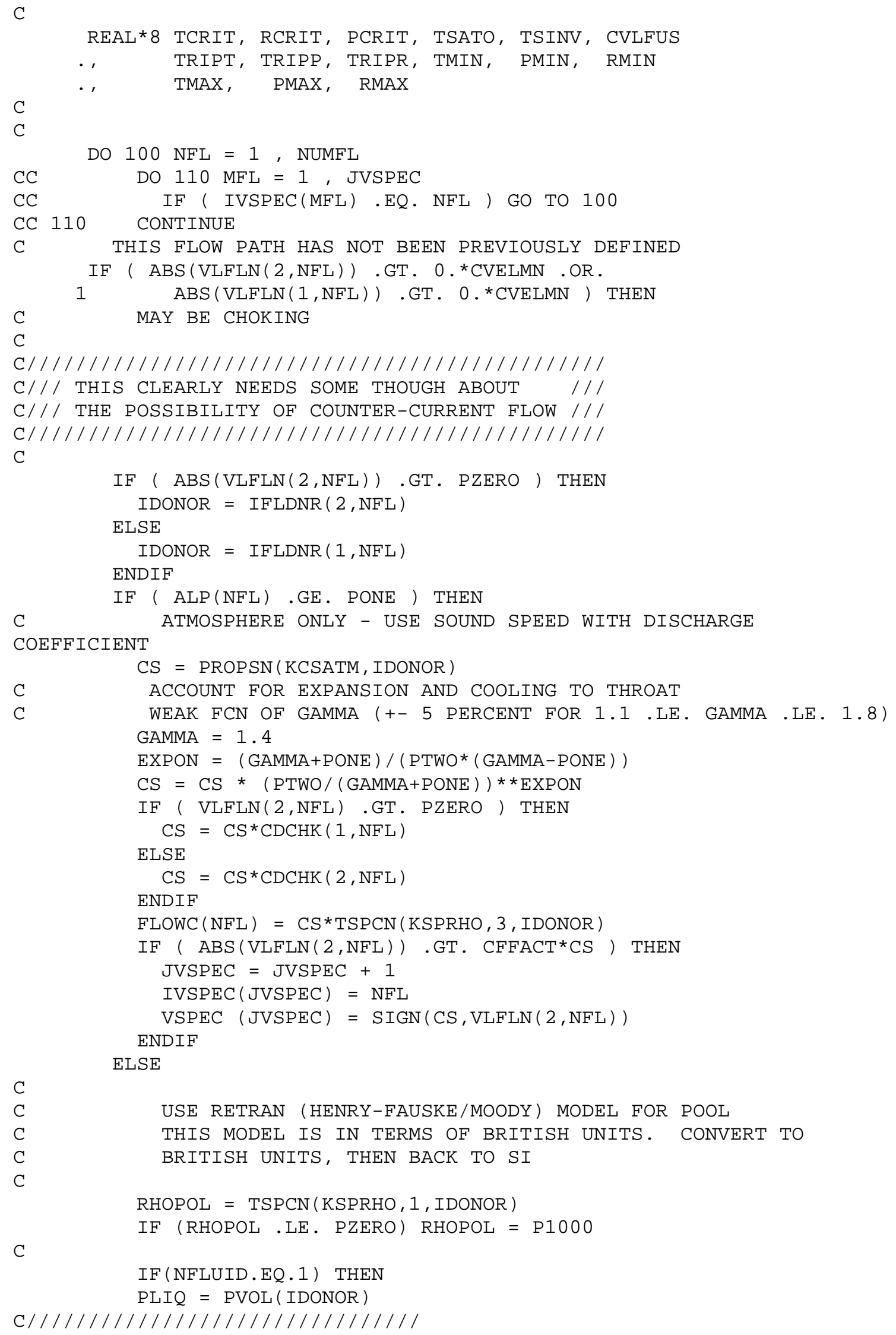




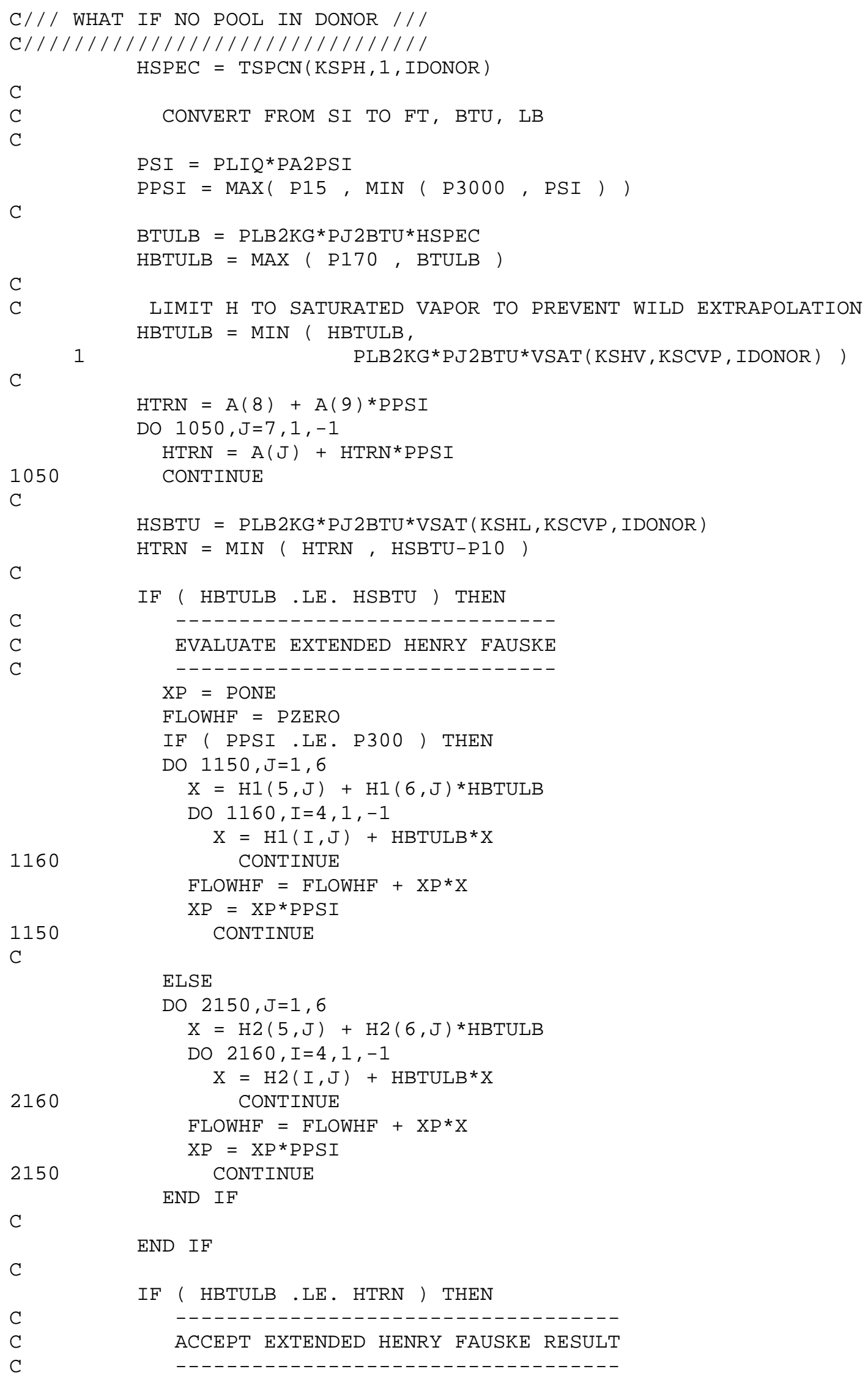


FLOWPL $=$ FLOWHF

C

C

C

C

3160

3150

ELSE

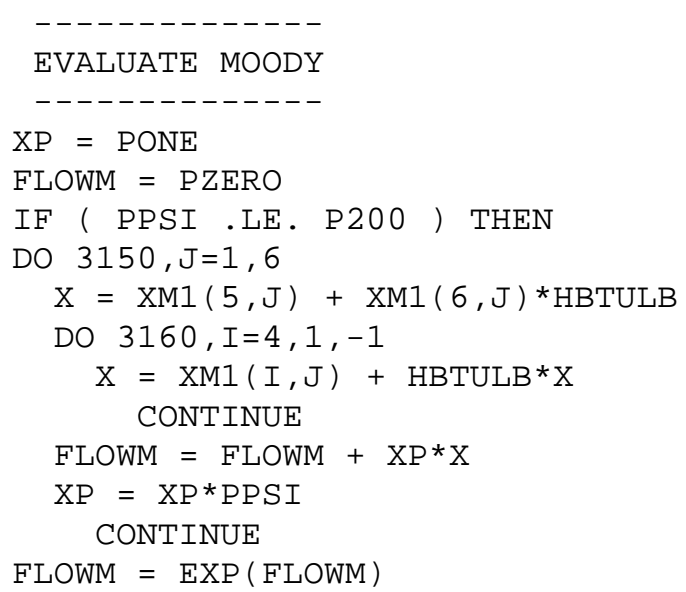

C

ELSE

DO $4150, \mathrm{~J}=1,6$

$\mathrm{X}=\mathrm{XM} 2(5, \mathrm{~J})+\mathrm{XM} 2(6, \mathrm{~J})$ *HBTULB

DO $4160, I=4,1,-1$

$\mathrm{X}=\mathrm{XM} 2(\mathrm{I}, \mathrm{J})+\mathrm{HBTULB} * \mathrm{X}$ CONTINUE

4160

FLOWM $=$ FLOWM $+X P * X$

$\mathrm{XP}=\mathrm{XP} * \mathrm{PPSI}$

4150 CONTINUE

END IF

C

IF ( hBtulb . Ge. HSBtU ) Then

ACCEPT MOODY RESULT

(1)

FLOWPL $=$ FLOWM

C

ELSE

C

C

C

CONSTRUCT WEIGHTED AVERAGE

FLOWPL $=$ FLOWHF +

1

(HBTULB-HTRN $)$ * (FLOWM-FLOWHF) / (HSBTU-HTRN)

END IF

C

END IF

C

C

IF ( BTULB . LT. P170) THEN INTERPOLATE TO ORIFICE EQUATION AT H $=0$ FLOWO $=$ PKG $2 L B * P F T 2 M * P F T 2 M * S Q R T(P T W O * R H O P O L * P L I Q)$ FLOWPL $=$ FLOWO + BTULB* $($ FLOWPL-FLOWO $) /$ P170 END IF

C

IF ( PSI .GT.P3000) FLOWPL=FLOWPL *SQRT (PSI/P3000)

NOW CONVERT BACK TO SI UNITS

FLOWC $(\mathrm{NFL})=\mathrm{FLOWPL} * \mathrm{PLB} 2 \mathrm{KG} * \mathrm{PM} 2 \mathrm{FT} * \mathrm{PM} 2 \mathrm{FT}$ 
$\mathrm{C}$

$C * *$ CALL HENRY-FAUSKE ROUTINE

$\mathrm{C}$

$$
\text { PLOSS }=0
$$

TPOL $=$ MIN $($ TEMPS $(1$, IDONOR $), \operatorname{VSAT}($ KSTS, KSCVP, IDONOR $)-.001)$

CALL GCSUB (PVOL (IDONOR), TPOL, PLOSS, FLOWC (NFL))

C FLOWC (NFL) $=$ RHOPOL ${ }^{*}$ PROPSN (KCSLPL, IDONOR)

ENDIF

$\mathrm{C}$

C

C

C

C

CONVERT MASS FLOW RATE PER UNIT AREA TO VELOCITY PER UNIT AREA

IF ( ALP (NFL) . LE. PZERO ) THEN

POOL ONLY - USE RETRAN MODEL WITH DISCHARGE COEFFICIENT $\mathrm{CS}=\mathrm{FLOWC}(\mathrm{NFL}) / \mathrm{RHOPOL}$

IF ( VLFLN $(1, N F L)$. GT. PZERO ) THEN

$\mathrm{CS}=\mathrm{CS}{ }^{*} \mathrm{CDCHK}(1, \mathrm{NFL})$

ELSE

$\mathrm{CS}=\mathrm{CS}{ }^{*} \mathrm{CDCHK}(2, \mathrm{NFL})$

ENDIF

FLOWC $($ NFL $)=C S *$ RHOPOL

IF ( $\operatorname{ABS}(\operatorname{VLFLN}(1, \mathrm{NFL}))$. GT. CFFACT*CS ) THEN

JVSPEC $=$ JVSPEC +1

IVSPEC (JVSPEC) $=$ NFL

$\operatorname{VSPEC}(\operatorname{JVSPEC})=\operatorname{SIGN}(\mathrm{CS}, \operatorname{VLFLN}(1, \operatorname{NFL}))$

ENDIF

C

$$
\text { ELSE }
$$
CSVAP $=$ PROPSN (KCSATM, IDONOR)

IF (CSVAP . LE. PZERO) CSVAP = P200

C

C

1.8

C ACCOUNT FOR EXPANSION AND COOLING TO THROAT

WEAK FCN OF GAMMA (+- 5 PERCENT FOR 1.1 . LE. GAMMA . LE.

GAMMA $=1.4$

$\mathrm{EXPON}=(\mathrm{GAMMA}+\mathrm{PONE}) /(\mathrm{PTWO} *(\mathrm{GAMMA}-\mathrm{PONE}))$

CSVAP $=$ CSVAP $*(\mathrm{PTWO} /(\mathrm{GAMMA}+\mathrm{PONE})) \star \star \mathrm{EXPON}$

RHOVAP $=$ PROPSN (KRHOAT, IDONOR)

IF (RHOVAP . LE. PZERO) RHOVAP = P10

C

$(\operatorname{ALP}($ NFL $) / C S V A P+($ PONE-ALP $($ NFL $)) *$ RHOPOL/FLOWC (NFL) )

FLOW $=\operatorname{ALP}(N F L) * \operatorname{VLFLN}(2, N F L) *$ RHOVAP +

$1 \quad(\mathrm{PONE}-\mathrm{ALP}(\mathrm{NFL})) * \operatorname{VLFLN}(1, \mathrm{NFL}) * \mathrm{RHOPOL}$

C

IF ( FLOW . GT. PZERO ) THEN

$\mathrm{CS}=\mathrm{CS}{ }^{*} \mathrm{CDCHK}(1, \mathrm{NFL})$

ELSE

$\mathrm{CS}=\mathrm{CS}{ }^{*} \mathrm{CDCHK}(2, \mathrm{NFL})$

ENDIF

RHOMIX $=\operatorname{ALP}(\mathrm{NFL}){ }^{\mathrm{RHOVAP}}+(\mathrm{PONE}-\mathrm{ALP}(\mathrm{NFL})){ }^{\mathrm{RHOPOL}}$

FLOWC $($ NFL $)=$ RHOMIX $*$ CS

C

DO $110 \mathrm{MFL}=1$, JVSPEC

$\mathrm{MFLS}=\mathrm{MFL}$

IF ( IVSPEC (MFL) .EQ. NFL ) GO TO 120 
110 CONTINUE

C

C

IF ( $\mathrm{ABS}$ (FLOW) . GT . CFFACT*FLOWC (NFL) ) THEN CHOKED FLOW

JVSPEC = JVSPEC +1

$\operatorname{IVSPEC}($ JVSPEC) $=\mathrm{NFL}$

$\operatorname{VSPEC}($ JVSPEC) $=\operatorname{SIGN}(\mathrm{CS}, \mathrm{FLOW})$

ENDIF

GO TO 100

120

DVSPEC = VSPEC (MFLS) $-\mathrm{CS}$

$\operatorname{VSPEC}(\mathrm{MFLS})=\operatorname{SIGN}(\mathrm{CS}, \mathrm{FLOW})$

IF (CS.NE.0.) DVSPEC = DVSPEC/CS

IF (ABS (DVSPEC) . GT $1 . \mathrm{E}-3)$ JVSPO $=0$

ENDIF

ENDIF

ENDIF

100 CONTINUE

RETURN

END

C

SUBROUTINE INITFLD

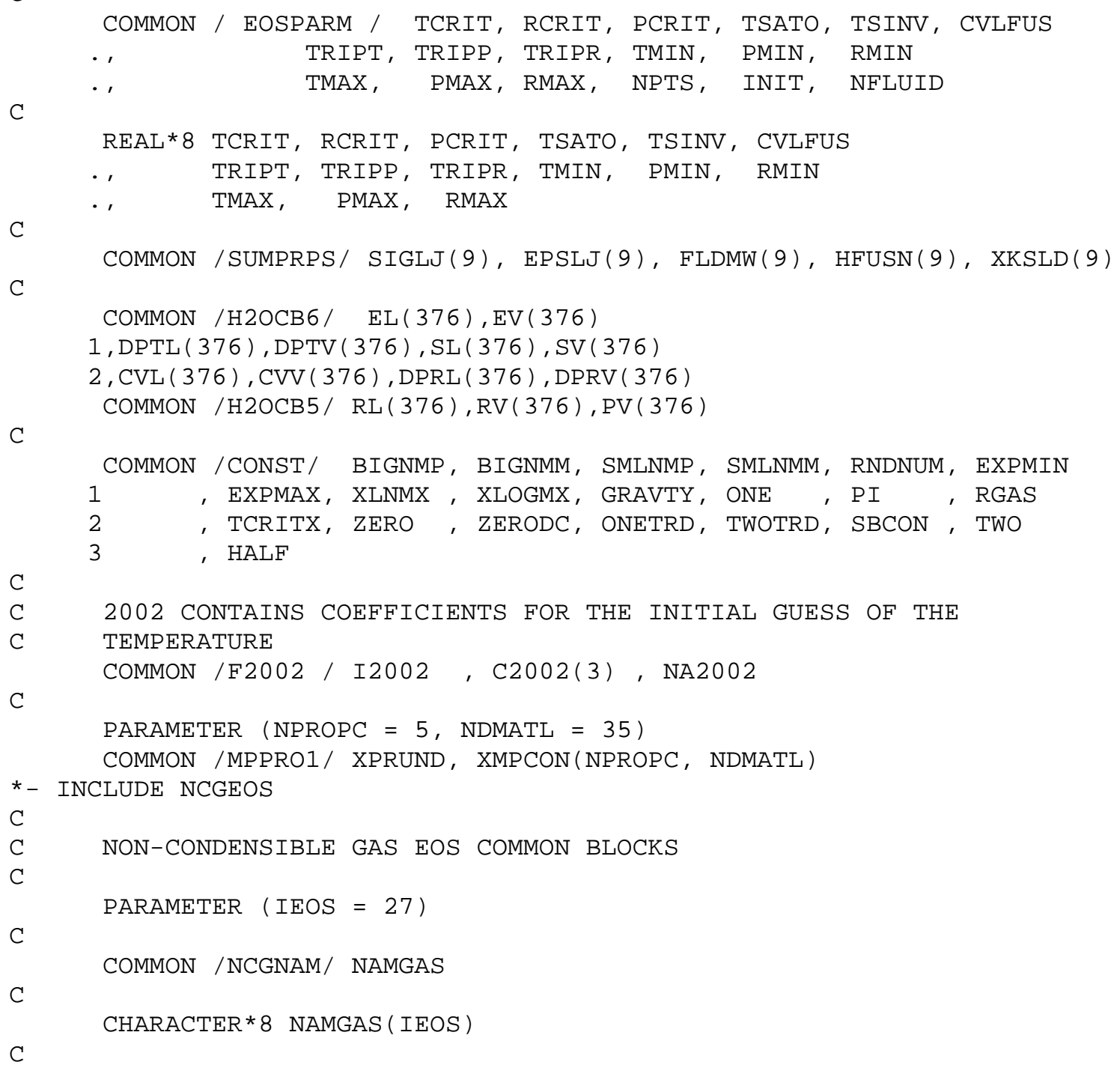




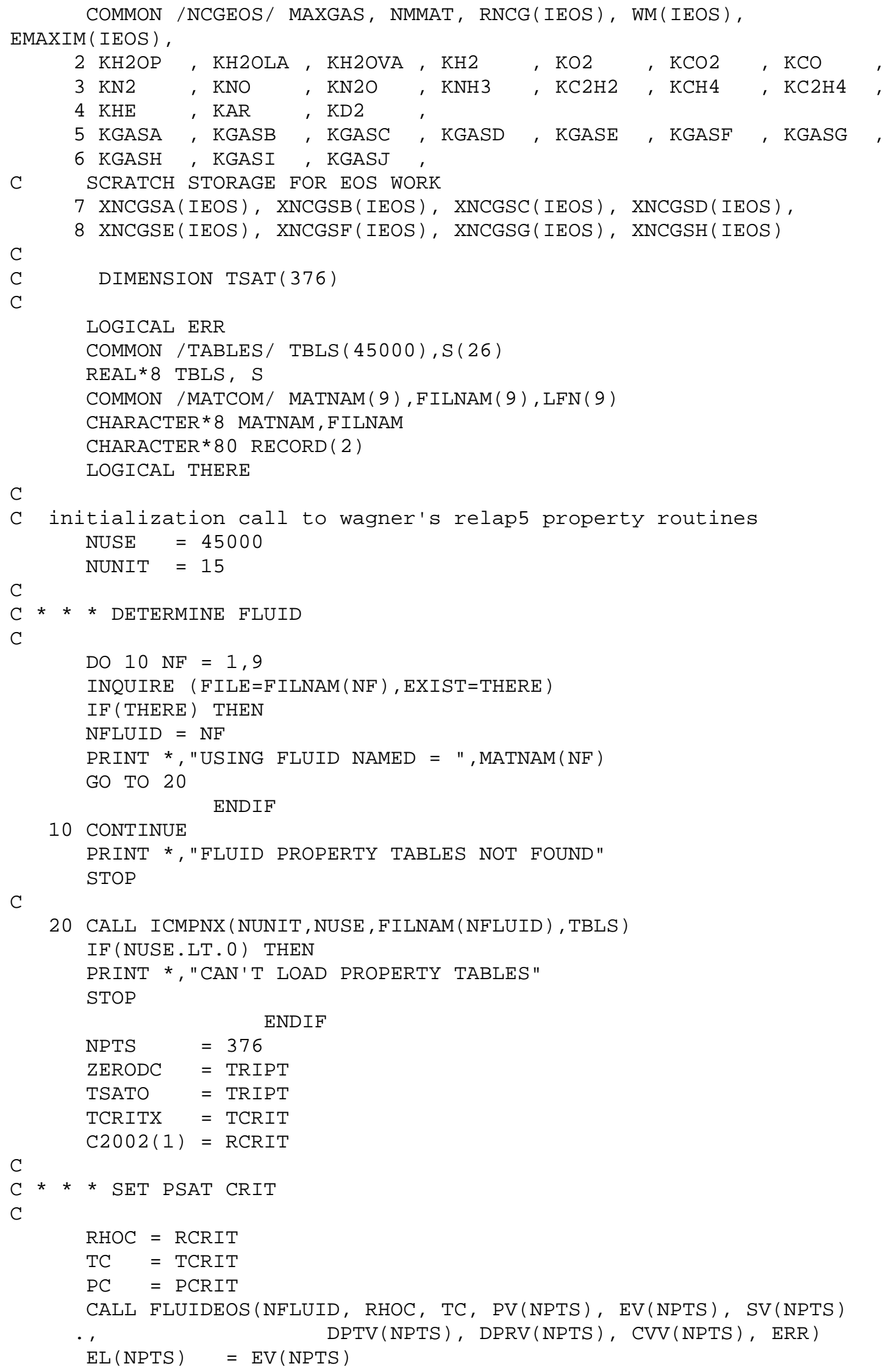




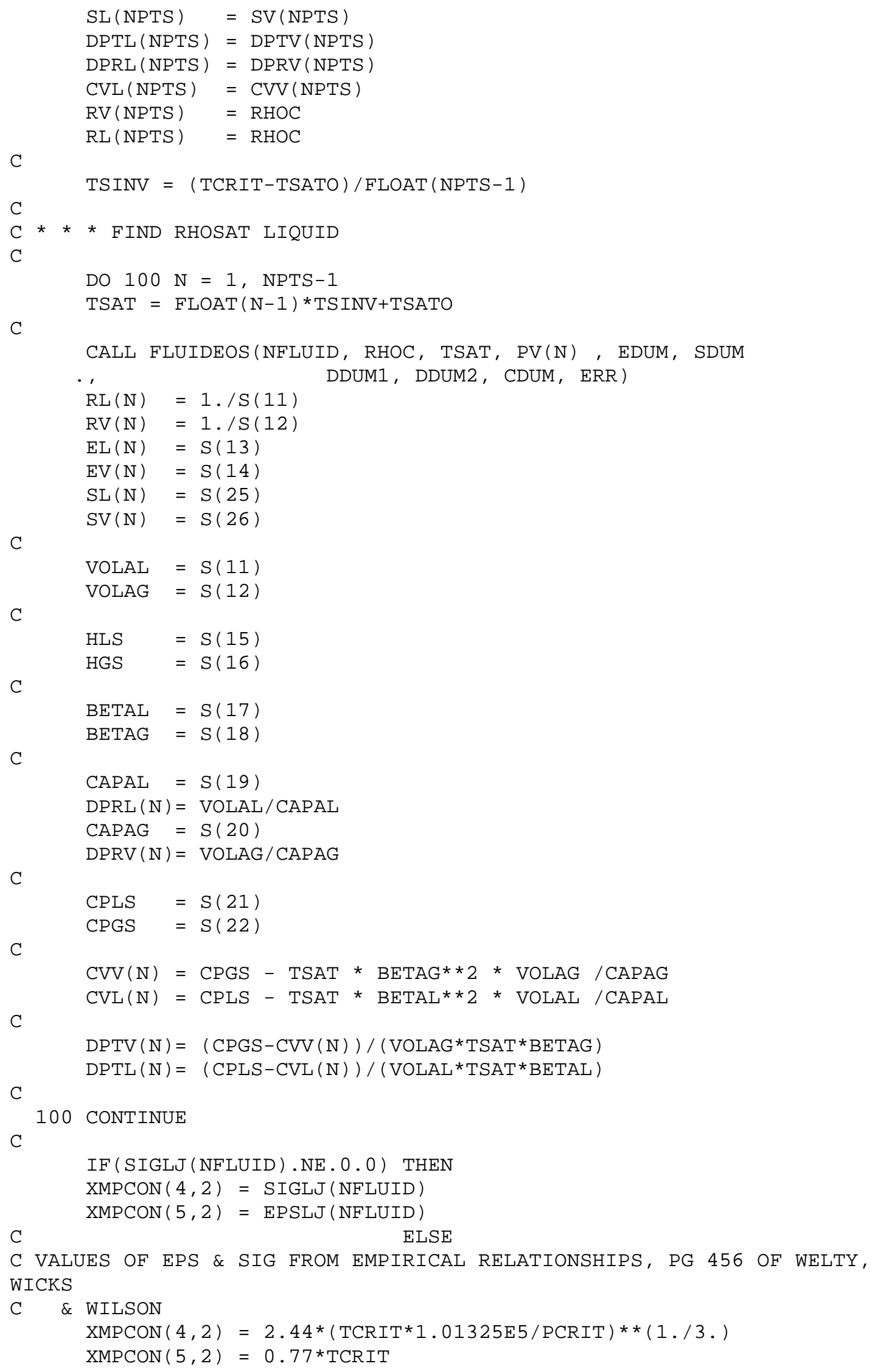




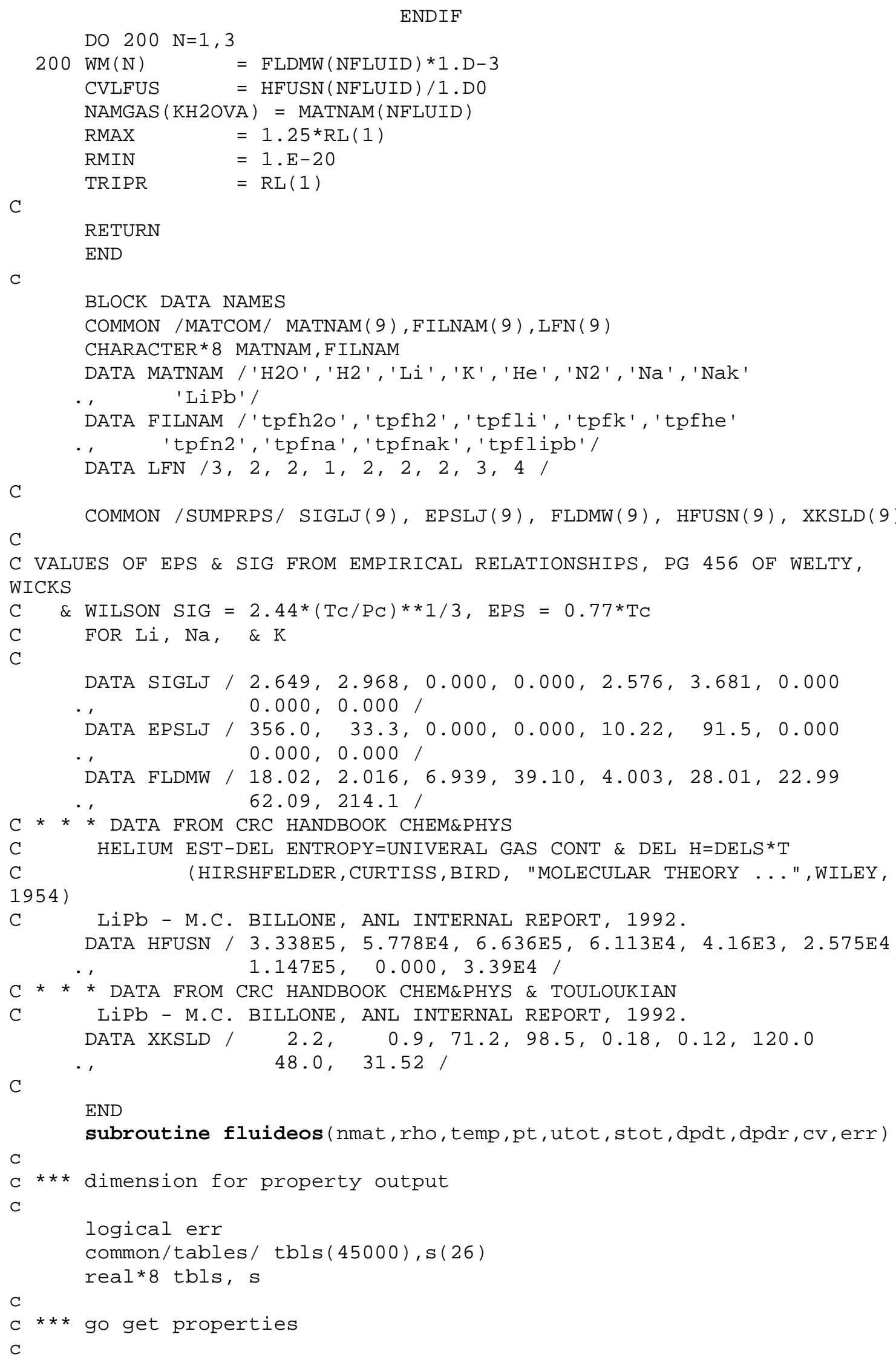




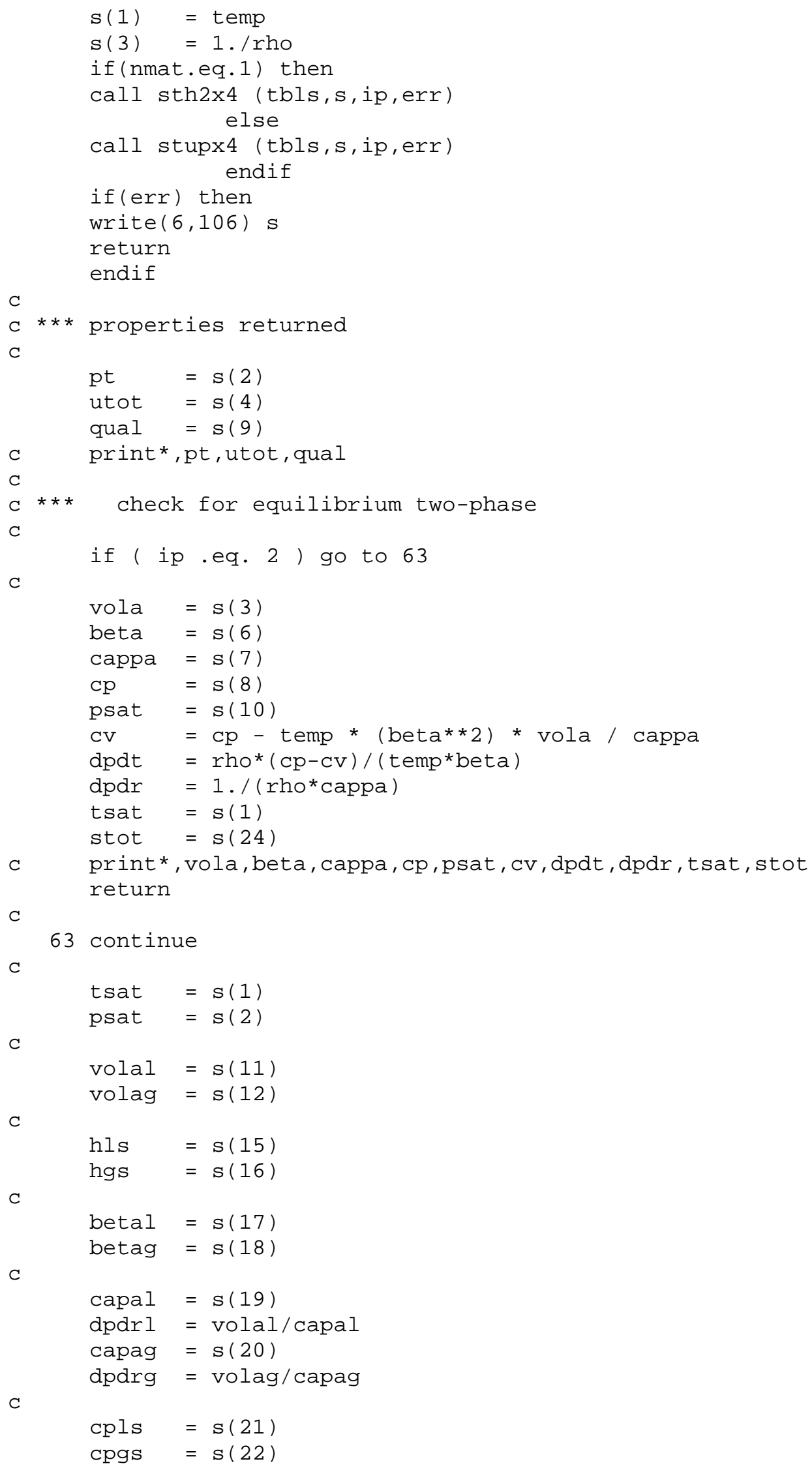




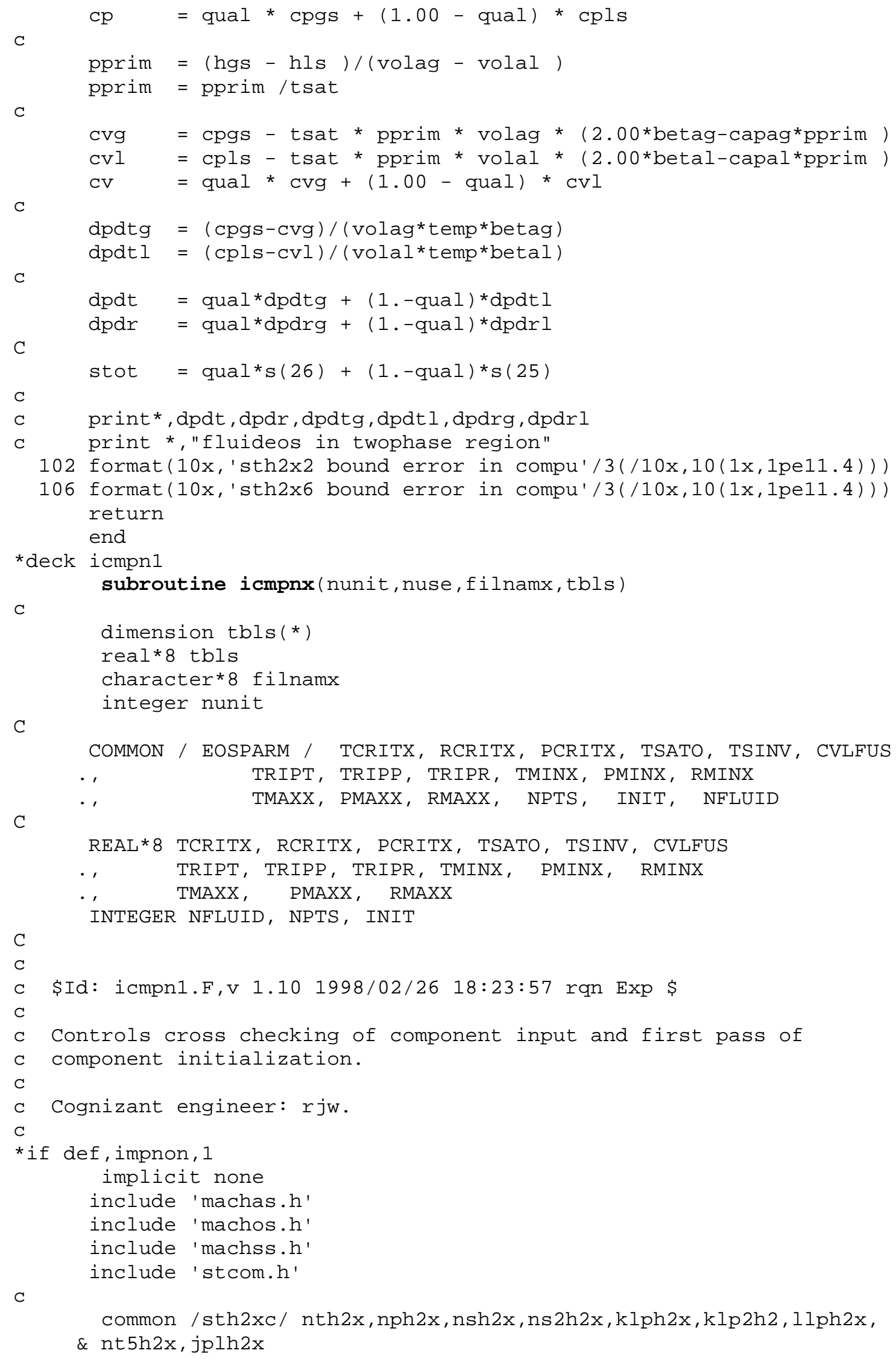




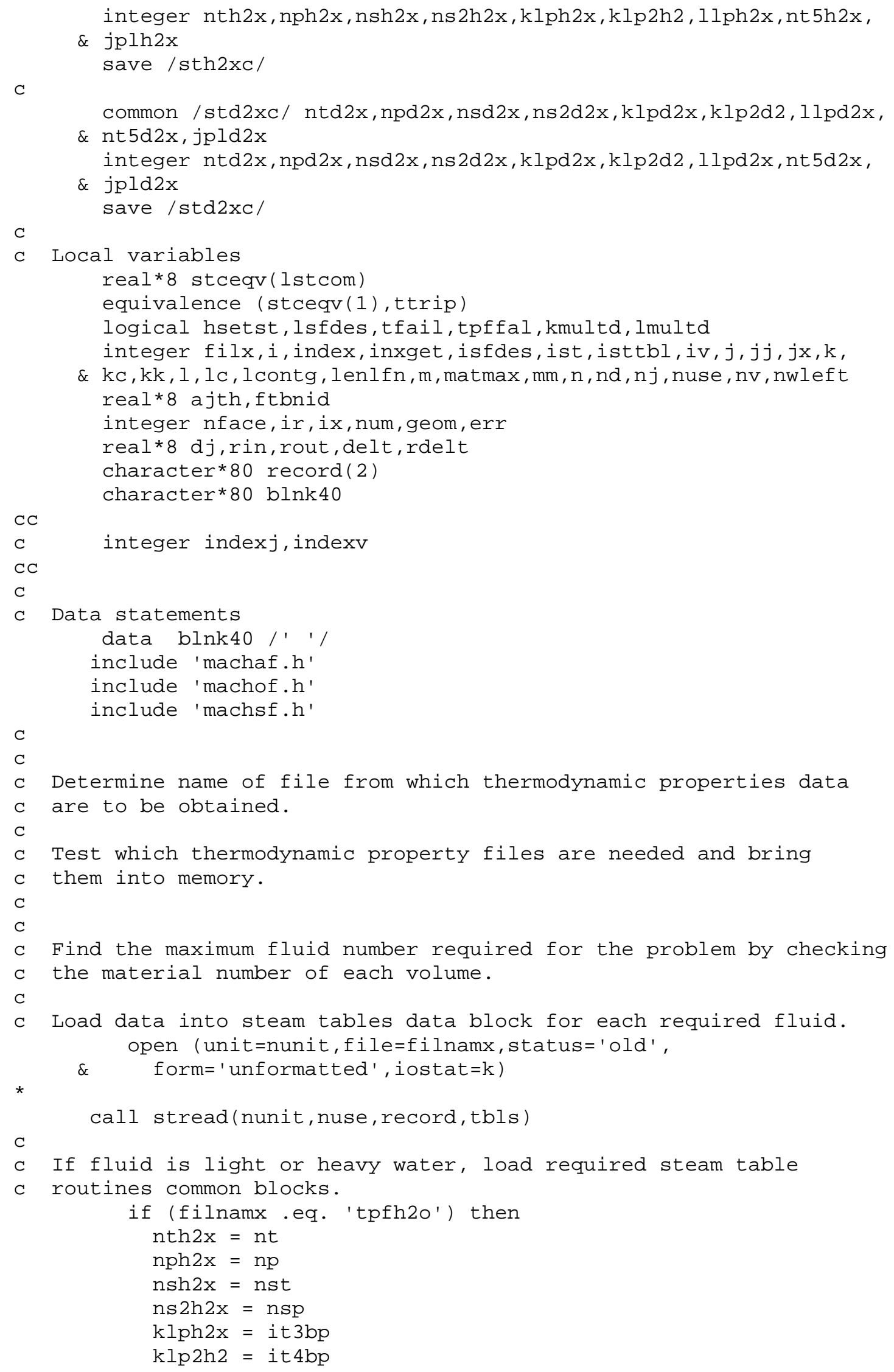




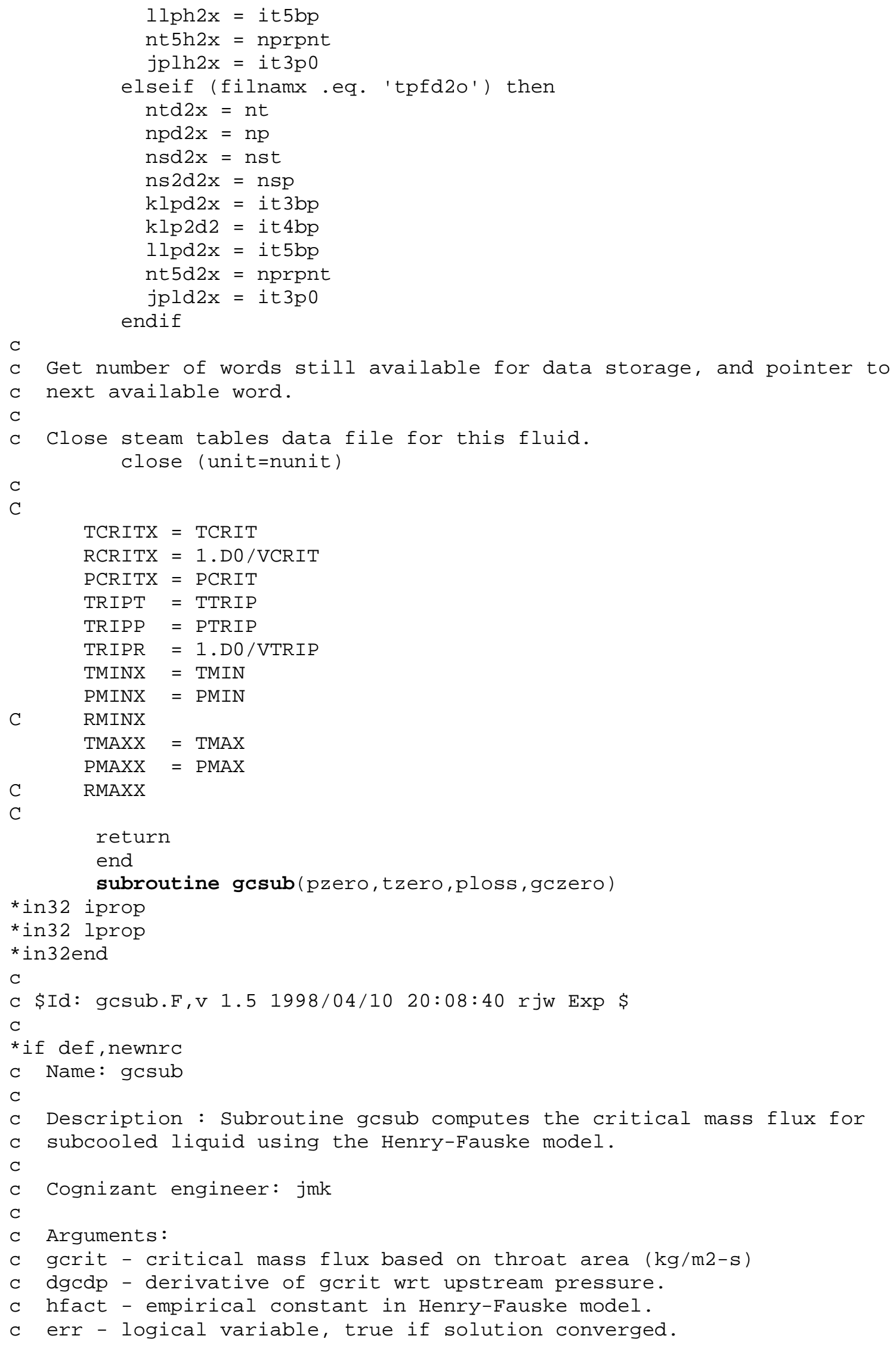




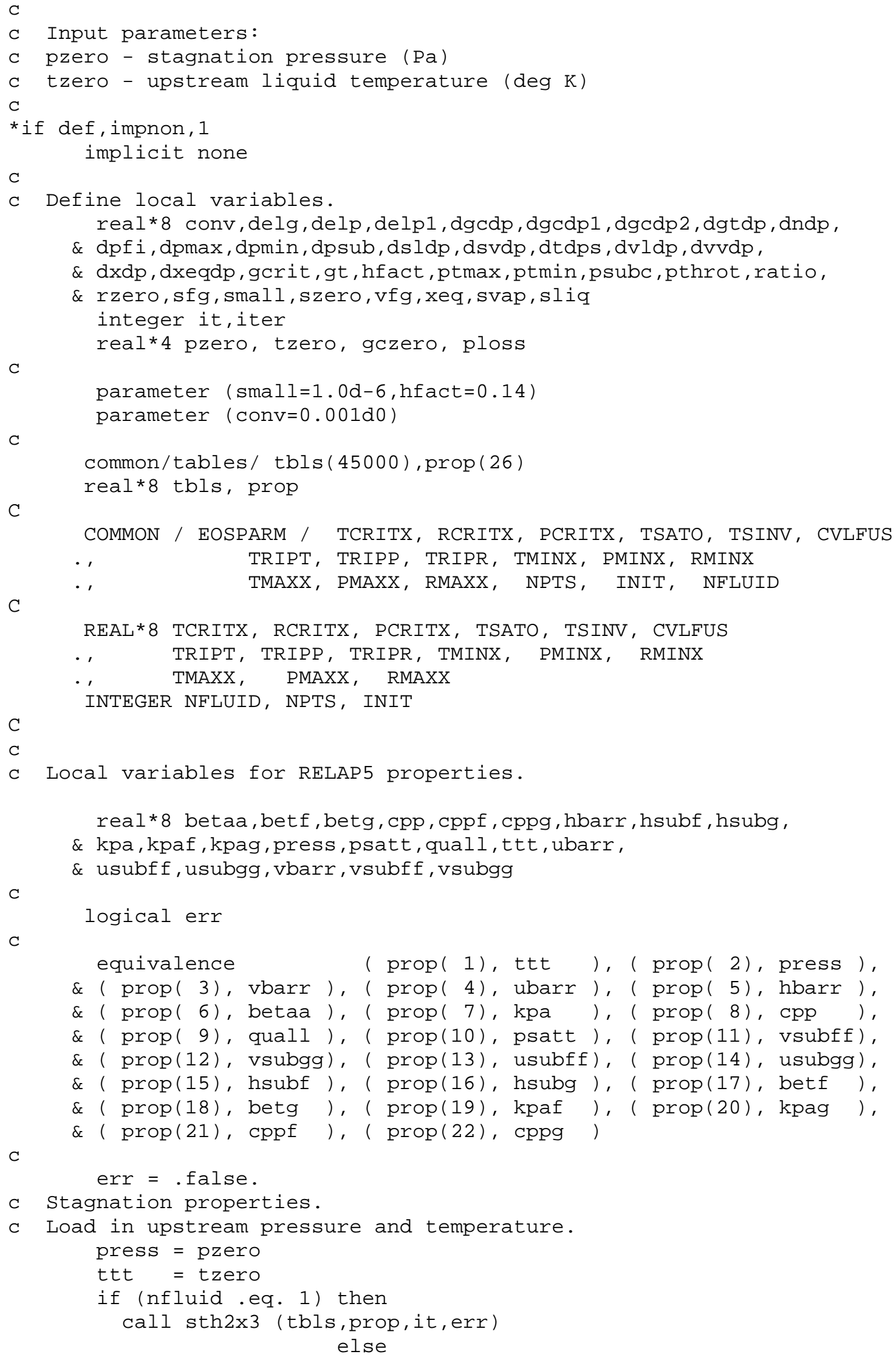


call strtp (tbls, prop, it, err)

endif

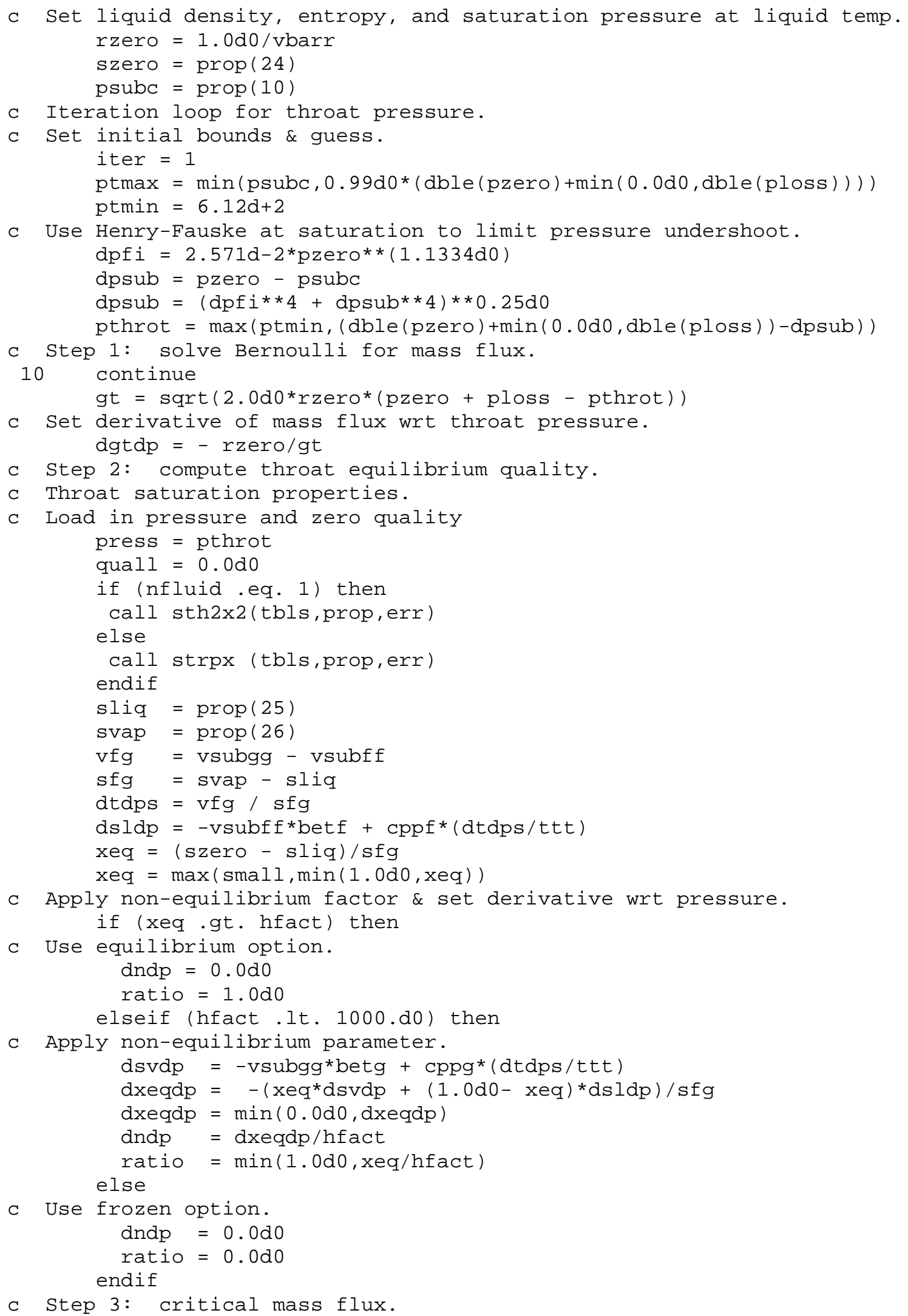




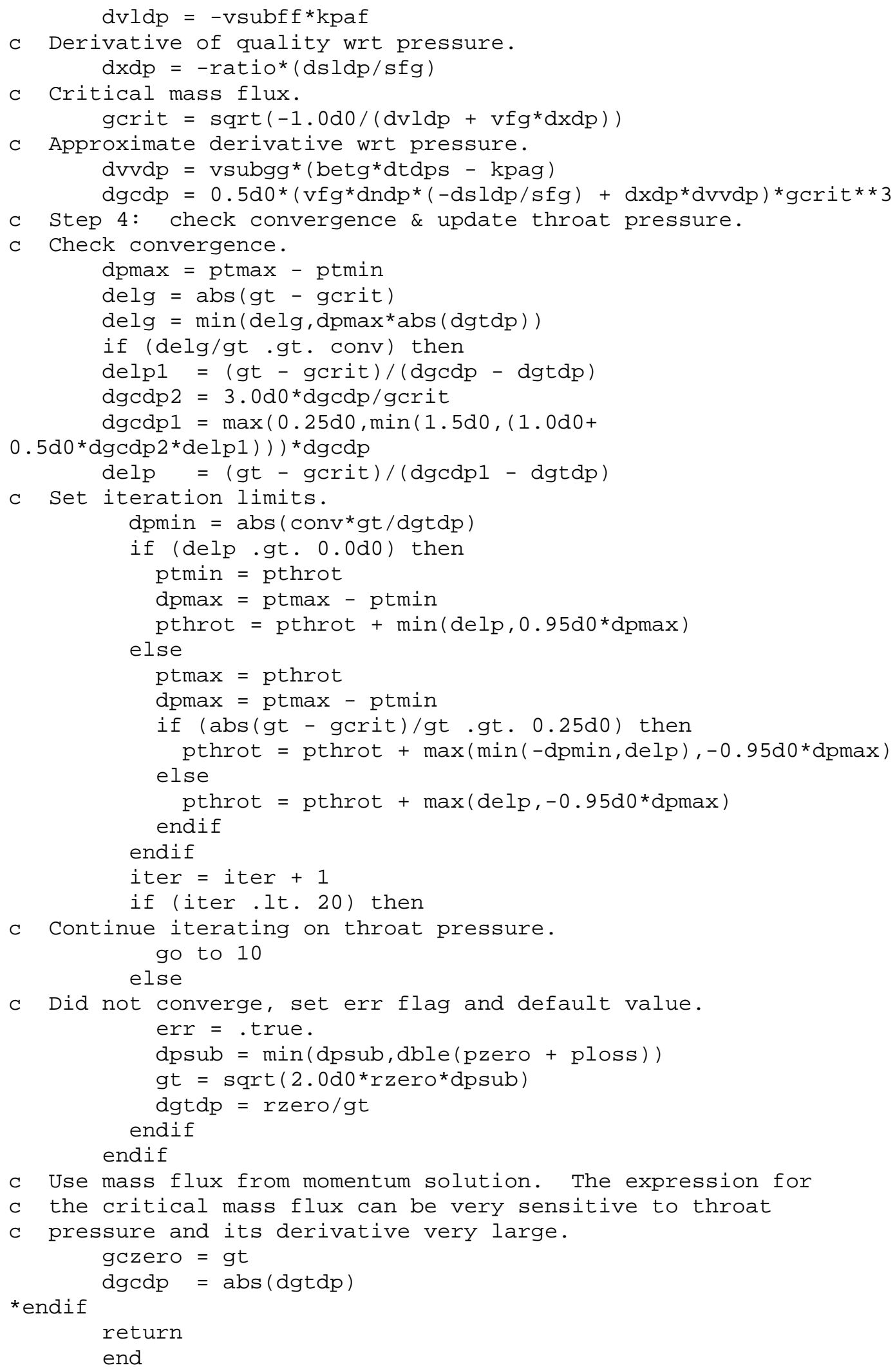




\section{Appendix B}

\section{FORTRAN Listing of MELCOR}

Modifications for Lithium-Air Reaction Kinetics 


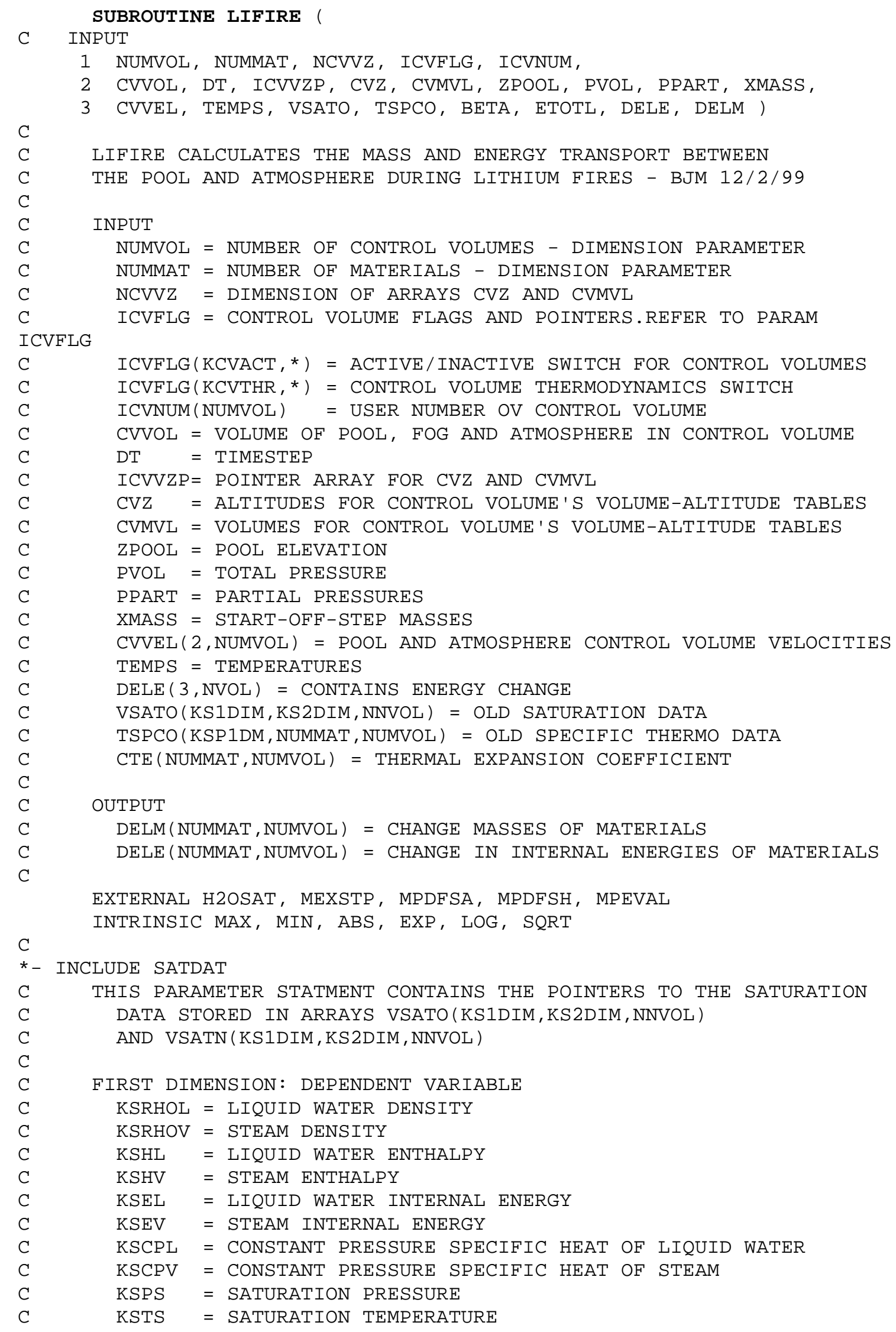




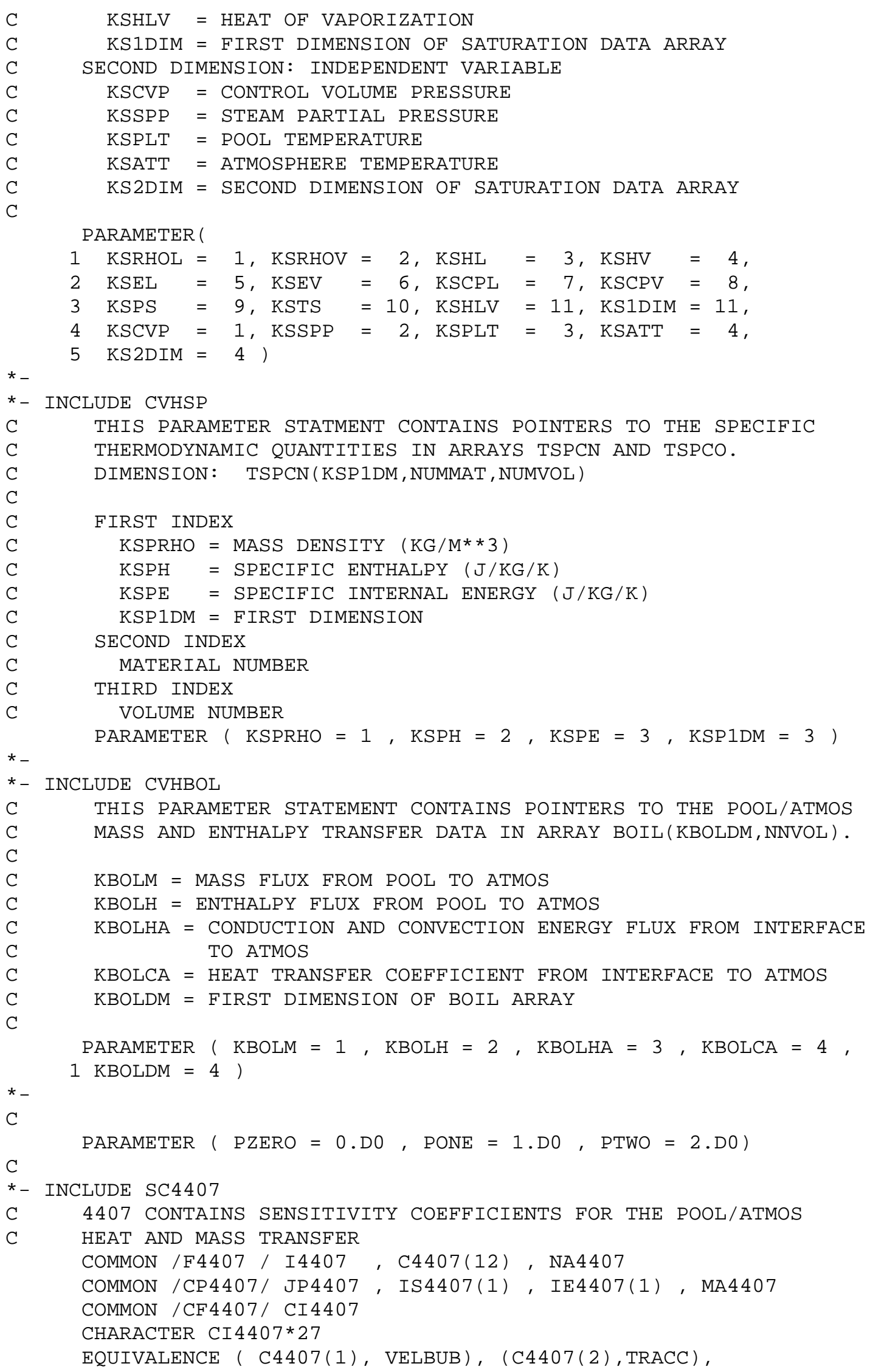




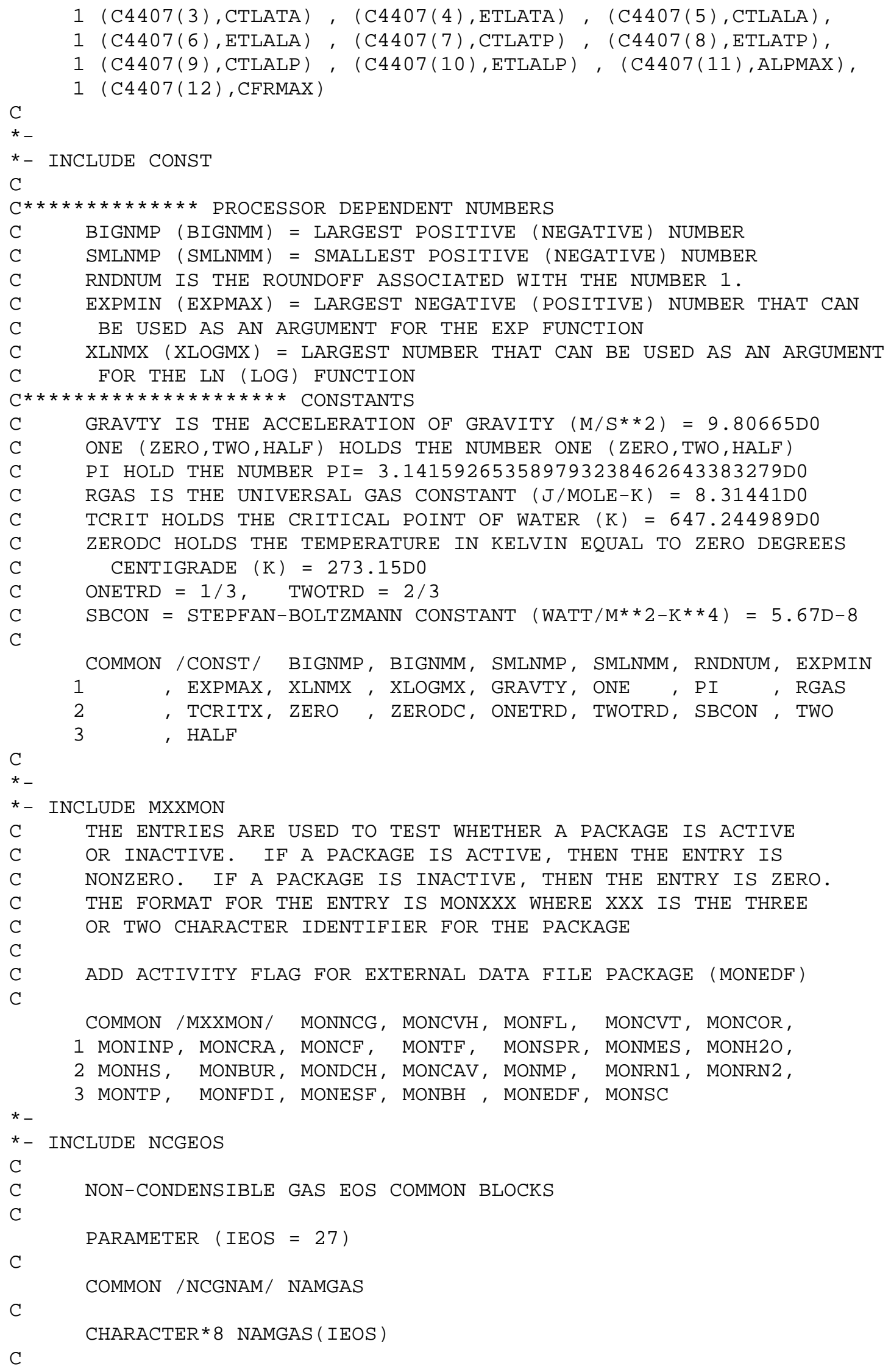




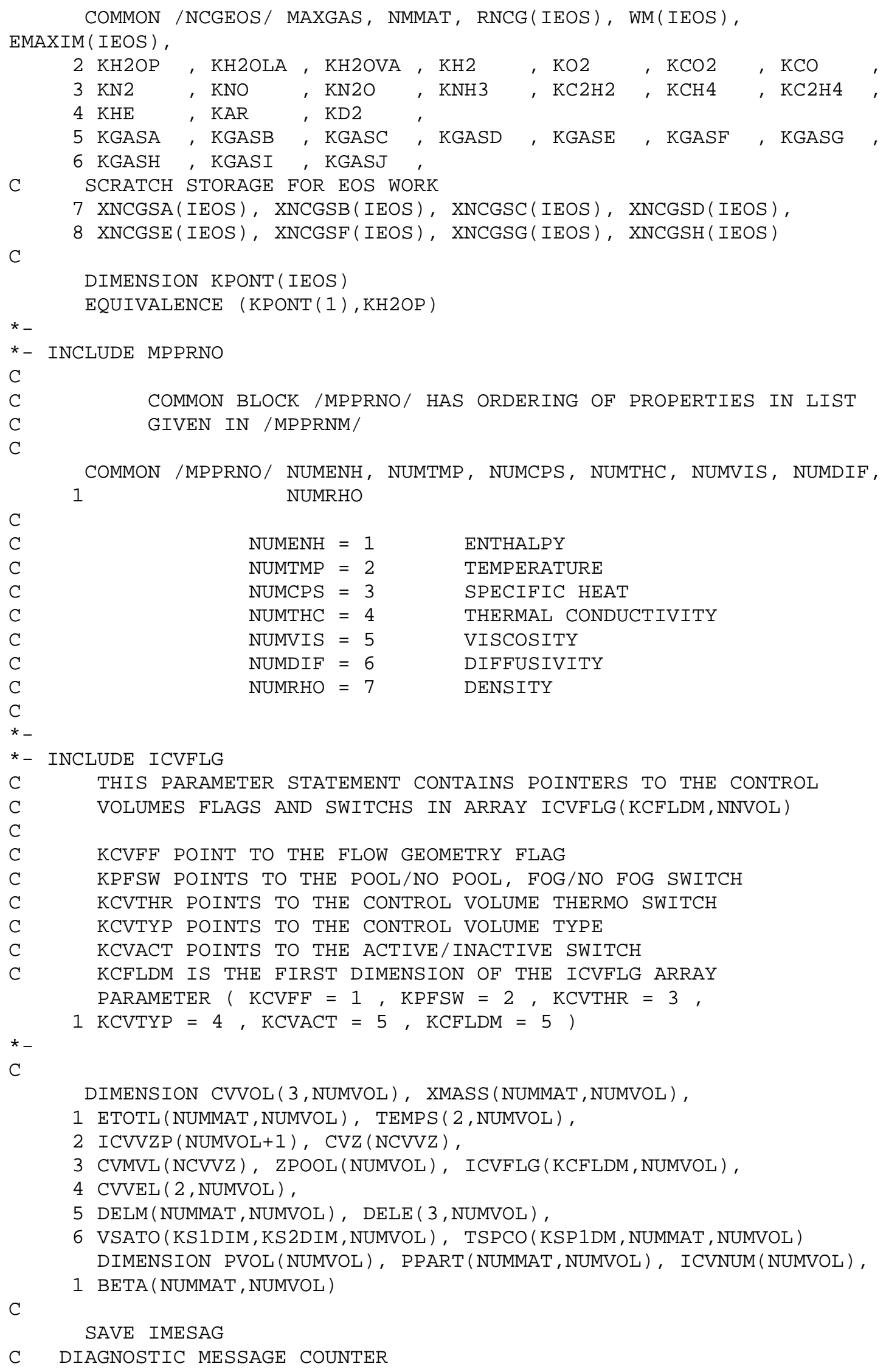




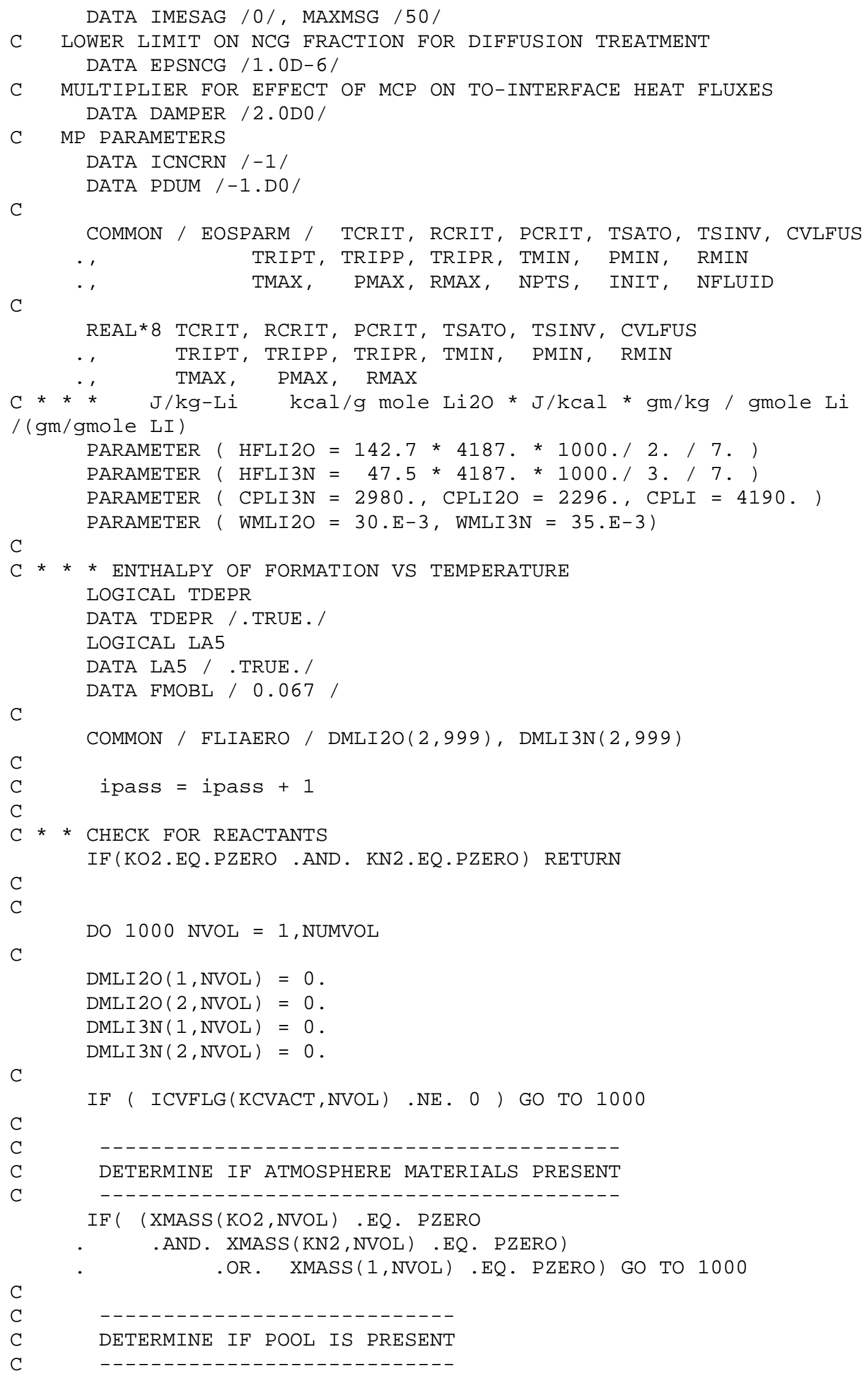


C

IF (XMASS $(1$, NVOL) .GT. PZERO .AND .

2 CVVOL $(1$, NVOL) .GT. PZERO ) THEN

C

C

C

C

$\mathrm{C}$

C

C

DO $110, N=\operatorname{ICVVZP~}($ NVOL $)+1, \operatorname{ICVVZP~}($ NVOL +1$)-1$

IF ( $\operatorname{CVZ}(\mathrm{N})$. GE. ZPOOL (NVOL) ) THEN

$\operatorname{SAREA}=(\operatorname{CVMVL}(\mathrm{N})-\operatorname{CVMVL}(\mathrm{N}-1)) /(\operatorname{CVZ}(\mathrm{N})-\operatorname{CVZ}(\mathrm{N}-1))$

$\mathrm{DIA}=\operatorname{SQRT}(\mathrm{SAREA} * 4 . / \mathrm{PI})$

GO TO 111

110 CONTINUE

ENDIF

111 CONTINUE

C

DZPOOL $=$ ZPOOL (NVOL) $-\mathrm{CVZ}($ ICVVZP (NVOL) $)$

IF (DZPOOL . LE. PZERO)

$1 \quad$ DZPOOL $=\operatorname{CVVOL}(1$, NVOL $) / \operatorname{SAREA}$

DZATMS $=$ CVZ $($ ICVVZP $($ NVOL +1$)-1)-$ ZPOOL $($ NVOL $)$

IF (DZATMS . LE. PZERO)

1 DZATMS $=(\operatorname{CVVOL}(1, \operatorname{NVOL})+\operatorname{CVVOL}(2, \operatorname{NVOL})) / \operatorname{SAREA}$

GO TO 1000

ELSE

ENDIF

$\mathrm{FPDOH}=\operatorname{MAX}(0,,(\mathrm{DIA} / \mathrm{DZPOOL}-0.89) /(16 .-0.89))$

$\mathrm{FPDOH}=\operatorname{MIN}(1, \mathrm{FPDOH})$

C

C

C

C

DENSITY, SPECIFIC HEAT, THERMAL EXPANSION COEFFICIENT

RHOL $=$ XMASS $(1$, NVOL $) / C V V O L ~(1, N V O L)$

SUMMAS $=$ PZERO

BETAA = PZERO

DO $115, \mathrm{NMAT}=3, \mathrm{NUMMAT}$

SUMMAS $=$ SUMMAS + XMASS (NMAT, NVOL)

BETAA = BETAA + BETA (NMAT, NVOL) *XMASS (NMAT, NVOL)

115 CONTINUE

RHOA = SUMMAS /CVVOL (3, NVOL $)$

IF (SUMMAS . NE . ZERO) THEN

BETAA = BETAA / SUMMAS

ELSE

$\operatorname{BETAA}=\operatorname{BETA}(3, \operatorname{NVOL})$

ENDIF

$\mathrm{C}$

C

C

C

C

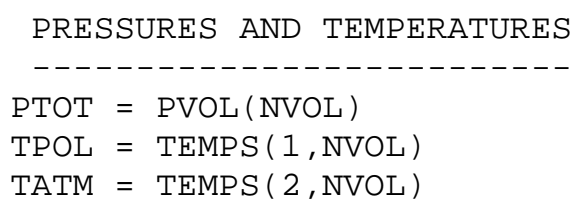




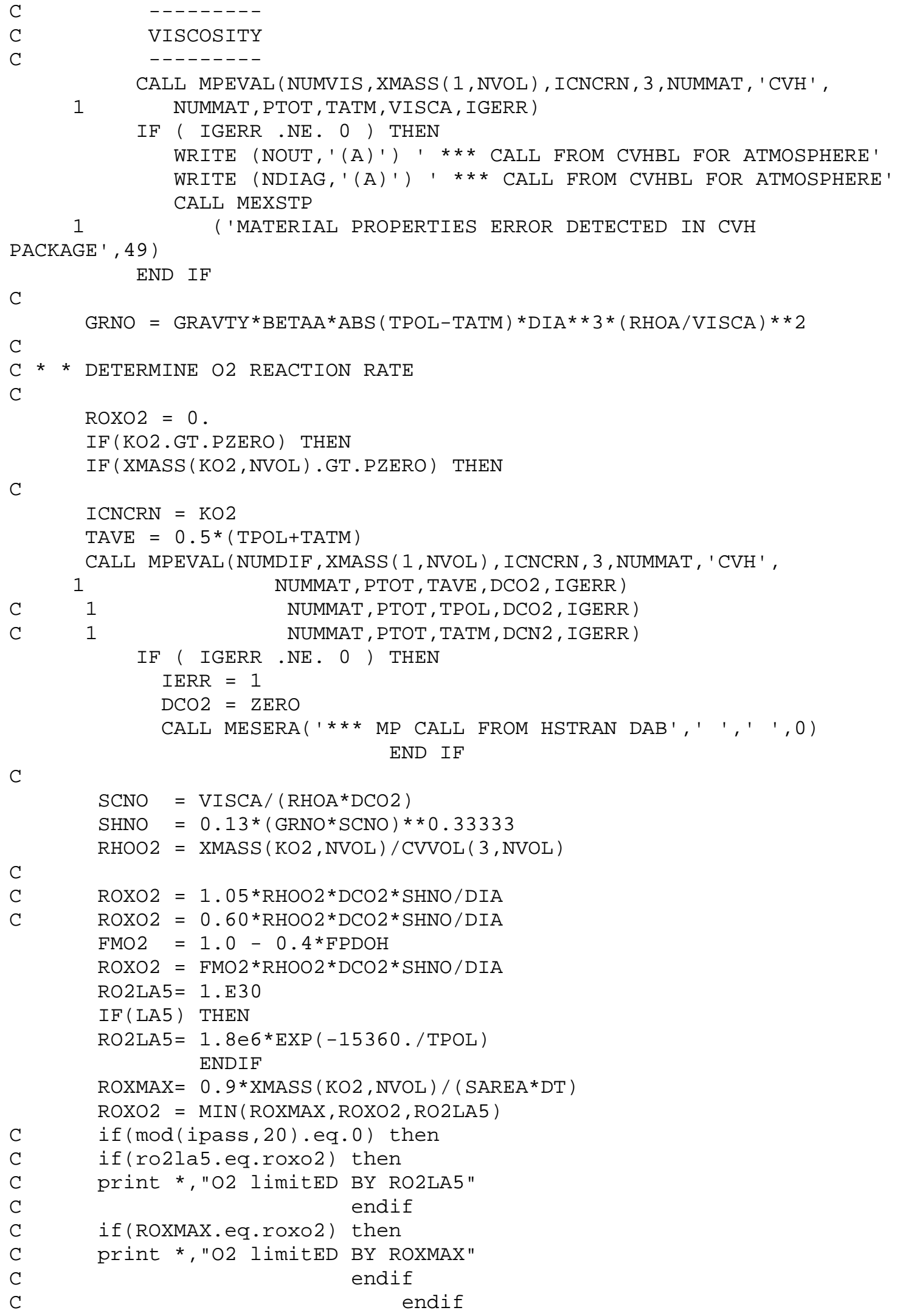




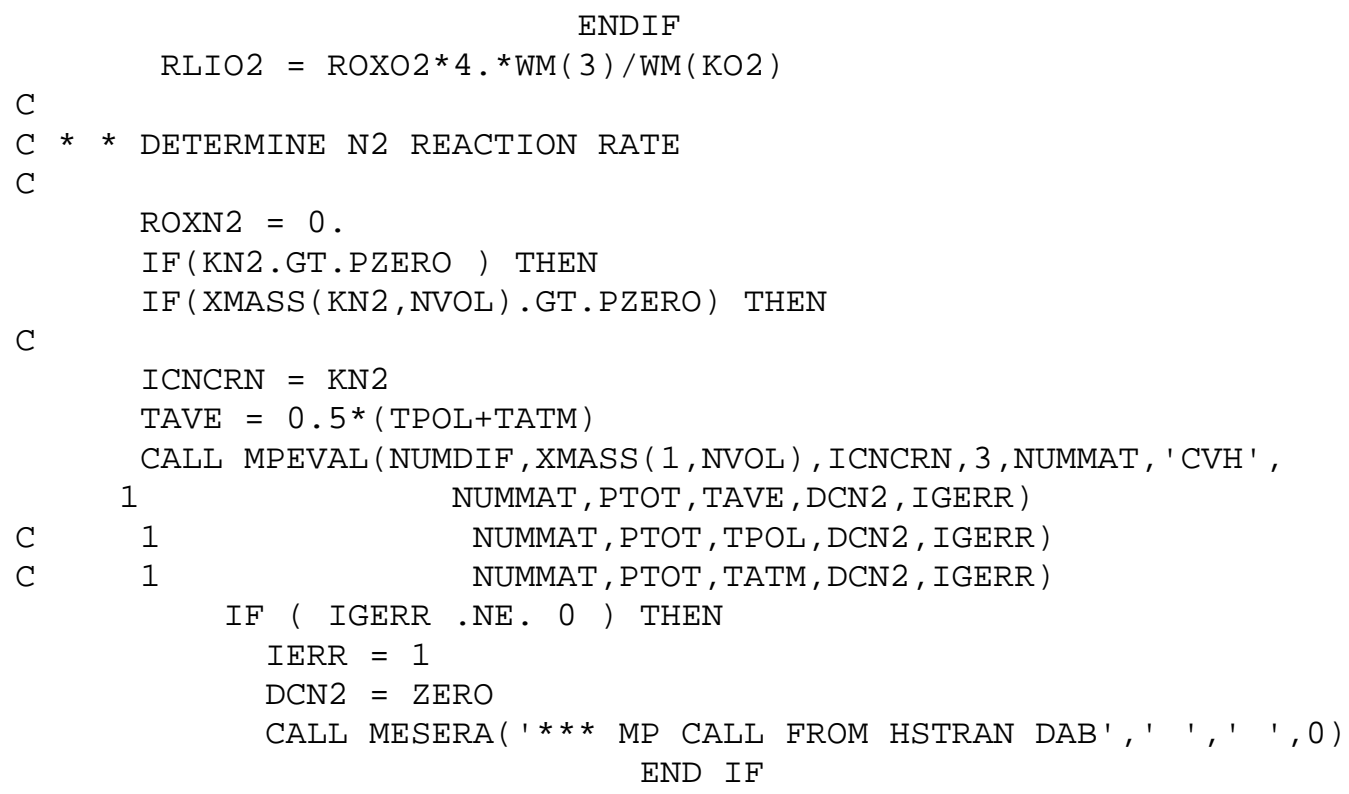

C 


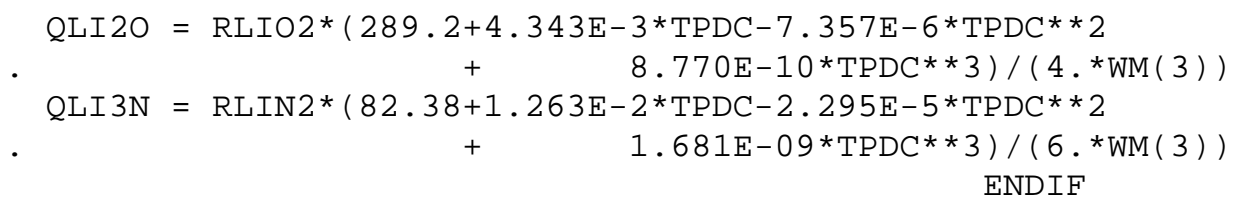

C

$\mathrm{C}$

C

DMLI $\quad=$ SAREA * ROXLI*DT

EBURN $\quad=$ EBURN + SAREA*QOXLI*DT

$\mathrm{FMOBL}=0.1-0.066 * \mathrm{FPDOH}$

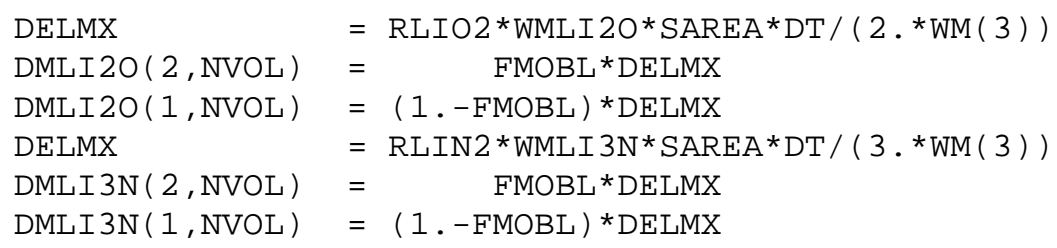

